GREGORIO BITTAR IVANOFF

AMBIENTES E ORGANIZAÇÕES VIRTUAIS: CULTURA DE SEGURANÇA E REGULAÇÃO ENTRE O DESENVOLVIMENTO DE PROGRAMAS COMPUTACIONAIS E ESTRUTURAS E PROCESSOS ORGANIZACIONAIS 
GREGORIO BITTAR IVANOFF

\title{
AMBIENTES E ORGANIZAÇÕES VIRTUAIS: CULTURA DE SEGURANÇA E REGULAÇÃO ENTRE O DESENVOLVIMENTO DE PROGRAMAS COMPUTACIONAIS E ESTRUTURAS E PROCESSOS ORGANIZACIONAIS
}

\author{
Dissertação apresentada à Escola Politécnica da \\ Universidade de São Paulo para a obtenção do \\ título de Mestre em Engenharia Elétrica \\ Área de Concentração: \\ Sistemas Digitais \\ Orientador: \\ Prof. Dr. Edison Spina
}




\section{Agradecimentos}

Agradeço ao orientador, Professor Doutor Edison Spina.

Agradeço a professores, colegas e colaboradores do Departamento de Engenharia de Computação e Sistemas Digitais e do Departamento de Engenharia da Produção, da Escola Politécnica da Universidade de São Paulo: Jorge Rady Almeida Júnior, João Batista Camargo Junior, Marco Túlio Carvalho de Andrade, Edson Gomi, Selma Shin Shimizu Melnikoff, Moacir Martucci Júnior, Jaime Sichman, Lucia Filgueiras, Afonso Carlos Fleury, Paulino Graciano Francischini, Israel Brunstein, Guilherme Ary Plonski, Mauro de Mesquita Spínola, Marcelo de Paula Pessôa, Laerte Sznelwar, Fausto Mascia, Bruno Maggi, José Belix, Marcio Augusto Silva, Gustavo Yamasaki M. Vieira, Joyce Martins Mendes, Carlos Daniel, André Fleury, Sergio Luiz dos Santos, Tiago Prado.

Agradeço a pesquisadores, professores, colegas e colaboradores do GAS - Grupo de Análise de Segurança do Departamento de Engenharia de Computação e Sistemas Digitais da Escola Politécnica da USP, do GetGC - Grupo de Estudos de Tecnologia em Gestão de Conhecimento da PUC SP e do MBIS da PUC SP, do eLabSoft Laboratório de Produção de Software do Departamento de Engenharia de Produção da Escola Politécnica da USP, do LInC Laboratório de Inteligência Coletiva da PUC SP, da UNICAMP - Universidade Estadual de Campinas, da School of Knowledge Science do Japan Advanced Institute of Science and Technology - JAIST, da UNERJ - Centro Universitário de Jaraguá do Sul: Fernando Antônio de Castro Giorno, José Carlos Arruda Alves, José Henrique Tarcia, Marcos Lara, Rogério da Costa, Lawrence Chung Koo, Roberto Mengato, Nelson Corrêa de Toledo Ferraz, Wilson Amorim, Eduardo Longo, Fábio Câmara Araújo de Carvalho, Mauricio Pimentel, Zilda Hernandes, Fernando Mori, Fernando Perez, Silvana Bassi, Fatima Galvanese, Neli Mengalli, Filipe Cassapo, José Bressan, Tadeu Cruz, Sheila Klein, Ralf Klein, Maria Carolina A. F. de Souza, Liliane Queiroz Antonio, André Saito, Pedro Guilherme Kraus. 
Agradeço a professores, colegas e colaboradores do Departamento de Psicologia Social e do Trabalho, do Instituto de Psicologia da USP: Sigmar Malvezzi, Lisete Barlach, Reinaldo Yonamine, Erico Renteria, Alonso Tejada, Rogerio Tadeu, Cassia Correa, Sandra Bertelli, Cristina Gattai.

Agradeço a professores, colegas e colaboradores da Faculdade de Economia, Administração e Contabilidade: André Fischer, Marisa Eboli, Liége Mariel Petroni, Flavio Hourneaux Junior, Sergio Mancini, Barend Doorakkers.

Agradeço a coordenadores, participantes, colaboradores e colegas de programas de pós-graduação, Master Business Information Systems MBIS da PUC SP, MBA em Economia e Gestão das Organizações de Saúde da PUC SP, MBA de Gestão de Operações - Produtos e Serviços, da Fundação Carlos Alberto Vanzolini, Especialização da Fundação Fritz Müller e Universidade Regional de Blumenau FURB, Especialização em Business Intelligence da FIAP, Especialização em Gestão de Serviços da FMU, Especialização em Gestão de Pessoas da UNISO Universidade de Sorocaba, Especialização em Gestão de Recursos Humanos da UNICID - Universidade Cidade de São Paulo: Tania Campos, Alexandre Campos Silva, Maria Cristina Amorim, Eduardo Perillo, Roberto Rottondaro, Reinaldo Pacheco, Norma Odebrecht, Pedro Paulo Wilhelm, Ana Helena Moreira, Luiz Claudio Gonçalves, Marcela Peçanha, Plinio Bernardi, Marcelo Treff.

Agradeço ao Instituto de Engenharia, à Associação Brasileira de Engenheiros Eletricistas, à SUCESU SC - Sociedade de Usuários de Informática e Telecomunicações de Santa Catarina, ao SEBRAE, ao SENAI, ao Instituto de Tecnologia de Software, à Sociedade Brasileira de Gestão de Conhecimento: Eduardo Ferreira Lafraia, José Olimpio Dias de Faria, João Oliva, Antonio Soares Pereto, Arnaldo Tassinari, Victor Manuel Vasconcelos, Venicio Fagundes, Antonio Carlos Larúbia, Marlon Claudio Cabrera, Sonia Rodrigues, Descartes de Souza Teixeira, Jaime Stabel, Heitor José Pereira, Marcelo Correa, Maria da Gloria Bataglia, Jean Jacques Salim, Sergio Storch, Maria Terezinha Angeloni, Eduardo Lapa, Alberto Sulaiman.

Agradeço a colaboradores e amigos de empresas participantes de projetos de pesquisa: Alcabyt Eletrônica, Force Line, Projectus Consultoria, Terra Forum, 
Tendência Consultoria, Zentech: José Jerônimo Rodrigues, Alberto Marcolino Rodrigues, Antonio Rodrigues, Eduardo Rodrigues, Osvaldo Codato, Rubens Shiruo, André Jesus, Carlos Eduardo da Costa, Hector Jorge Temprano, Carlos Eduardo Pires, Marcio Ramos, Marcio Cancellara, Alexandre Grain de Carvalho, Elínea Colman Ribeiro, Jussara Cancellara, Paulo Sergio Forte Martini, José Claudio Terra, Carmem Rittner, Edison Gomes, Marcio Hsu.

Agradeço a minha esposa Roseli e ao meu filho Mikhael, aos meus pais Dimetri e Teresinha e a todos os familiares pelo apoio e compreensão durante todo o processo de desenvolvimento desta dissertação. 


\section{FICHA CATALOGRÁFICA}

\section{Ivanoff, Gregorio Bittar}

Ambientes e organizações virtuais: cultura de segurança e regulação entre o desenvolvimento de programas computacionais e estruturas e processos organizacionais / G.B. Ivanoff. -São Paulo, 2006.

$89 \mathrm{p}$.

Dissertação (Mestrado) - Escola Politécnica da Universidade de São Paulo. Departamento de Engenharia de Computação e Sistemas Digitais.

1.Softwares 2.Segurança de software 3.Processos organizacionais de desenvolvimento de software I.Universidade de São Paulo. Escola Politécnica. Departamento de Engenharia de Computação e Sistemas Digitais II.t. 


\section{Resumo}

Estruturas e processos de desenvolvimento de programas computacionais e estruturas e processos organizacionais que incluem os programas, quando considerados separadamente, resultam em estudos de segurança de programas computacionais que, em geral, levam em conta apenas ambientes e organizações tradicionais.

Ambientes e organizações virtuais podem ser utilizados para representar a regulação entre diferentes estruturas e processos, resultando em melhores interpretações sobre o desenvolvimento da segurança de programas computacionais.

Esta atividade de pesquisa explora temas de conteúdo, práticas e artefatos como componentes da cultura de segurança em uma organização virtual de pequeno porte voltada para a inovação.

Os temas de conteúdo propostos para a organização virtual específica são: adaptabilidade, dependabilidade, compatibilidade, credibilidade, confiança e mobilidade.

As práticas e artefatos identificados envolvem, entre outros, a comunicação entre projetistas, desenvolvedores e usuários, a coordenação colaborativa de atividades, a gestão de dependências e o manejo de mudanças e da adaptação.

A atividade de pesquisa foi baseada na metodologia Grounded Theory ou Teoria Fundamentada em Dados e identifica como desafios: a falta de adaptação dos programas computacionais a novas circunstâncias do ambiente, a falta de correspondência entre o programa computacional e a realidade, e a falta de credibilidade e confiança nos programas.

As conclusões despertam a atenção para a exploração de limites de segurança na relação entre pessoas e programas computacionais, e especificamente, para a mudança de condições perigosas, para a possibilidade da mobilidade virtual em diferentes estruturas e processos, e para a necessidade de apoio à perspectiva de inteligência do ambiente. 


\begin{abstract}
Software development structures and processes and organizational structures and processes that include the programs, when considered separately, result in studies of software safety and security that, in general, take into account only traditional environments and organizations.

Virtual environments and organizations may be utilized to represent the regulation between different structures and processes, resulting in better interpretations of software safety and security development.

This research activity explores content themes, practices and artifacts as components of the safety and security culture in a small virtual organization dedicated to innovation.

Content themes proposed for the specific virtual organization are: adaptability, dependability, compatibility, credibility, trust and mobility.

Practices and artifacts identified involve, among others, the communication between designers, developers and users, the collaborative coordination of activities, the dependencies management and the handling of changes and adaptation.

The research activity is based on Grounded Theory methodology and identifies as challenges: the absence of software adaptation to new ambient circumstances, the absence of correspondence between software and reality, and the absence of credibility and confidence in software.

Conclusions call the attention to the exploration of safety and security limits to the relation between people and software and specifically, to the change of dangerous conditions, to the possibility of virtual mobility in different structures and processes, and to the necessity of supporting the ambient intelligence perspective.
\end{abstract}




\section{Sumário}

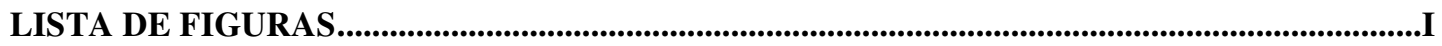

LISTA DE TABELAS ............................................................................................................................. II

LISTA DE ABREVIATURAS............................................................................................. III

1 INTRODUÇÃO .............................................................................................................................. 1

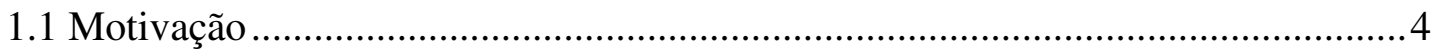

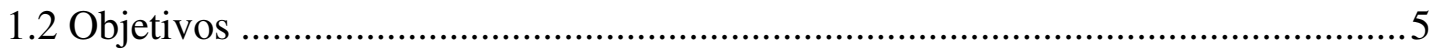

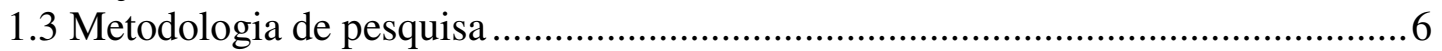

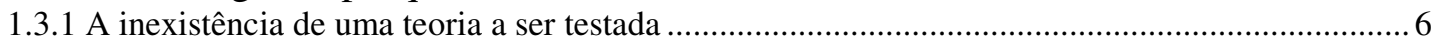

1.3.2 Passos da atividade de pesquisa.......................................................................................

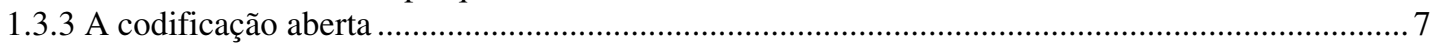

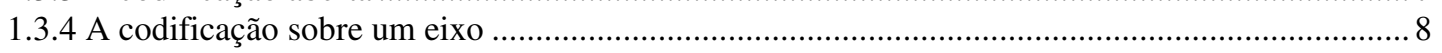

1.3.5 A integração entre estrutura e processo ………………......................................................

1.3.6 A decisão sobre a categoria central de pesquisa ..................................................................... 9

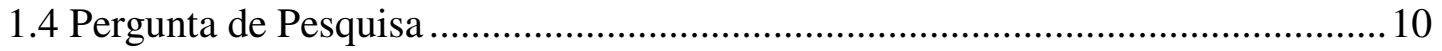

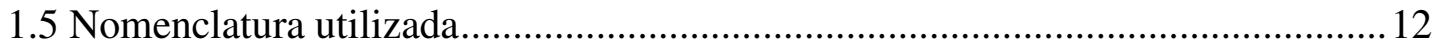

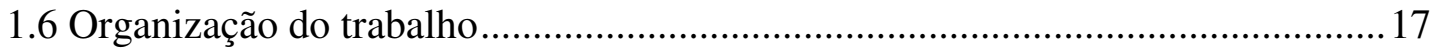

2 COMO A AÇÃO / INTERAÇÃO EVOLUI................................................................................. 19

2.1 Descontinuidades entre diferentes níveis de contextos ..........................................19

2.2 Comunicação entre desenvolvedores e usuários ................................................... 19

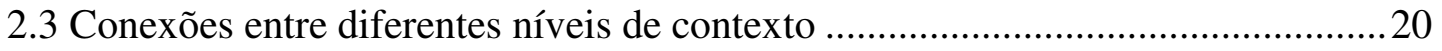

2.4 Ambientes e organizações que incluem usuários e desenvolvedores...................21

\section{EFEITOS INDESEJÁVEIS DE DEPENDÊNCIAS E RUPTURAS EM ESTRUTURAS E}

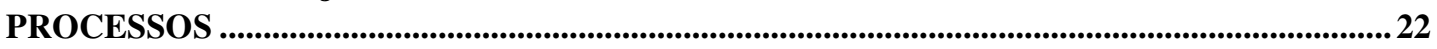

3.1 A falta de adaptação dos programas computacionais a novas circunstâncias do

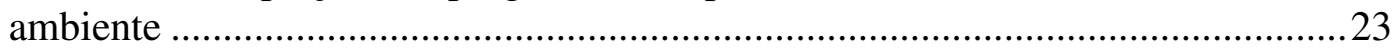

3.2 A falta de correspondência entre o programa computacional e a realidade .........27

3.3 A falta de credibilidade e confiança nos programas..........................................28

3.4 Aspectos principais de efeitos indesejáveis de dependências e rupturas em

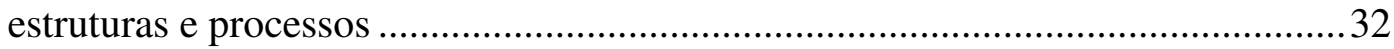

4 . A REPRESENTAÇÃO DE DIFERENTES ESTRUTURAS E PROCESSOS............................33

4.1 A organização como sistema distribuído de conhecimento ...................................33

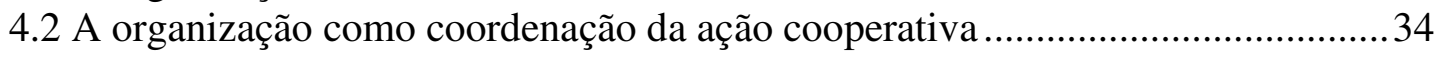

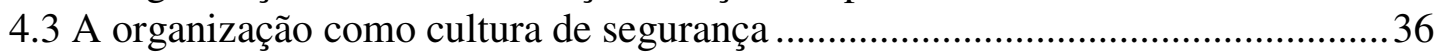

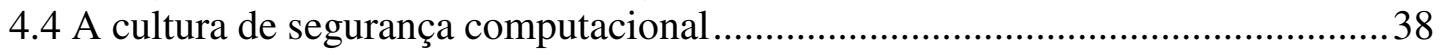

4.5 Aspectos principais da representação de diferentes estruturas e processos ..........42

4.5.1 Fundamentos conceituais da cultura de segurança em ambientes e organizações virtuais ........... 42

4.5.2 Apoio de ferramentas e funções dos ambientes e da organização virtual ..................................... 42

5 TEMAS DE CONTEÚDO PROPOSTOS PARA A REGULAÇÃO DE DIFERENTES ESTRUTURAS E PROCESSOS NOS AMBIENTES E NA ORGANIZAÇÃO VIRTUAL

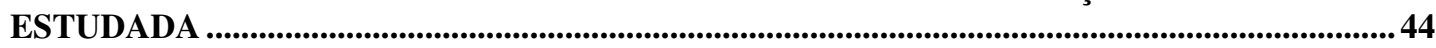

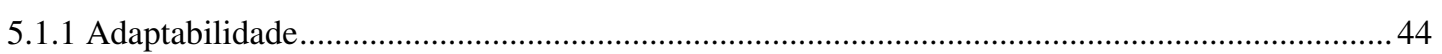




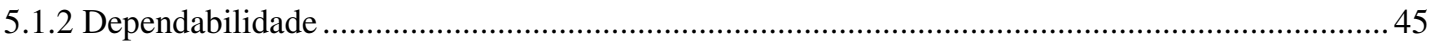

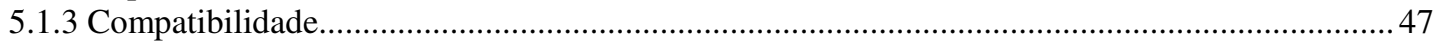

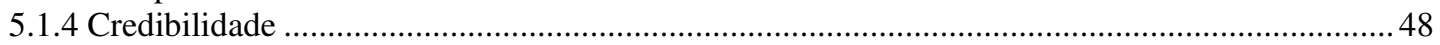

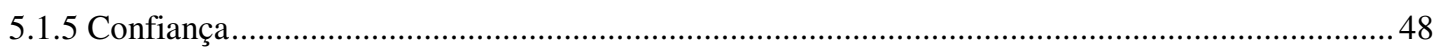

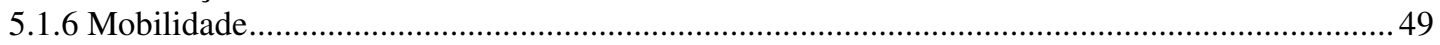

\section{CULTURA DE SEGURANÇA E REGULAÇÃO DE DIFERENTES ESTRUTURAS E} PROCESSOS NOS AMBIENTES E NA ORGANIZAÇÃO VIRTUAL ESTUDADA .................51

6.1 Artefatos da cultura de segurança nos ambientes e na organização virtual estudada

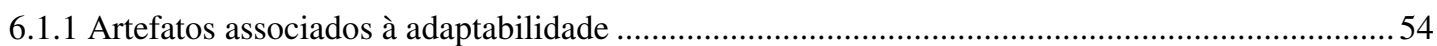

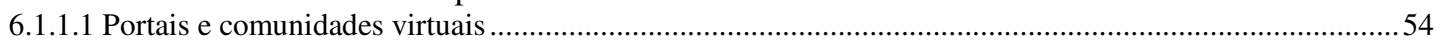

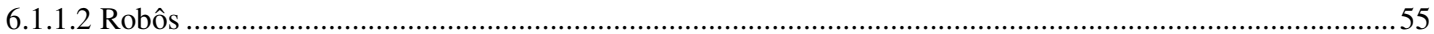

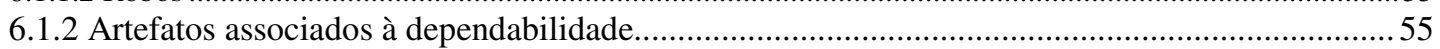

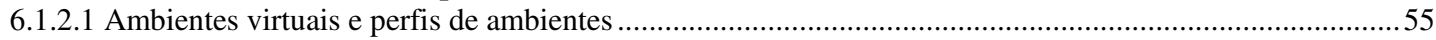

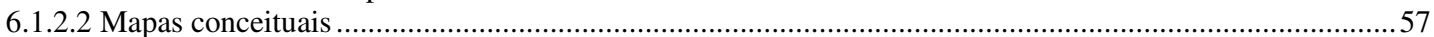

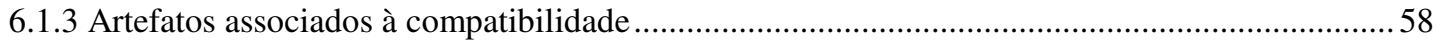

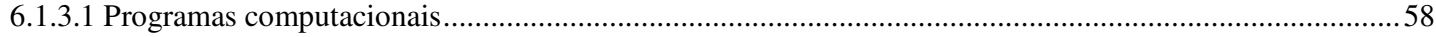

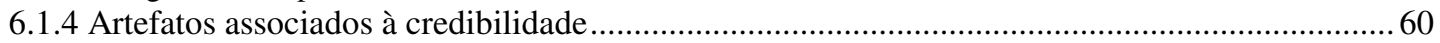

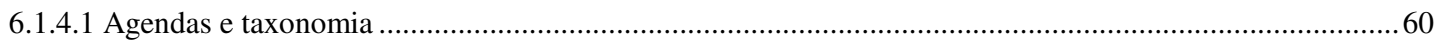

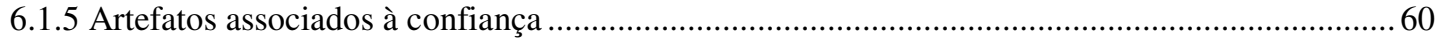

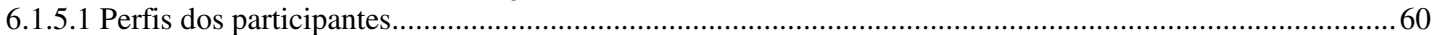

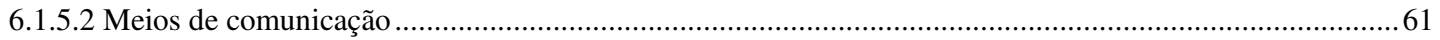

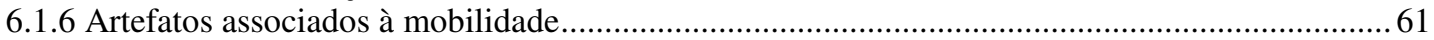

6.1.6.1 Sistema de gestão de conteúdos em hipertexto...............................................................................61

6.2 Práticas da cultura de segurança nos ambientes e na organização virtual estudada

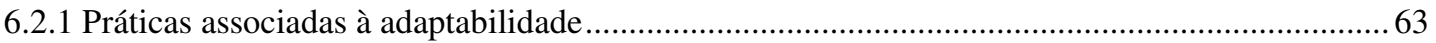

6.2.1.1 Apoio do sistema de gestão de conteúdos em hipertexto para o registro de atividades .............................63

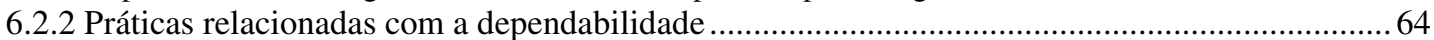

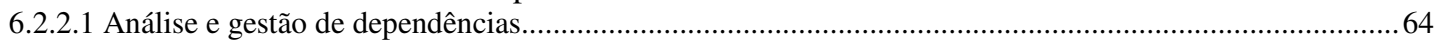

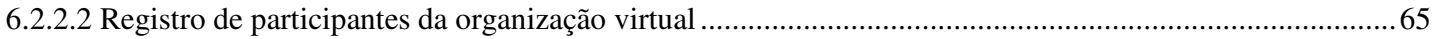

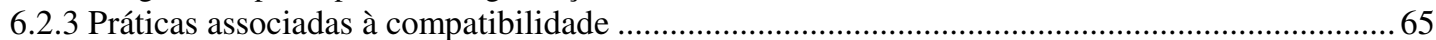

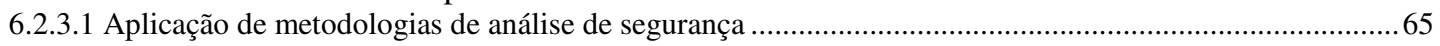

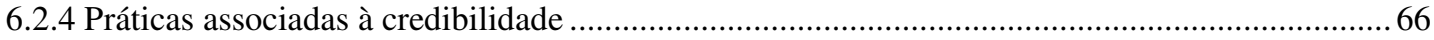

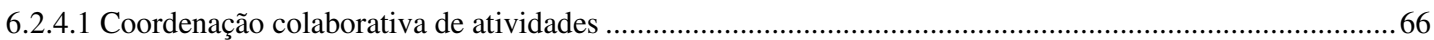

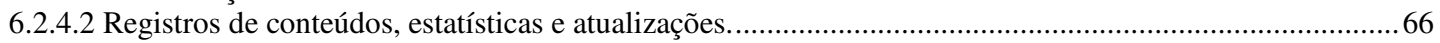

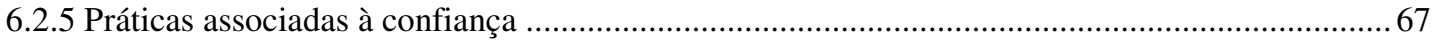

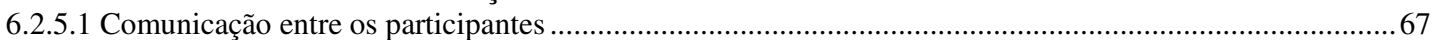

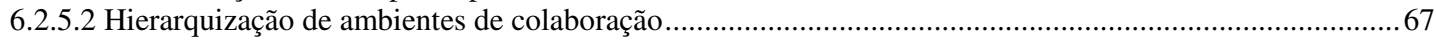

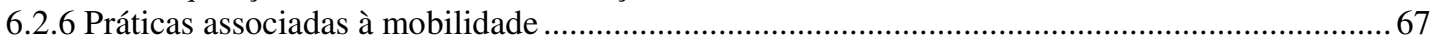

6.2.6.1 Registro de programas e de estruturas e processos ..........................................................................67

6.2.6.2 Registro de senhas e de procedimentos de acesso ...............................................................................68

6.3 Aspectos principais da cultura de segurança e da regulação de diferentes

estruturas e processos nos ambientes e na organização virtual estudada .............69

7 LIMITES DE SEGURANÇA NA RELAÇÃO ENTRE PESSOAS E PROGRAMAS

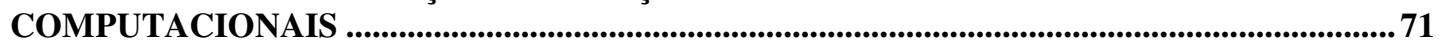

7.1 A mudança de condições perigosas .........................................................71

7.2 Mobilidade virtual em diferentes estruturas e processos.................................73

7.2.1 Mobilidade na relação do homem com o trabalho ............................................................. 73

7.2.2 Mobilidade na relação do homem com a tecnologia......................................................... 77

7.2.3 Mobilidade virtual de pessoas e programas computacionais .................................................. 78

7.3 Apoiando a perspectiva de inteligência do ambiente ..................................... 79

7.4 Considerações finais .................................................................... 80

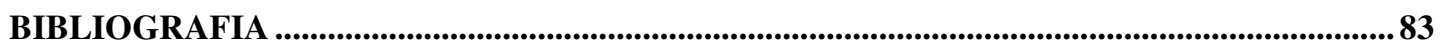




\section{Lista de Figuras}

Figura 1 - Representação do ambiente e da organização virtual, da cultura de segurança e de estruturas e processos envolvidos

Figura 2 - Representação esquemática dos componentes da cultura de segurança e de estruturas e processos 3

Figura 3 - Processo de desenvolvimento do Linux, baseado no processo de desenvolvimento de código aberto de JØRGENSEN, 2001

Figura 4 - Mapa conceitual da página Web com o título "Mapas Mentais", no sistema de gestão de conteúdos em hipertexto. 58

Figura 5 - Exemplo de página de conteúdos, produzida por programa computacional, com mapa conceitual que representa a organização virtual e seus ambientes ...59

Figura 6 - Diagrama do espaço de conversação do Setor de Atenção à Saúde do Adulto do Centro de Saúde Escola Samuel Barnsley Pessoa, em 2001 ..............76

Figura 7 - Descrição sumária dos conteúdos das conversas mapeadas .......................77

Figura 8 - Modelo de organização virtual apresentado pela cidade de Halton, no Reino Unido 


\section{Lista de Tabelas}

Tabela 1 - Temas de conteúdo propostos para a regulação de diferentes estruturas e processos nos ambientes e na organização virtual estudada ..............................50

Tabela 2 - Artefatos da cultura de segurança nos ambientes e na organização virtual

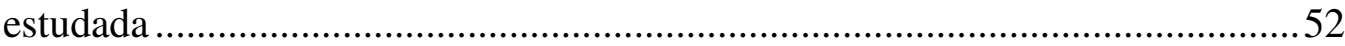

Tabela 3 - Práticas da cultura de segurança nos ambientes e na organização virtual

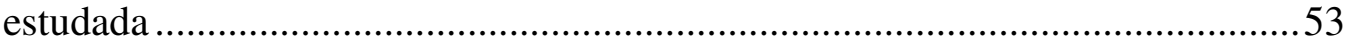

Tabela 4 - Cultura de segurança nos ambientes e na organização virtual estudada ..70 


\section{Lista de Abreviaturas}

CORDIS - Community Research \& Development Information Service, European research and development $(R \& D)$ and innovation activities

CSCW - Computer Supported Cooperative Work

FIDIS - Future of Identity in the Information Society

GAS - Grupo de Análise de Segurança do Departamento PCS USP

GetGC - Grupo de Estudos de Tecnologia em Gestão de Conhecimento

NITRD - (USA) National Coordination Office for Networking and Information

Technology Research and Development, National Coordination Office (NCO), President's Information Technology Advisory Committee (PITAC), a private-sector panel of leading IT executives and researchers that provides expert independent advice to the President on IT R\&D issues.

PCS - Departamento de Engenharia de Computação e Sistemas Digitais

TIC - Tecnologias de informática e comunicação

USP - Universidade de São Paulo 


\section{INTRODUÇÃO}

Dependências técnicas, entre módulos de programas, equipamentos, dispositivos, sistemas e aplicações; dependências sociais, entre indivíduos, grupos e organizações; e, rupturas, consideradas como propriedades inesperadas nos eventos (MALVEZZI, 2003), apresentam interferências importantes sobre a segurança de programas computacionais.

Estruturas e processos de desenvolvimento de programas computacionais e estruturas e processos organizacionais que incluem os programas são, em geral, estudados separadamente e se referem a ambientes e organizações tradicionais.

Ambientes e organizações virtuais podem ser usados para representar a regulação entre diferentes estruturas e processos facilitando a interpretação de efeitos de dependências e rupturas sobre a segurança de programas computacionais.

Ambientes virtuais podem ser definidos, de forma simplificada, como ambientes apoiados ou não por sistemas computacionais que integram informações, objetos e processos, e que também integram agentes que se movem por diferentes ambientes e interagem uns com os outros (adaptado de LANDAUER; BELLMAN, 2001, p. 507). Organizações virtuais são redes temporárias de indivíduos que não se localizam em um escritório central e que, em geral, não têm uma estrutura legal comum. A operação das organizações virtuais se apóia nas competências centrais das partes envolvidas e no uso de tecnologias de informática e comunicação. Os participantes de organizações virtuais atuam através de auto-gestão e de auto-responsabilização e podem apresentar uma identidade única a clientes quando disponibilizam produtos e/ou serviços (adaptado de EMPIRICA, 2001). As organizações virtuais podem se relacionar com outras organizações e podem, também, se comportar informalmente como empresas tradicionais. Em alguns casos se institucionalizam, deixando de operar como organizações virtuais.

Esta atividade de pesquisa explora, em uma organização virtual de pequeno porte voltada para a inovação, a regulação entre:

- estruturas e processos de desenvolvimento de programas computacionais, e 
- $\quad$ estruturas e processos organizacionais que incluem os programas.

Como resultado, a pesquisa identifica temas de conteúdo, práticas e artefatos, como componentes de cultura de segurança dos ambientes e da organização virtual estudada.

A Figura 1 mostra a organização virtual como um elemento que decorre de estruturas e processos de desenvolvimento de programas computacionais e que influencia estruturas e processos organizacionais que incluem os programas. Ambientes virtuais também podem ser integrados neste modelo e representam um meio adicional para que a organização virtual desenvolva suas atividades. A organização virtual nem sempre depende exclusivamente de ambientes virtuais para a sua operação, que pode ser também realizada através de encontros presenciais dos participantes.

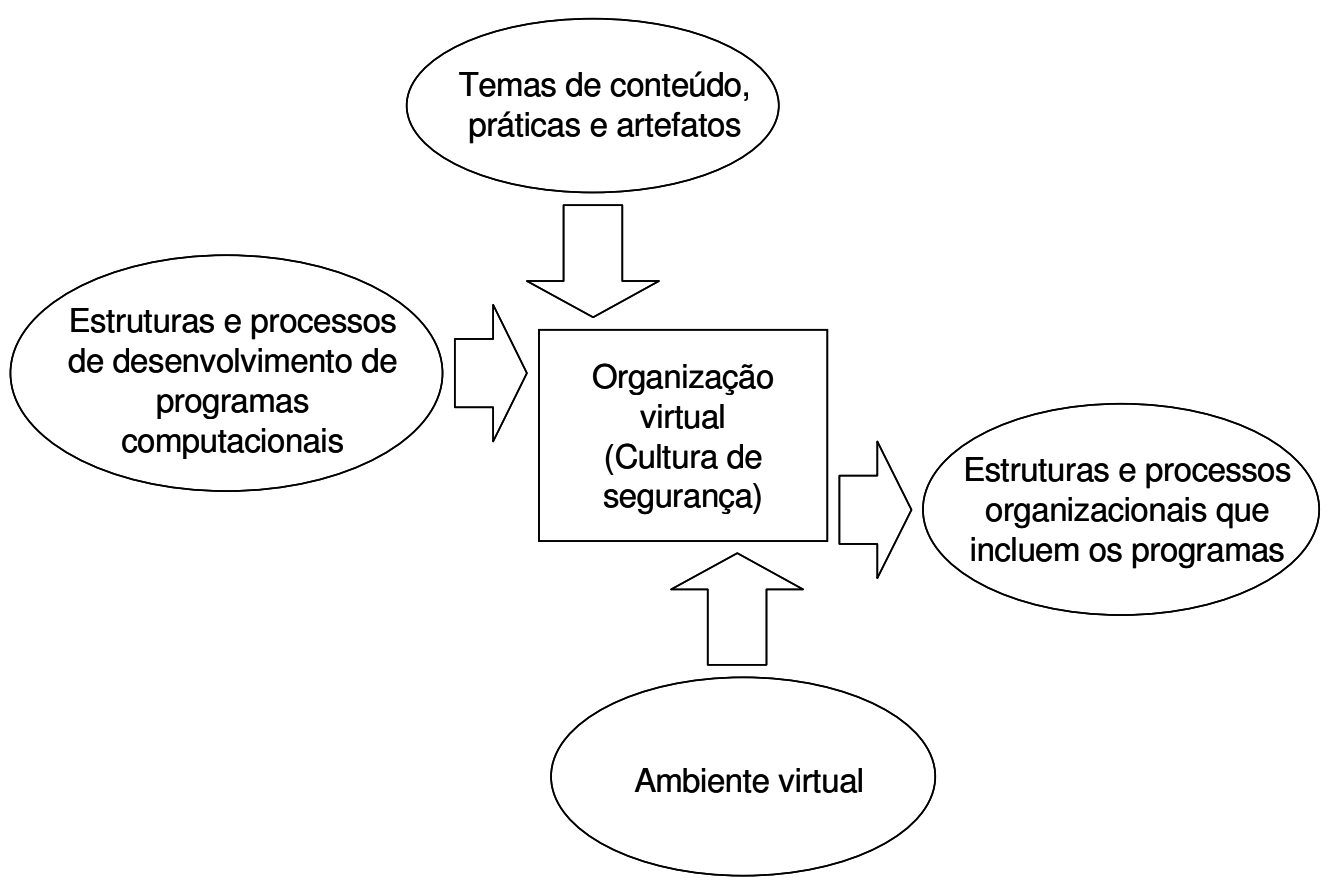

Figura 1 - Representação do ambiente e da organização virtual, da cultura de segurança e de estruturas e processos envolvidos

A análise de temas de conteúdo, práticas e artefatos permite explorar, em diferentes estruturas e processos, a cultura de segurança e os efeitos de dependências e rupturas sobre a segurança de programas computacionais.

Os principais temas de conteúdo propostos para representar a regulação entre as diferentes estruturas e processos, para os ambientes e para a organização virtual 
estudada, são: adaptabilidade, dependabilidade, compatibilidade, credibilidade, confiança e mobilidade.

As práticas e artefatos identificados envolvem, entre outros, a comunicação entre projetistas, desenvolvedores e usuários, a coordenação colaborativa de atividades, a gestão de dependências e o manejo de mudanças e da adaptação.

Os temas de conteúdo, práticas e artefatos e os demais conceitos associados foram estabelecidos e identificados durante a etapa de codificação aberta da metodologia de pesquisa (grounded theory open coding).

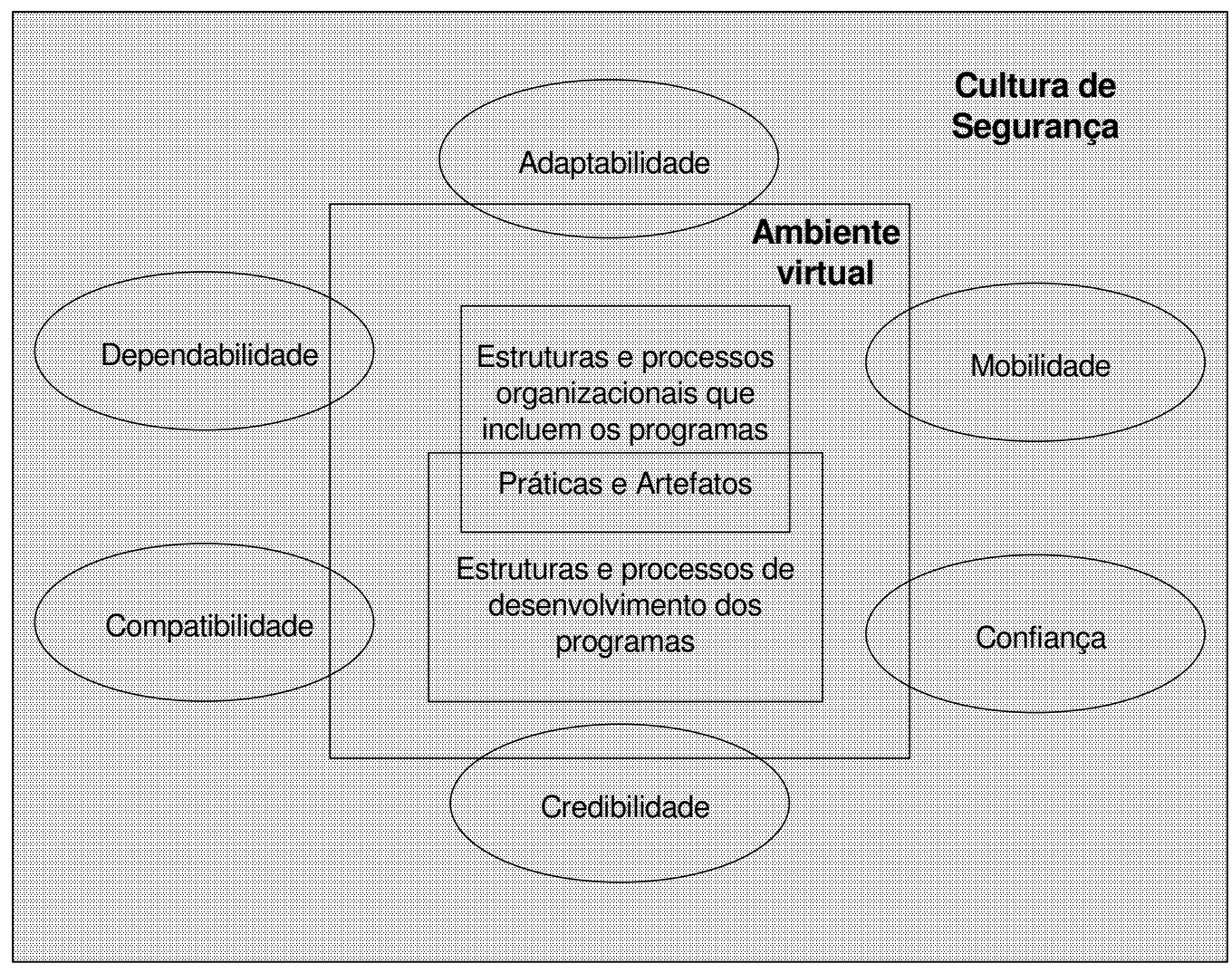

Figura 2 - Representação esquemática dos componentes da cultura de segurança e de estruturas e processos

$\mathrm{Na}$ etapa de codificação sobre um eixo (grounded theory axial coding), da metodologia de pesquisa, os temas de conteúdo, práticas e artefatos são relacionados com a categoria central de pesquisa. A cultura de segurança em ambientes $e$ organizações virtuais, segundo a metodologia grounded theory, foi identificada como a categoria central de pesquisa. 
A Figura 2 ilustra os principais componentes da cultura de segurança - temas de conteúdo, práticas e artefatos, e as diferentes estruturas e processos envolvidos.

Um programa específico para a gestão de conteúdos em hipertexto, baseado em Web, foi utilizado como apoio para a operação dos ambientes e da organização virtual estudada.

Os aspectos de desenvolvimento e de segurança de programas foram explorados tanto nesse programa como em outros programas e facilidades que foram integrados e utilizados.

Além da importância dos conceitos de ambientes e organizações virtuais, a atividade de pesquisa permite perceber a relevância e a emergência dos conceitos de inteligência do ambiente e de mobilidade virtual em diferentes estruturas e processos. Para o desenvolvimento da compreensão dos conceitos apresentados, deve ser ressaltada a importância da necessidade de contínua verificação de efeitos indesejáveis de dependências e rupturas em diferentes estruturas e processos.

\subsection{Motivação}

Os programas computacionais transformam a maneira como as pessoas vivem, aprendem, trabalham e se divertem. Também são componentes críticos que determinam o propósito de sistemas e aplicações em que estejam incluídos (ALMEIDA JÚNIOR, 2003, p. 143).

Uma imensa expansão da oferta de programas computacionais e de facilidades para o seu desenvolvimento está provocando mudanças importantes no conceito de segurança de programas computacionais.

Segundo ELLIOTT e SCACCHI (2003, p. 18), estudos combinando a perspectiva de cultura com tecnologia de informação (TI) são raros.

Quando finalmente estão em operação, os programas computacionais integram diferentes conceitos e culturas, em geral decorrentes de sucessivas etapas de simplificação. As bases segundo as quais esses conceitos e culturas se estabeleceram são, em geral, difíceis de serem revistas com mais detalhes. 
Para todos os públicos envolvidos - desenvolvedores, administradores e usuários, os programas são sujeitos a diferentes categorizações. Requisitos de segurança também sofrem variações importantes e estão sujeitos a contextos e culturas muito diferentes. A atividade de pesquisa explora variações em sequiências de ação / interação em diferentes estruturas e processos - acontecimentos e eventos que podem ou não ocorrer em seqüências ou formas contínuas (STRAUSS; CORBIN, 1998).

O desenvolvimento dos programas é considerado tanto como a ação de desenvolver ou construir, quanto como algo que já está desenvolvido ou construído, mas que ainda está sujeito a mudanças e à adaptação.

Esta abordagem também considera a possibilidade de superposição entre diferentes estruturas e processos, considerando que os programas também são utilizados por estruturas e processos organizacionais dedicados ao seu desenvolvimento, como, por exemplo, em fábricas de software.

Os conceitos de ambiente e organização virtual foram fundamentados a partir dos conceitos de sistemas de conhecimento, de coordenação de ações cooperativas, de organização como cultura e de segurança dos programas.

O conceito de cultura de segurança em ambientes e organizações virtuais é apresentado como alternativa para a representação da regulação entre diferentes estruturas e processos associados a programas computacionais e para o desenvolvimento da segurança de programas computacionais.

\subsection{Objetivos}

A demanda por processos de desenvolvimento de programas mais seguros e confiáveis encontra reforço, por exemplo, em iniciativas do governo dos Estados Unidos para a construção de programas computacionais mais robustos e que atendam demandas de ambientes desafiadores em uma sociedade crescentemente automatizada e interconectada (NITRD, 2006).

O objetivo desta atividade de pesquisa é desenvolver a segurança de programas computacionais através da exploração e caracterização da cultura de segurança em ambientes e organizações virtuais. 
Esse objetivo implica em estabelecer maior proximidade de atividades e culturas de segurança dos públicos envolvidos com estruturas e processos de desenvolvimento dos programas e com estruturas e processos organizacionais que incluem os programas.

\subsection{Metodologia de pesquisa}

A sugestão para a utilização da metodologia de pesquisa Grounded Theory surgiu a partir de debates, no Departamento de Engenharia de Produção da Escola Politécnica da Universidade de São Paulo (DANIEL, Carlos, 2004, informação pessoal), sobre os conceitos de ambiente e organização virtual, e, sobre a forma como estavam sendo conduzidos os trabalhos de pesquisa, com o acompanhamento da evolução de uma organização virtual existente.

A opção pela metodologia Grounded Theory foi reforçada a partir da identificação de textos e referências que também a utilizaram.

Os textos diretamente relacionados com a atividade de pesquisa são:

- GRINTER (1996), sobre a questão de dependências técnicas e sociais no desenvolvimento de programas computacionais;

- STAR e RUHLEDER (1996), sobre o projeto e o acesso em grandes espaços de informação;

- ELLIOTT e SCACCHI (2003) sobre o desenvolvimento de programas computacionais em uma cultura de organização virtual.

\subsubsection{A inexistência de uma teoria a ser testada}

Segundo LEVACOV (2004), a metodologia Grounded Theory, é "uma teoria indutiva baseada na análise sistemática dos dados. O pesquisador aproxima-se do assunto a ser investigado sem uma teoria a ser testada, mas, pelo contrário, com o desejo de entender uma determinada situação e como e porque seus participantes agem de determinada maneira, como e porque determinado fenômeno ou situação se desdobra deste ou daquele modo. Através de métodos variados de coletas de dados, reúne-se um volume de informações sobre o fenômeno observado. Comparando-as, 
codificando-as, extraindo as regularidades, enfim, seguindo detalhados métodos de extração de sentido destas informações, o pesquisador termina então, nas suas conclusões, com algumas teorias que emergiram desta análise rigorosa e sistemática”.

\subsubsection{Passos da atividade de pesquisa}

Vários dos passos sugeridos por STRAUSS e CORBIN (1998) foram adotados para a realização da atividade de pesquisa. Dentre esses passos, merecem destaque:

- a análise através do exame microscópico dos dados;

- as operações básicas de fazer perguntas e fazer comparações;

- a codificação aberta (open coding);

- a codificação sobre um eixo (axial coding);

- a codificação seletiva (selective coding); e

- a codificação para processos (coding for process).

\subsubsection{A codificação aberta}

A codificação aberta é o processo analítico através do qual os conceitos são identificados e as suas propriedades e dimensões são descobertas nos dados (STRAUSS; CORBIN, 1998, p. 101).

Segundo STRAUSS e CORBIN (1998), os conceitos representam os blocos construtivos de uma teoria.

Propriedades são as características de uma categoria (categorias são conceitos que representam fenômenos). $\mathrm{O}$ delineamento de propriedades define e dá significado às categorias.

As dimensões representam os limites ao longo dos quais as propriedades gerais de uma categoria variam. Fornecem especificações às categorias e variação à teoria.

Sub-categorias são conceitos que pertencem a uma categoria, fornecendo a esta categoria maior clarificação e especificação. 


\subsubsection{A codificação sobre um eixo}

Na codificação sobre um eixo, as categorias são relacionadas às suas sub-categorias para formar explicações mais completas e precisas sobre o fenômeno estudado. As sub-categorias, por sua vez, respondem questões sobre o fenômeno (tais como: quando, onde, por quê, quem, como, e com quais conseqüências), dando, portanto, maior poder de explicação ao conceito.

Nessa fase, as atividades envolvidas são:

- Dispor de propriedades e dimensões de cada uma das categorias;

- Identificar a variedade de condições, ações e interações, e conseqüências, associadas com o fenômeno;

- Relacionar cada categoria com suas sub-categorias através de colocações que denotem como essas categorias estão relacionadas umas com as outras; e,

- Buscar por pistas nos dados que denotem como as categorias maiores poderiam se relacionar umas com as outras.

O objetivo da codificação sobre um eixo é o de começar a reconstrução de dados que foram "fraturados" em etapas anteriores da metodologia de pesquisa (codificação aberta).

STRAUSS e CORBIN (1998, p.127) sugerem que estrutura e processo sejam analisados em conjunto durante a fase de codificação sobre um eixo.

Segundo STRAUSS e CORBIN (1998, p. 123) estrutura é o contexto condicional no qual uma categoria (fenômeno) está situada.

O processo pode ser descrito como um conjunto de séries de seqüências de ação / interação que evoluem, e que ocorrem sobre o espaço e o tempo, mudando e às vezes permanecendo as mesmas, em resposta à situação ou ao contexto. Nesta perspectiva, processos podem ser representados por acontecimentos e eventos que podem ou não ocorrer em sequiências ou formas contínuas (STRAUSS; CORBIN, 1998, Cap. 11 Coding for Process, p. 166). 


\subsubsection{A integração entre estrutura e processo}

Os autores apresentam uma ferramenta analítica, denominada paradigma, para ajudar na integração de estrutura e processo.

Segundo STRAUSS e CORBIN (1998, p. 127), ao responder as questões quando, onde, por quê, quem, como, e, com quais conseqüências, o analista torna-se capaz de relacionar estrutura e processo.

Segundo os autores a estrutura ou condições cria as circunstâncias nas quais os problemas, os desafios, os acontecimentos, ou os eventos, pertencentes a um fenômeno, estão situados ou emergem. O processo, por outro lado, denota a ação e a interação sobre o tempo, de pessoas, organizações, e de comunidades, em resposta a certos problemas e desafios.

Segundo STRAUSS e CORBIN (1998, Cap. 11, Coding for Process, p. 165), "estágios e fases poderiam não ser o melhor caminho para obter explicações sobre o que está acontecendo em uma dada situação”. Os autores argumentam que a ação / interação é mais descritiva sobre o que está acontecendo e que "nem tudo que é processo pode ser reduzido a estágios ou fases, nem deveria sê-lo".

STRAUSS e CORBIN (1998, p. 127) afirmam que combinar estrutura e processo ajuda a abordar parte da complexidade, que, por sua vez, representa parte importante da vida. Os autores afirmam que se deve entender ambos, estrutura e processo, para capturar a natureza evolutiva e dinâmica dos eventos.

\subsubsection{A decisão sobre a categoria central de pesquisa}

STRAUSS e CORBIN (1998, p. 143) indicam que a codificação seletiva (selective coding) é a atividade da metodologia de pesquisa onde ocorre o processo de integração e de refinamento da teoria que está sendo construída.

O primeiro passo da integração segundo STRAUSS e CORBIN (1998, p. 146), é decidir a categoria central de pesquisa, aquela que representa o tema central de pesquisa e que também é uma abstração. Nesta atividade de pesquisa elegeu-se como 
categoria central de pesquisa a cultura de segurança em ambientes e organizações virtuais.

STRAUSS (1987 apud STRAUSS e CORBIN, 1998, p. 147), indica critérios para a escolha da categoria central:

- Todas as outras grandes categorias podem estar relacionadas com a categoria central;

- A categoria central deve aparecer, com freqüência, nos dados;

- A explicação que evolui pelo relacionamento das categorias é lógica e consistente;

- O nome ou frase utilizado para descrever a categoria central deveria ser suficientemente abstrato, permitindo sua aplicação em outras áreas de pesquisa, e promovendo o desenvolvimento de uma teoria mais geral;

- Com o refinamento analítico do conceito, através da integração com outros conceitos, a teoria cresce em profundidade e poder explicativo;

- Quando as condições variam, a explicação se sustenta, sendo possível explicar também casos contraditórios ou alternativos relacionados com a idéia central.

\subsection{Pergunta de Pesquisa}

Como desenvolver a cultura e a segurança de programas computacionais em ambientes e organizações virtuais?

IANNACCI (2003) apresenta uma proposta de modelo de gestão, para o processo de desenvolvimento de programas computacionais (processo de desenvolvimento do Linux, baseado no processo de desenvolvimento de código aberto de JØRGENSEN, 2001), que inclui uma curiosa inversão envolvendo as atividades de codificação, revisão, eliminação de erros, montagem e liberação de programas computacionais. Os processos de desenvolvimento e produção dos programas decorrem da montagem e da liberação dos programas, ou seja, estão inseridos após a montagem e liberação 
dos programas, e, realimentam a codificação, representada como a etapa inicial do processo.

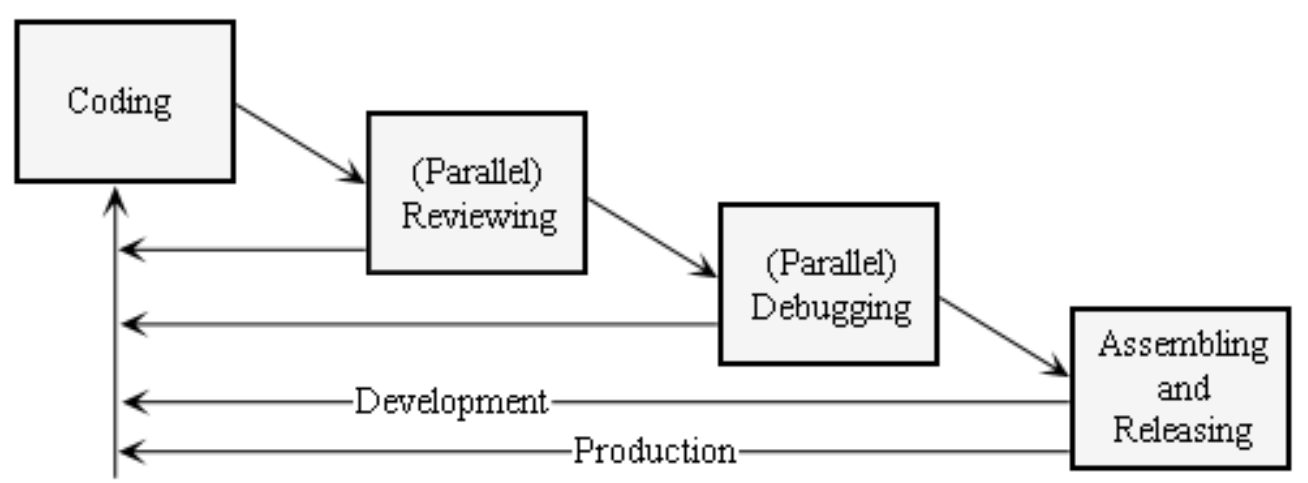

Figura 3 - Processo de desenvolvimento do Linux, baseado no processo de desenvolvimento de código aberto de JØRGENSEN, 2001

IANNACCI (2003) apresenta um interessante debate sobre ciclos dos programas, indicando que o processo de desenvolvimento estudado - diferentemente de processos que se apóiam sobre as fases de planejamento, análise, projeto e implementação - está apoiado principalmente na implementação (FELLER e FITZGERALD, 2001 apud IANNACCI, 2003).

$\mathrm{O}$ aspecto fundamental apresentado pelo autor é de que quanto mais simples o código apresentado por um desenvolvedor a seus pares, mais retornos esse desenvolvedor obtém de outros desenvolvedores envolvidos no processo.

IANNACCI (2003) define ciclos de dupla interação identificando dois comportamentos conectados entre si, de forma que sua ação é coordenada, e, identifica esses comportamentos em duas atividades: a atividade instrumental, por exemplo, o anúncio de um problema que necessita de uma correção, conectado com a atividade inicial de teste de código; e, a atividade de conclusão, por exemplo, de dispor de um programa que funciona adequadamente, sendo que esta atividade de conclusão é, por sua vez, dependente, de maneira incerta, sobre a atividade de correção do problema proposto.

IANNACCI (2003) entende, que utilizando esse processo:

- os desenvolvedores concretizam (enact) suas habilidades de programação e produzem novas alternativas de programação;

- as atividades de concretização implicam em novos usos para o programa; e, 
- o processo como um todo reforça a aplicação dos ciclos de dupla interação entre os desenvolvedores.

Pode-se então considerar que este modelo leva em conta a disponibilidade de ambientes e organizações virtuais. Ambos, ambientes e organizações virtuais estão disponíveis para a comunicação entre os desenvolvedores e podem ser utilizados para apoiar a atividade de desenvolvimento dos programas computacionais.

Os desenvolvedores não precisam necessariamente pertencer às mesmas organizações e também não precisar trabalhar fisicamente juntos. Mesmo assim e nesse caso, seguindo regras relacionadas a programas de código aberto, são capazes de produzir códigos confiáveis, e de agir e interagir para que dependências e rupturas sejam resolvidas de modo satisfatório.

O exemplo citado por IANNACCI (2003) mostra que novos conceitos, práticas e artefatos podem ser criados e utilizados. Aspectos como incerteza, concretização de habilidades de programação, entre outros, são considerados a priori no modelo proposto.

\subsection{Nomenclatura utilizada}

Neste item são apresentados os principais conceitos relacionados com a cultura de segurança em ambientes e organizações virtuais.

Adaptabilidade - É um dos temas de conteúdo propostos para a regulação de diferentes estruturas e processos, nos ambientes e na organização virtual estudada, e está relacionada com: personalização de programas, estruturas, processos e ambientes, quando aplicável; criação de índices de acessos a conteúdos relacionados; utilização de robôs.

Compatibilidade - É um dos temas de conteúdo propostos para a regulação de diferentes estruturas e processos, nos ambientes e na organização virtual estudada, e está relacionada com: registro, produção, desenvolvimento e utilização de estruturas, processos e programas computacionais; acesso e integração de conteúdos e programas disponíveis na Internet; aplicação de metodologias de análise de segurança. 
Confiança - É um dos temas de conteúdo propostos para a regulação de diferentes estruturas e processos, nos ambientes e na organização virtual estudada, e está relacionada com: registro de participantes e de autorizações de acesso (indivíduos, grupos e ambientes virtuais); integração e comunicação através de portais e comunidades virtuais; encontros presenciais e virtuais.

Coordenação colaborativa de atividades - Envolve projetistas, desenvolvedores e usuários e está relacionada com estruturas e processos de desenvolvimento de programas computacionais e com estruturas e processos organizacionais que incluem os programas. Inclui atividades de análise, gestão de dependências, de coordenação e de tomada de decisões.

Credibilidade - É um dos temas de conteúdo propostos para a regulação de diferentes estruturas e processos, nos ambientes e na organização virtual estudada, e está relacionada com: utilização de agendas, taxonomia e documentação; registros de aspectos de segurança, estatísticas, atualizações, procedimentos e melhores práticas; foco nos assuntos de interesse da organização virtual.

Cultura de segurança computacional - Indicada por ALMEIDA JÚNIOR (2003, 4.1.2. Comparação da Cultura de Segurança) a partir da reunião de duas culturas de segurança de desenvolvimento de sistemas: a cultura estabelecida para sistemas críticos e a cultura estabelecida para sistemas de informação.

Dependabilidade - É um dos temas de conteúdo propostos para a regulação de diferentes estruturas e processos, nos ambientes e na organização virtual estudada, e está relacionada com: utilização de diferentes versões de programas; análise de dependências técnicas e sociais; planejamento sobre as fases de recuperação de desastres.

Desafios do desenvolvimento de programas computacionais - Incluem a necessidade de coordenação de ações cooperativas entre desenvolvedores, administradores e usuários, o manejo e a interpretação de dependências técnicas, entre módulos de programas, equipamentos, dispositivos, sistemas e aplicações, de dependências sociais, entre indivíduos, grupos e organizações, e, de rupturas, vistas como propriedades inesperadas de eventos. Estão relacionados com processos de adaptação de pessoas, organizações, sistemas e aplicações e com a influência 
recíproca entre esses processos de adaptação e o processo evolutivo dos programas computacionais.

Gestão de conteúdos em hipertexto, baseada em Web - Abstração conceitual do programa computacional WIKI, definido como uma coleção de páginas Web interligadas, que pode ser expandida livremente; um sistema em hipertexto para armazenar e modificar informação; um banco de dados, onde cada página é facilmente modificada por qualquer usuário autorizado ou não, utilizando um navegador Web (LEUF; CUNNINGHAM, 2001 apud MATTISON, 2003).

Gestão de dependências - Conforme tese apresentada por GRINTER (1996), para obtenção de doutorado em filosofia da informação e ciência da computação, é uma das razões pelas quais a coordenação entre desenvolvedores de programas computacionais se estabelece. Está relacionada com a gestão de configurações de programas computacionais, e, por conseqüência, com a identificação de componentes de programas computacionais nos sistemas, com a sua organização e seqüenciamento e com o controle de mudanças dos programas computacionais, durante as atividades de desenvolvimento. Para a autora a gestão de configurações é a parte do desenvolvimento de programas computacionais que identifica as dependências existentes, e as atividades que desenvolvedores, gerentes e organizações conduzem para administrá-las. O principal argumento da autora, com relação a dependências, é que são relações técnicas entre códigos que criam e refletem relações sociais entre indivíduos, grupos e organizações.

Grau de dependência de módulos de programas computacionais - Segundo a metodologia de análise de segurança para sistemas críticos utilizada pelo GAS Grupo de Análise de Segurança do Departamento de Engenharia de Computação e Sistemas Digitais da Escola Politécnica da USP, na fase de análise de módulos de programas computacionais, procede-se à análise de todas as rotinas que constituem o software embutido no Sistema Crítico, seja a rotina responsável direta ou indiretamente por aspectos de Segurança Crítica. Este procedimento está ligado ao fato de que os módulos de software apresentam alto grau de dependência entre si (ALMEIDA JÚNIOR, 2003). As dependências entre módulos se caracterizam 
quando um determinado módulo chama rotinas ou acessa variáveis declaradas em outros módulos.

Metodologia de análise de segurança para sistemas críticos - O GAS segue, para os sistemas críticos, uma metodologia de análise de segurança composta pelos seguintes processos principais (ALMEIDA JÚNIOR et al., 2002 apud ALMEIDA JÚNIOR, 2003, 2.5.2. Metodologia de Análise de Segurança):

- Determinação dos Requisitos Gerais de Segurança,

- Mapeamento dos Requisitos Gerais de Segurança,

- Análise dos Módulos Responsáveis pela Segurança, e

- Avaliação do Grau de Segurança.

Mobilidade - É um dos temas de conteúdo propostos para a regulação de diferentes estruturas e processos, nos ambientes e na organização virtual estudada, e está relacionada com: trabalho colaborativo apoiado por computador (gestão de conteúdos em hipertexto, baseada em Web, gestão de programas e configurações, utilização de portais).

Níveis de comunicação e descontinuidades em hierarquias de informação Trata-se de maneira mais formal para entender os processos de comunicação envolvidos no desenvolvimento de infra-estruturas (STAR e RUHLEDER, 1996). As autoras estudam o equilíbrio, ou a falta de equilíbrio, entre linguagem e prática através de comunidades e partes de organizações. As autoras seguem o modelo de BATESON (1998), que distingue três níveis em qualquer sistema de comunicação. No primeiro nível estão as colocações ou afirmações diretas baseadas em fatos. $\mathrm{O}$ segundo nível caracteriza o contexto, ou meta-mensagem, onde ocorre uma classificação da mensagem estabelecida no primeiro nível. No terceiro nível, ocorre a avaliação do contexto em si. A mesma classificação de níveis pode ser usada para abstrair níveis de aprendizagem considerando: o aprender, o aprender a aprender, e, o aprender sobre teorias da aprendizagem e paradigmas de educação. Para o objetivo de seu trabalho, as autoras identificam três níveis (ou ordens) de desafios que aparecem no processo de desenvolvimento de infra-estruturas e na comunicação entre desenvolvedores e usuários em sistemas que envolvem o trabalho colaborativo 
apoiado por computador. Os desafios de primeira ordem podem ser resolvidos com a redistribuição ou aumento de recursos ainda disponíveis, incluindo a informação. Os desafios de segunda ordem se originam de efeitos contextuais imprevistos ou desconhecidos. Os desafios de terceira ordem são inerentemente políticos ou envolvem disputas permanentes. As autoras argumentam que as descontinuidades ocorrem entre contextos e não entre sistemas e pessoas ou entre tecnologia e organização. Na implementação de sistemas de informação em larga escala, o projeto de sistemas de comunicação e troca de mensagens que não levam em conta as descontinuidades entre diferentes níveis de contexto, tem como conseqüência organizações divididas e confusas, sistemas sem uso ou evitados, e a criação de circunstâncias que reforçam disparidades no horizonte organizacional.

Organização virtual - São redes temporárias de indivíduos que não se localizam em um escritório central. Em geral, não têm uma estrutura legal comum e atuam através de auto-gestão e de auto-responsabilização. Apresentam uma identidade única a clientes e podem disponibilizar produtos e/ou serviços. Sua operação se apóia nas competências centrais das partes envolvidas e no uso de tecnologias de informática e comunicação. Relacionam-se com outras organizações, podem comportar-se como empresas tradicionais, e, em alguns casos, institucionalizam-se, deixando de operar como organizações virtuais. Podem ser utilizadas para colaborar com a interpretação da regulação entre estruturas e processos de desenvolvimento dos programas e estruturas e processos organizacionais que incluem os programas.

Desenvolvimento de programas computacionais - Inclui tanto o desenvolvimento como a utilização dos programas. Pode ser entendido como a ação de desenvolver ou construir (foco no processo), e como algo que já está desenvolvido ou construído, mas que ainda está sujeito a mudanças e à adaptação (foco na estrutura).

Sistemas distribuídos de conhecimento - Segundo TSOUKAS (1996), firmas são sistemas descentralizados que não dispõem de uma "mente" supervisora. Além do conhecimento nunca estar [totalmente] disponível para um [único] agente específico, este agente também não tem condições de estabelecer completa e antecipadamente que tipo, quando e onde, um determinado conhecimento prático será relevante. Em qualquer instante, o conhecimento de uma firma é o resultado indeterminado de 
indivíduos tentando administrar as tensões inevitáveis entre expectativas normativas - relacionadas com os papéis que desempenham, disposições - [organizações] formadas no curso de socializações passadas, e, contextos locais - conhecimento local de circunstâncias particulares de tempo e lugar.

TWIKI - Programa de gestão de conteúdos em hipertexto, baseado em Web. Tratase do programa selecionado para apoiar a regulação de diferentes estruturas e processos e a representação dos ambientes e da organização virtual estudada. A decisão para a seleção do programa foi tomada a partir da análise de suas funcionalidades, incluindo as funções de segurança. Inclui mais funcionalidades que o programa WIKI. Disponível em <http://www.twiki.org >.

WIKI - Programa simplificado de gestão de conteúdos em hipertexto, baseado em Web. Trata-se de programa cuja utilização permite absorver os principais conceitos propostos por uma família de programas de código aberto. O programa não dispõe de muitas funcionalidades, mas pela sua simplicidade, torna-se muito fácil de utilizar e de aprender. Disponível em <http://www.wiki.org $>$.

\subsection{Organização do trabalho}

O capítulo 2 mostra como a ação e a interação evoluem, através da exploração de diferentes estruturas e processos e da comunicação entre desenvolvedores e usuários. É abordada a questão da descontinuidade entre diferentes níveis de contexto e a proposta de ambientes e organizações virtuais, que incluam desenvolvedores e usuários.

O capítulo 3 aborda, como o problema da dissertação, os efeitos indesejáveis de dependências e rupturas em diferentes estruturas e processos. Os efeitos indesejáveis de dependências e rupturas são percebidos na falta de adaptação dos programas computacionais a novas circunstâncias do ambiente, na falta de correspondência entre o programa computacional e a realidade, e na falta de credibilidade e confiança sobre os programas.

O capítulo 4 apresenta os fundamentos conceituais relacionados com a categoria central de pesquisa cultura de segurança em ambientes e organizações virtuais. $\mathrm{O}$ capítulo identifica os conceitos de sistema de conhecimento, de coordenação da ação 
cooperativa, de organização com cultura de segurança e de cultura de segurança computacional.

No capítulo 5 é apresentada a proposta de temas de conteúdo para a regulação de diferentes estruturas e processos nos ambientes e na organização virtual estudada. No capítulo 6 são apresentados, como resultados de pesquisa, as práticas e artefatos que caracterizam a cultura de segurança da organização virtual de pequeno porte estudada.

No capítulo 7 é apresentada uma reflexão sobre os limites de segurança na relação entre pessoas e programas computacionais, incluindo a mudança de condições perigosas, o conceito de mobilidade virtual em diferentes estruturas e processos e a necessidade de apoio à perspectiva de inteligência do ambiente. 


\section{COMO A AÇÃO / INTERAÇÃO EVOLUI}

A exploração conjunta de estruturas e processos de desenvolvimento dos programas e de estruturas processos organizacionais que incluem os programas busca explicações sobre como a ação / interação evolui.

Pesquisas sobre o trabalho colaborativo apoiado por computador em grandes espaços de informação revelam a existência de situações ambíguas entre diferentes níveis de contextos de comunicação, informação ou aprendizagem.

\subsection{Descontinuidades entre diferentes níveis de contextos}

STAR e RUHLEDER (1996) apontam a existência de descontinuidades entre diferentes níveis de contextos de comunicação, informação ou aprendizagem, e descrevem como double bind, uma situação desagradavelmente difícil ou complicada, em que mensagens são transmitidas simultaneamente em diferentes níveis de contexto, ou em que uma resposta é demandada em um nível de contexto superior e negada em um nível inferior. As autoras fazem referência ao trabalho de BATESON (1978, The Logical Categories of Learning and Communication, p. 279308) sobre aprendizagem e comunicação.

Essas situações ambíguas, que emergem como paradoxos lógicos, mostraram-se muito relevantes para esta atividade de pesquisa em função de que se trata de fenômeno de reconhecimento muito difícil. Além disso, um segundo problema associado às situações ambíguas é que, uma vez identificadas, ainda assim é muito difícil explicitar o problema de tal forma que outras partes envolvidas o reconheçam como tal.

\subsection{Comunicação entre desenvolvedores e usuários}

O modelo proposto por BATESON (1978), distingue três níveis em qualquer sistema de comunicação. No primeiro nível estão as colocações ou afirmações diretas baseadas em fatos. O segundo nível caracteriza o contexto, ou meta-mensagem, onde 
ocorre uma classificação da mensagem estabelecida no primeiro nível. No terceiro nível ocorre a avaliação do contexto em si.

Para o objetivo de seu trabalho, as autoras identificam três níveis (ou ordens) de desafios que aparecem no processo de desenvolvimento de infra-estruturas e na comunicação entre desenvolvedores e usuários em sistemas que envolvem o trabalho colaborativo apoiado por computador. Os desafios de primeira ordem podem ser resolvidos com a redistribuição ou aumento de recursos ainda disponíveis, incluindo a informação. Os desafios de segunda ordem se originam de efeitos contextuais imprevistos ou desconhecidos, provavelmente associados à interação de duas ou mais questões de primeira ordem. Os desafios de terceira ordem são inerentemente políticos ou envolvem disputas permanentes, e podem emergir da interação entre questões de ordem inferior.

STAR e RUHLEDER (1996) entendem que a dinâmica de poder e a autoridade são importantes para as dificuldades de identificação e explicitação de situações ambíguas. As autoras citam o exemplo de usuários que recebem ferramentas computacionais muito complexas ou que recebem informações insuficientes para a utilização destas ferramentas e, quando falham ao usar as ferramentas, são apontados como resistentes à tecnologia. $\mathrm{O}$ mesmo problema pode ocorrer de forma inversa quando os usuários esperam que os desenvolvedores possam captar adequadamente os seus requisitos e com isso produzirem sistemas que resolvam problemas de grande complexidade. Os problemas de comunicação são, na opinião das autoras, decorrentes de descontinuidades de linguagem e do contexto no qual o processo de concepção e utilização de sistemas e ferramentas ocorre.

\subsection{Conexões entre diferentes níveis de contexto}

STAR e RUHLEDER (1996) entendem que times de desenvolvimento multidisciplinares apoiados por pesquisadores que participam de forma ativa podem colaborar para que usuários e projetistas conectem os diferentes níveis do contexto. O compartilhamento de entendimento entre níveis formais e informais pode ajudar a identificar as situações ambíguas classificando adequadamente as diversas mensagens em seus respectivos níveis. As autoras entendem que este 
compartilhamento necessita de contextos institucionais e que uma política de recompensas deve ser elaborada para garantir este tipo de colaboração.

STAR e RUHLEDER (1996) citam também a questão de competências técnicas de usuários, apontando que estes recebem treinamento apenas para questões técnicas de primeira ordem, ou seja, relacionadas apenas com colocações ou afirmações diretas baseadas em fatos.

As autoras entendem que problemas mais complexos, como, por exemplo, a implementação de uma tecnologia particular de trabalho em grupo, requer competências conceituais de segunda ou terceira ordem. As autoras sugerem que mecanismos institucionais sejam disponibilizados para ajudar os indivíduos a localizar as competências desenvolvidas, em contextos técnicos que capacitem os usuários para o seu uso efetivo em diversas aplicações e a desenvolver e manter o conhecimento necessário que lhes permita entender e resolver problemas de segunda e terceira ordem assim que surjam, ao longo do tempo.

\subsection{Ambientes e organizações que incluem usuários e desenvolvedores}

A pesquisa de STAR e RUHLEDER (1996) esteve relacionada com o esforço de implantação de um sistema colaborativo de apoio a pesquisadores na área de biologia. As soluções apontadas, entretanto, podem ser aplicáveis a diferentes

estruturas e processos que incluam situações ambíguas entre usuários e desenvolvedores. 


\section{EFEITOS INDESEJÁVEIS DE DEPENDÊNCIAS E RUPTURAS EM ESTRUTURAS E PROCESSOS}

Dependências e rupturas podem ser benéficas, com efeitos relacionados à autonomia (YANAY, 1994), ao crescimento e ao desenvolvimento, mas também podem ter efeitos indesejáveis. Dependências e rupturas podem ter origem em estruturas e processos de desenvolvimento de programas computacionais e em estruturas e processos organizacionais que incluem os programas.

No desenvolvimento de programas computacionais, dependências podem ser categorizadas como dependências técnicas e dependências sociais (GRINTER, 1996).

Efeitos indesejáveis de dependências e rupturas não estão necessariamente associados apenas com intenções negativas. Intenções positivas também podem provocar efeitos indesejáveis.

A mudança de versão ou a aplicação de correções para a solução de problemas de segurança são exemplos de ações que podem limitar o uso de programas computacionais. A não aplicação das correções ou a não realização de mudanças de versão deixaria brechas de segurança que tornariam o sistema inseguro. A aplicação das modificações ou a realização da mudança de versão, entretanto, pode impedir a execução de atividades, em função das novas limitações impostas.

Efeitos indesejáveis de dependências e rupturas são percebidos desde atividades simples como aquisição, configuração e instalação, até outras mais críticas e complexas, como na ocorrência de condições perigosas, em que o programa computacional contribui, tanto pela omissão (falha em fazer algo requisitado), quanto por executar algo que não deveria ser realizado ou ainda, por fazê-lo no momento errado ou na seqüência incorreta (ALMEIDA JÚNIOR, 2003). Dependências e rupturas também podem provocar interferências mútuas. 


\subsection{A falta de adaptação dos programas computacionais a novas circunstâncias do ambiente}

Apesar de que os programas computacionais estão continuamente se adaptando a novas condições do ambiente, os usos e condições com os quais estão envolvidos freqüentemente mudam mais que a capacidade de adaptação dos programas.

As mudanças que afetam os programas computacionais decorrem de indivíduos e grupos, de processos sociais, do ambiente e das organizações. Uma possível explicação para o ritmo e pressão crescente das mudanças decorre do fato de que a utilização dos programas está intensamente interligada com a utilização de redes de comunicação e, também, de maneira mais ampla, com o avanço da Internet.

As pesquisas indicam que não só está aumentando o número de usuários como estão aumentando os tipos de públicos e também os usos que se fazem dos programas. As circunstâncias do ambiente se alteram tanto por fatores técnicos como por fatores sociais.

Notícia veiculada pela AGÊNCIA ESTADO (2005) informa sobre resultados de pesquisa que avalia públicos, características e ambientes de navegação, na Internet, em dez países. A pesquisa mostra que, nos países de primeiro mundo, "no mínimo $90 \%$ das pessoas que têm acesso à internet a usam em casa. No Brasil, apenas $58 \%$ a usam na residência”.

O coordenador de análises da empresa de pesquisas informa: "Nosso internauta não tem dinheiro para bancar o custo de ter um computador, uma linha telefônica e um provedor de acesso, mas não desiste de ser um usuário. Ele usa os vários pontos disponíveis na cidade e navega. [...] o internauta brasileiro tem sido atraído pelos comunicadores instantâneos (MSN Messenger ou ICQ, por exemplo), blogs, fotologs, comunidades (como o Orkut), sites das operadoras de telefonia móvel e salas de bate-papo com muito mais intensidade que os de países desenvolvidos. [...] A internet se tornou um meio de inclusão de jovens no Brasil que não têm acesso a outro entretenimento e a usam em cybercafés e na escola. A inclusão ocorre até em lanchonetes, escolas e bibliotecas, ao contrário dos outros países. É o jeitinho brasileiro." 
ZUBOFF e MAXMIN (2003, p. 324) explicam a demanda pela Internet: "o crescimento exponencial da participação da Internet em geral, e o comércio eletrônico em particular, podem ser explicados pela forma na qual o novo ambiente, embora inconscientemente, se oferecia como antídoto à experiência de uma individualidade persistentemente frustrada". Os autores entendem que a Internet proporciona, naturalmente, algum alívio sob a forma de auto-apoio (ZUBOFF e MAXMIN, 2003, p. 326). Segundo os autores "Recursos de informações e comunidades on-line permitiram que indivíduos recebessem um apoio próprio ou um apoio de companheiros, quando as organizações tradicionais não conseguiam suprir suas necessidades".

Segundo ZUBOFF e MAXMIN (2003, p. 326), as pessoas utilizam a Internet com o objetivo de controlar atividades cruciais dentro do espaço individual: "Em 2001, cerca de 52 milhões de usuários da Internet buscavam informações sobre saúde em sites da Web ou em grupos de bate-papo e foros de discussão - é mais do que os que compravam on-line, acompanhavam cotações da bolsa ou verificavam placares de jogos esportivos. As motivações por apoio incluíram a conveniência on-line (93\%), o fato de conseguir mais informações do que em outras fontes, como seus médicos (83\%) e o bem-vindo anonimato de suas buscas e perguntas (80\%)".

ZUBOFF e MAXMIN (2003, p. 348) afirmam que as pessoas estarão mais interessadas no apoio do que em facilidades automatizadas, como, por exemplo, e de forma isolada, pela simples oferta de agentes inteligentes que viajam entre diferentes sites, coletando dados e completando transações. Os autores entendem que as pessoas desejarão garantir que reservas em hotéis impliquem em quartos disponíveis na sua chegada, que empresas de seguros aceitem reivindicações legítimas e forneçam serviços rápidos, que médicos não sintam pressões financeiras desordenadas que resultem em tratamentos fragmentados e superficiais, e, que computadores adquiridos estejam configurados conforme as especificações, que funcionem e que elas também saibam como usá-los. Os autores entendem que o apoio não pode ser automatizado ou comoditizado, mas que, sem a inteligência e a complexidade do novo ambiente virtual, o avanço na economia de apoio é inconcebível. ZUBOFF e MAXMIN (2003, p. 350) entendem que o ambiente digital [virtual] não é o destino; é a ponte para o próximo episódio do capitalismo. 
A demanda pela Internet parece ser, entretanto, apenas uma válvula de escape. A questão mais profunda pode estar no estresse com o qual as pessoas convivem em seu dia a dia.

ZUBOFF e MAXMIN (2003, p. 143) afirmam: "Os psicólogos sabem que grande parte do estresse que as pessoas sofrem na vida contemporânea resulta de experiências repetitivas associadas com as pressões do tempo". Os autores afirmam também que os psicólogos valorizam, nos tempos atuais, um tipo de estresse mais ubíquo e insidioso, chamado de estresse crônico, de características contínuas e normalmente não detectadas. Segundo os autores: "O excesso de estresse, porém, provoca sofrimento físico e mental e pode até [...] causar colapso. [...] entre esses fatores de estresse incluem-se "demandas excessivas sobre tarefas ou papéis [...] excesso de complexidade, incerteza, conflito, restrições de escolha ou remuneração inadequada $[\ldots] "$

Segundo os autores, o estresse crônico da atualidade é vivido internamente: "as pessoas ficam ansiosas ou sofrem quando suas ações ou pensamentos são sujeitos a interrupções”. ZUBOFF e MAXMIN (2003, p. 144) afirmam que um dos processos organizados e contínuos mais importantes da vida moderna é o estabelecimento e a manutenção da identidade, e citam que no âmago do estresse moderno encontra-se a experiência de identidade fracassada ou interrompida.

Segundo os autores: "quando as experiências da pessoa a impedem de ter sua própria identidade, e contradizem a noção de seu próprio eu, elas geram uma reação ao estresse [com] ansiedade, exaustão, indiferença, raiva e uma diversidade de sintomas físicos - da fadiga à depressão, passando por doenças auto-imunes, úlceras, hipertensão arterial, obesidade e doenças cardíacas".

ZUBOFF e MAXMIN (2003, p. 146) citam estudos que sugerem que quando conseguem manter e verificar os aspectos mais valorizados de sua identidade, as pessoas vivem mais, são mais felizes e mais saudáveis.

Em 2005, o Departamento de Engenharia de Computação e Sistemas Digitais da Escola Politécnica da Universidade de São Paulo, promoveu um encontro com um representante da Universidade de Karlstad, da Suécia. Na sua apresentação, o 
palestrante indicou os projetos de pesquisa conduzidos por aquela universidade, no contexto das iniciativas de pesquisa e desenvolvimento da Comunidade Européia.

Dentre essas iniciativas de pesquisa, está o Projeto FIDIS - Future of Identity in the Information Society.

O projeto FIDIS está inserido no contexto de um programa maior (EIS - European Information Society) e atende intenções de desenvolvimento de tecnologias que forneçam confiança e segurança de informação, ao mesmo tempo em que preservam a identidade dos indivíduos.

As informações divulgadas sobre o projeto indicam que a representação digital de características pessoais mudará as maneiras de identificar os indivíduos, e que, as identidades digitais suplementares, chamadas de identidades virtuais, deverão incorporar conceitos e fornecer possibilidades como a utilização de pseudônimos e a manutenção do anonimato nas situações e contextos envolvendo segurança, lucro, conveniência e mesmo para o lazer. As informações indicam também que existem diferenças culturais importantes entre os países da Comunidade Européia e que estas diferenças deverão ser levadas em conta no desenvolvimento da tecnologia.

O tema de identidade é tratado em grande profundidade em disciplina de pósgraduação (PST-5716 - O Homem e o Trabalho na Administração Tradicional e na Emergente), oferecida pelo Instituto de Psicologia da Universidade de São Paulo.

A questão do estresse, como colocada, indica que a adaptação das pessoas e dos programas computacionais será necessária em espaços que integrem ambientes físicos, mentais e virtuais (KROGH et al., 2001). Novas realidades se configuram reforçando o interesse pela exploração de aspectos de segurança e justificando os esforços para o desenvolvimento de uma cultura de segurança em diferentes estruturas e processos.

Os programas computacionais também deverão levar em conta a personalização de necessidades, considerando que os ambientes, contextos e situações a que estarão sujeitos poderão sofrer grandes variações. 


\subsection{A falta de correspondência entre o programa computacional e a realidade}

"Sistemas travam na estréia do BTMU" é o título de uma matéria publicada em janeiro de 2006, no Jornal Gazeta Mercantil: "O Banco Tokyo-Mitsubishi UFJ (BTMU), maior entidade do mundo em ativos, abriu ontem suas portas com três meses de atraso e afetado por erros de informática. No final do dia foram contabilizados uma dezena de casos de mau funcionamento em entradas de dinheiro realizadas por contas corporativas atribuídos a um defeito nos programas de computador, segundo a agência local Kyodo" (EFE Tóquio, 2006).

A matéria informa, ainda, que os repetidos erros de informática confirmaram a incerteza do mundo financeiro japonês, sobre a fusão de sistemas computadorizados de dois bancos até então rivais. Informa também que, um equívoco recente, na introdução de uma ordem de venda, que não pode ser freada a tempo nos computadores, provocou a queda de quase $2 \%$ no indicador da bolsa Nikkei, e, a perda, pela Mizuho Securities, intermediária da negociação, de 27 bilhões de ienes (US\$ 225 milhões).

Os problemas no início de operações do BTMU lembraram o fiasco do banco Mizuho, outro gigante mundial cujos caixas eletrônicos não funcionaram no dia de sua inauguração em abril de 2002. Atrasos dos pagamentos e transações causados por problemas de seus sistemas provocaram ações de indenizações milionárias.

Apesar dos esforços dos empregados do BMTU, "o sistema está longe de estar terminado e o processo de integração levará [ainda] dois anos". Os caixas eletrônicos, de um dos bancos participantes da fusão não reconheceram, no início da operação do banco, o sistema de identificação biométrico que é disponível como opção para os clientes do outro banco, e os depósitos a prazo fixo só puderam ser acessados a partir de terminais de um dos bancos.

O aspecto da fusão de dois bancos até então concorrentes destaca a questão das diferenças entre estruturas e processos de desenvolvimento dos programas e estruturas e processos organizacionais que incluem os programas. Os programas são desenvolvidos em uma realidade e sua utilização acontece em realidades diferentes. 


\subsection{A falta de credibilidade e confiança nos programas}

LAPRIE (1982 apud LALA, 2000) apresenta o conceito de dependabilidade como uma estrutura que incorpora a confiabilidade e a disponibilidade como características distintivas da especificação de um sistema. $\mathrm{O}$ autor indica que tanto a confiabilidade como a disponibilidade podem descrever a dependabilidade de um sistema. Se o sistema for não reparável, então a dependabilidade pode ser caracterizada pela sua confiabilidade. Por outro lado, se o sistema for reparável, a disponibilidade pode ser usada para caracterizar a dependabilidade.

JOHNSON e MALEK (1998 apud LALA, 2000) indicam que diversos pacotes de programas computacionais foram desenvolvidos para analisar a dependabilidade de sistemas complexos. O autor informa que muitos dos pacotes desenvolvidos requerem, como entradas, diagramas de blocos de confiabilidade, árvores de falhas ou diagramas de Markov, e que, infelizmente, essas formas de modelos de entradas são extremamente difíceis de desenvolver para sistemas multiprocessados, como os que estão sendo progressivamente utilizados em aplicações críticas. DAS (1990 apud LALA, 2000) defende que mais atividade de pesquisa é necessária para a avaliação eficiente da dependabilidade em sistemas multiprocessados.

ALMEIDA JÚNIOR (2003, 4.2.5. O Aspecto Software em Sistemas Críticos e em Sistemas de Informação) alerta sobre os fatores que limitam a aplicação de programas computacionais. A partir dessa indicação, pode-se entender a importância crítica dos programas computacionais como os componentes que determinam o propósito de seus processadores, e, por conseqüência, de sistemas e de aplicações em que estejam incluídos.

Segundo ALMEIDA JÚNIOR (2003), o hardware de computador é projetado para ser de propósito geral, ou seja, necessita de um software associado para que possa realizar alguma função útil. O software carregado no computador é que determina a função que a máquina irá executar (SAFEWARE, 2002 apud ALMEIDA JÚNIOR, 2003). ALMEIDA JÚNIOR (2003) aponta que a grande fonte de riscos do programa computacional está na facilidade de se alterar um código de programa, e, por conseqüência, o propósito de um computador. 
O autor reforça que: "Os fatores limitantes em um software são determinados pela criatividade de analistas e não por fatores físicos" (SAFEWARE, 2002 apud ALMEIDA JÚNIOR, 2003). Sobre a questão do ambiente, ALMEIDA JÚNIOR (2003), citando PIRIE (1999), indica situações em que o software realiza exatamente o que estava especificado e mesmo assim não representa um programa seguro.

O autor reforça ainda que "Não há formas diretas de se medir o nível de confiabilidade ou mantenabilidade de um software", e sugere que o software representa ainda a maior fonte de dúvidas e problemas na implementação de Sistemas Críticos e de Sistemas de Informação.

O contínuo avanço tecnológico dos programas e de suas aplicações incrementa a complexidade de análise e a falta de credibilidade e confiança nos programas.

Um dos aspectos mais interessantes está relacionado com a questão da mobilidade de programas computacionais.

KANGAS (2000), aborda o tema de sistemas embarcados e de técnicas que capacitem as pessoas a interagir com diversos sistemas localizados no ambiente, a qualquer momento. A tese apresentada por KANGAS (2000) sugere uma abordagem em que componentes de programas computacionais podem ser transferidos dinamicamente (códigos móveis), e capacitam a interação em contextos com sistemas embarcados. A idéia principal do autor é a de que o dispositivo de controle transportado pelo usuário obtenha código móvel do sistema embarcado, que, uma vez executado, cria uma interface virtual que permite ao usuário interagir com o sistema. $\mathrm{O}$ autor pretende prover uma técnica de uso geral que permita ao usuário, através de um único dispositivo de controle, interagir com diversos tipos de sistemas embarcados. KANGAS (2000) entende que a abordagem é flexível, dinâmica e adaptativa, e, ao mesmo tempo, requer poucos recursos dos sistemas embarcados. $\mathrm{O}$ autor defende que a flexibilidade, o dinamismo e a adaptabilidade são devidos ao fato de que o código móvel é uma entidade ativa, que pode tomar decisões dinâmicas durante a sua operação. O autor sugere, concluindo, que os códigos móveis podem, ainda, estar autocontidos nos próprios sistemas embarcados, e que sua abordagem deve ser levada em conta no projeto de novos sistemas embarcados no futuro. 
SATOH (2004a) sugere uma estrutura baseada em agentes móveis para a inteligência do ambiente. A idéia da infra-estrutura é a de prover funcionalidades computacionais de apoio e informações a pessoas, lugares e objetos. Usando sistemas de localização de rotas, a estrutura permitirá a navegação de agentes móveis baseados em Java para computadores móveis ou fixos próximos das entidades e lugares com os quais os agentes estão relacionados, mesmo quando as localizações se modificam. Os usuários poderão acessar seus serviços personalizados tanto de dispositivos fixos no ambiente como de dispositivos portáteis.

SATOH (2004b) sugere também, critérios de seleção de agentes móveis, não apenas de acordo com suas capacidades de desempenhar as tarefas desejadas para a aplicação, mas também de acordo com suas capacidades de mobilidade. A abordagem de seleção de agentes móveis é realizada de acordo com itinerários entre múltiplos servidores.

SATOH (2005) indica ainda um modelo de mundo para serviços conscientes de local e de usuário em ambientes computacionais ubíquos. O modelo pode ser dinamicamente organizado em forma de árvore baseada em uma dada região geográfica, como um andar de um prédio, por exemplo, e cada nó da árvore pode ser construído como um componente executável de programa computacional. O autor argumenta que seu modelo é único quando comparado a outras abordagens, porque pode ser administrado por múltiplos computadores, sob demanda, e porque pode prover uma visão unificada dos locais, não apenas de entidades e espaços físicos, incluindo usuários e objetos, mas também de serviços e dispositivos computacionais. $\mathrm{O}$ autor indica que um protótipo desta abordagem foi construído em um sistema de agente móvel baseado em Java. Os programas também podem viabilizar capacidades de adaptação a dispositivos, com relação a mudanças em aspectos do ambiente.

TAKAGI et al. (2005) propõe uma estrutura para aquisição de informações de contexto para um dispositivo pessoal que equipa uma variedade de sensores. A estrutura captura informações de contexto de um usuário e do ambiente que o rodeia. As aplicações que operam no dispositivo pessoal mudam seu comportamento, se adaptando às informações capturadas. A estrutura adota o modelo de quadro negro 
(blackboard) para recuperar informações, precisas e de elevado nível abstrato, de contexto e de múltiplos módulos de análise.

HART et al. (2004) pesquisaram o uso de dispositivos eletrônicos portáteis como apoio à memória e organizacional em pacientes expostos a traumas cerebrais. Como resultados, dentre as funções preferidas pelos participantes da pesquisa, estavam:

- acompanhar o dinheiro gasto,

- lembrar de coisas a fazer, e

- lembrar o que outras pessoas falam.

Os autores concluem que dispositivos portáteis são aceitáveis e desejados por consumidores expostos a traumas cerebrais, de moderados a severos, e para usos como apoios compensatórios. Foram consideradas como barreiras mais "salientes" ao uso e ao acesso, tanto por usuários como por não usuários, os aspectos de simplicidade de uso, dependabilidade técnica e durabilidade. Esses aspectos ganharam maior destaque que características físicas, como tamanho, cor e modalidades de entrada e saída específicas. A habilidade de desempenhar múltiplas funções também foi considerada importante, apesar de poder apresentar incompatibilidade com a simplicidade de operação.

Os argumentos de LALA (2000) reforçam a afirmação de ALMEIDA JÚNIOR (2003) sobre a indisponibilidade de formas diretas de mensuração do nível de confiabilidade ou mantenabilidade de um programa computacional. As pesquisas de KANGAS (2000) e SATOH (2004a, 2004b, 2005) mostram o interesse e o desenvolvimento de programas que se movem através de múltiplos processadores. TAKAGI et al. (2005) e HART et al. (2004) ilustram as possibilidades de dispositivos portáteis, e HART et al. (2004) indica que a dependabilidade é uma questão crítica, apontada como barreira mais "saliente" ao uso e ao acesso.

Todos esses argumentos reforçam a necessidade de interpretação integrada de estruturas e processos de desenvolvimento e estruturas e processos organizacionais que incluem os programas, para o desenvolvimento da credibilidade e confiança nos programas. 


\subsection{Aspectos principais de efeitos indesejáveis de dependências e rupturas em estruturas e processos}

Dependências e rupturas podem ter efeitos indesejáveis e estão relacionadas com indivíduos e grupos, com processos sociais, com o ambiente e com as organizações.

Dependências e rupturas têm implicações diretas sobre estruturas e processos de desenvolvimento de programas computacionais e sobre estruturas e processos organizacionais que incluem os programas. Podem ocasionar fracassos, entre muitos outros efeitos indesejáveis.

As dependências ocorrem tanto por aspectos técnicos, relacionados com dependências entre módulos de programas, equipamentos e dispositivos, como por aspectos sociais, decorrentes de dependências e de relações entre indivíduos, grupos e organizações.

Aspectos positivos de dependências e rupturas em diferentes estruturas e processos estão relacionados com o crescimento e o desenvolvimento. 


\section{4 . A REPRESENTAÇÃO DE DIFERENTES ESTRUTURAS E PROCESSOS}

Diferentes visões colaboram para enriquecer a categorização de ambientes e organizações virtuais. Dentre essas visões, destacam-se as visões de organização de TSOUKAS (1996), como sistema de conhecimento, e de MAGGI (2006), como coordenação da ação cooperativa (regulação de processos de ação e decisão). A visão da organização como cultura de segurança se baseia em ELLIOTT e SCACCHI (2003). ALMEIDA JÚNIOR (2003) descreve a questão da cultura de segurança computacional.

\subsection{A organização como sistema distribuído de conhecimento}

TSOUKAS (1996) apresenta uma abordagem conceitual sobre sistemas distribuídos de conhecimento.

Segundo TSOUKAS (1996), firmas são sistemas descentralizados que não dispõem de uma "mente" supervisora. São, portanto, sistemas distribuídos de conhecimento. Além do conhecimento nunca estar [totalmente] disponível para um [único] agente específico, este agente também não tem condições de estabelecer completa e antecipadamente que tipo, quando e onde, um determinado conhecimento prático será relevante.

Segundo o autor, em qualquer ponto do tempo, o conhecimento de uma firma é o resultado indeterminado de indivíduos tentando administrar as tensões inevitáveis entre:

- as expectativas normativas, relacionadas com os papéis que desempenham;

- as disposições, [organizações] formadas no curso de socializações passadas; e,

- os contextos locais, conhecimento local de circunstâncias particulares de tempo e lugar. 
O ambiente e a organização virtual podem ser caracterizados, portanto, como um sistema distribuído de conhecimento, composto de estruturas e processos de desenvolvimento de programas computacionais e de estruturas e processos organizacionais que incluem os programas.

\subsection{A organização como coordenação da ação cooperativa}

Segundo MAGGI (2006), a organização pode ser entendida como processo de ações e decisões. Os conceitos e hipóteses que caracterizam a teoria do agir organizacional estão relacionados de forma simplificada com os seguintes aspectos:

- o tempo é considerado como uma variável fundamental;

- a separação entre organização e sujeito agente não é permitida;

- a noção de agir indica a relação entre a conduta de um sujeito humano e seu sentido subjetivo e objetivo;

- a organização é entendida como processo de ações e decisões;

- o agir organizacional concerne tanto aos processos de ação de um sujeito singular quanto aos processos de ação coletiva e, por outro lado, todo processo organizacional está em relação com outros processos;

- o agir organizacional ordena as ações do processo em direção a um objetivo perseguido;

- o processo de ações e decisões se auto-organiza;

- as regras são produzidas, re-elaboradas e construídas no decorrer do desenvolvimento do processo (regulação ou estruturação do processo);

- as regras são produzidas de maneira heterônoma ou autônoma nos diferentes níveis de decisão do processo;

- a regulação do processo de ação concerne à coordenação das ações e à coordenação do desenvolvimento das ações;

- a estruturação e o processo variam em termos de forma e no tempo; e, 
- a avaliação do processo de ação concerne à congruência da variabilidade de seus componentes, integrando a congruência em relação ao bem-estar dos sujeitos agentes.

A teoria do agir organizacional representa um outro ponto de vista sobre o trabalho, o bem-estar e a aprendizagem, em comparação com os "paradigmas objetivistas, próprios de uma visão mecanicista e organicista, em que o sistema seria prédeterminado aos sujeitos", e, também, em comparação com o "ponto de vista subjetivista, para o qual o sistema só existe através da construção dos atores, de suas interações, podendo ser definido como único para todos, mas que só pode ser visto e entendido a posteriori" (SZNELWAR, L., Apresentação da edição brasileira, In: MAGGI, 2006).

A interpretação da organização (diferentes estruturas e processos) como processo de ações e decisões permite perceber o significado do conceito de qualidade como qualidade de vida, tanto para os indivíduos que atuam no desenvolvimento dos programas como para aqueles que os utilizam, incluindo a possibilidade de que sejam os mesmos indivíduos que constroem e utilizam os programas.

Em sua proposta teórica, o autor relaciona a coordenação das ações e a coordenação do desenvolvimento das ações com a comunicação.

MAGGI (2006) faz referência à contribuição de BARNARD (1938), e indica que os temas tratados por esse autor, diferentemente do que se possa pensar a princípio, são:

- a ação cooperativa e seus componentes;

- a definição da organização formal e as relações entre organização informal e formal; e,

- a autoridade definida em referência à participação do indivíduo no processo organizacional.

Segundo MAGGI (2006), BARNARD (1938) parte do estudo da ação intencional do sujeito e da ação cooperativa entre dois ou mais indivíduos para chegar a uma teoria da organização enquanto coordenação de ações cooperativas. MAGGI (2006) sugere que a existência da organização formal se apóia sobre a tendência natural dos indivíduos a cooperar, e indica que, se existe uma tendência espontânea que conduz à 
formação de um tal sistema [cooperativo], o mesmo não se pode dizer quanto a seu governo. Esses elementos não teriam uma relação durável se sobre eles não agisse uma coordenação consciente e pré-ordenada com vista a objetivos explícitos. O autor entende que "este subsistema de coordenação da ação cooperativa [...] constitui a organização".

A partir do conceito de organização como coordenação consciente das ações, MAGGI (2006) coloca a questão da comunicação. Para o autor, “A comunicação constitui o tecido conectivo da organização, o que determina os modos de coordenação. Pela comunicação, é possível compartilhar os fins comuns e é também possível coordenar as ações com vistas à obtenção de um resultado. A comunicação que caracteriza a organização é aquela dotada de autoridade. O autor reforça que, "definida dessa maneira, a autoridade evidentemente não coincide com a hierarquia".

A partir da visão de MAGGI (2006), o ambiente e a organização virtual podem ser utilizados para colaborar com a interpretação da regulação entre estruturas e processos de desenvolvimento de programas computacionais e estruturas e processos organizacionais que incluem os programas.

A possibilidade de utilização do conceito de ambiente virtual também estaria contemplada já que tanto nas estruturas e processos de desenvolvimento de programas como nas estruturas e processos organizacionais, a utilização desta forma de interação está disponível. A representação de diferentes estruturas e processos no ambiente e na organização virtual colabora com a interpretação da regulação.

\subsection{A organização como cultura de segurança}

ELLIOTT e SCACCHI (2003) apontam que a perspectiva da cultura organizacional é estudada por vários autores (MARTIN; SCHEIN; TRICE e BEYER; OTT). Segundo ELLIOTT e SCACCHI (2003, p. 12), organizações têm culturas que formam e fornecem aos membros, indicações sobre futuros cursos de ação. Segundo os autores, a cultura organizacional colabora para que indivíduos e grupos administrem incertezas e ambigüidades, ao mesmo tempo em que oferecem algum grau de ordem à vida social. 
Segundo ELLIOTT e SCACCHI (2003, p. 12) formas culturais em organizações facilitam às pessoas fazerem sentido do seu mundo e podem ser caracterizadas em quatro categorias: símbolos, linguagem, narrativas e práticas.

ELLIOTT e SCACCHI (2003, p. 13) se apóiam no trabalho de MEYERSON e MARTIN para apresentar os três paradigmas de mudança cultural:

- integração,

- diferenciação, e

- ambigüidade.

Na integração, a cultura é definida como aquela que é compartilhada por uma dada organização. Na diferenciação, a cultura decorre de inconsistências, falta de consenso e de fontes de conteúdo cultural, centradas em não líderes. $\mathrm{Na}$ ambigüidade, diferentemente da integração e da diferenciação, a cultura tem como prioridade o compartilhamento do valor relacionado com a consciência da ambigüidade. Neste último caso, a cultura está em contínua mutação.

Segundo ELLIOTT e SCACCHI (2003, p. 17) práticas são manifestações da cultura da organização e podem ser formais e informais. ELLIOTT e SCACCHI (2003) fazem referência ao trabalho de MARTIN (2002), indicando os quatro diferentes tipos de prática formais:

- estrutura ou estrutura organizacional,

- tecnologia e tarefas,

- regras e procedimentos, e

- controles financeiros.

ELLIOTT e SCACCHI (2003) indicam normas como métodos desenvolvidos para fazer as atividades. Os autores citam, como exemplo, em comunidades virtuais, as regras sociais estabelecidas através da interação via Web.

Segundo ELLIOTT e SCACCHI (2003, p. 17), estrutura se refere à estrutura organizacional relacionada, por exemplo, a detalhadas descrições de cargos (em organizações de modelo mecanicista), ou a responsabilidades de definição mais aberta, ou ainda, a times multifuncionais (em organizações de modelo organicista). 
ELLIOTT e SCACCHI (2003, p. 17) entendem que a estrutura pode incluir o formato da hierarquia (verticalizada ou horizontalizada), critérios de diferenciação, e o equilíbrio de dispositivos para integração e diferenciação.

Segundo ELLIOTT e SCACCHI (2003, p. 17), estudos sobre a cultura de organizações típicas [tradicionais] incluem a observação do estilo que as pessoas adotam para se vestir, do ambiente de escritórios e da arquitetura de edifícios. Em ambientes e organizações virtuais, os autores sugerem observar o conteúdo de textos, gráficos e figuras e a organização de websites.

\subsection{A cultura de segurança computacional}

Os sistemas críticos provavelmente representam a situação em que a demanda por segurança atinge seus níveis mais elevados. Segundo ALMEIDA JÚNIOR (2003, 4.2.2. Classificação dos Sistemas Críticos e Sistemas de Informação), em uma das possibilidades de classificação, os sistemas são considerados críticos quando falhas ocasionam conseqüências consideradas como inaceitáveis.

ALMEIDA JÚNIOR (2003, 6.1.2. Cultura de Segurança, p. 176), indica que a cultura de segurança computacional pode ser interpretada a partir da fusão de sistemas críticos e de sistemas de informação. O autor aponta diferenças nas preocupações presentes em sistemas críticos, "em falhas do próprio sistema, e nas preocupações em sistemas de informação, em invasões aos sistemas”. O autor também aponta a "necessidade de uma cultura global de segurança nas organizações e a questão da aproximação das culturas de segurança”.

ALMEIDA JÚNIOR (2003, p. 4-5) propõe adotar o termo Aplicação Crítica quanto a Segurança, ou mais resumidamente, Aplicação Crítica, para denominar o objeto supervisionado e controlado e o termo Sistema de Supervisão e Controle, ou mais sucintamente Sistema Crítico, para designar os equipamentos, circuitos e seu software [programa computacional] associado, os quais realizam a supervisão e controle sobre a Aplicação Crítica. ALMEIDA JÚNIOR (2003, p. 56-62) indica como aplicações críticas: geração nuclear de energia, processos químicos, aviação comercial e área aeroespacial, transporte metro-ferroviário, equipamentos médicos, indústria em geral. 
Para ALMEIDA JÚNIOR (2003), uma planta química ou um avião são exemplos de aplicações críticas e seus circuitos e programas computacionais são exemplos de sistemas críticos, específicos a cada aplicação.

ALMEIDA JÚNIOR (2003, p. 104-116) indica como aplicações de sistemas de informação: sistemas de suporte à decisão, gerenciamento de relações com os clientes, centrais de atendimento, gerência do conhecimento, sistemas de gestão empresarial, inteligência empresarial, comércio eletrônico, aplicações multimídia. O autor (ALMEIDA JÚNIOR, 2003, 6.1. Conclusões e Contribuições, 6.1.7. Aplicações, p. 179) aponta para a "aproximação gradual das considerações sobre as consequiências decorrentes de disfunções de Sistemas Críticos e Sistemas de Informação, sugerindo que as aplicações poderão ser consideradas como unificadas, produzindo as Aplicações de Sistemas Computacionais”.

Nos sistemas críticos, módulos de programas computacionais apresentam alto grau de dependência entre si. As dependências entre módulos se caracterizam quando um determinado módulo chama rotinas ou acessa variáveis declaradas em outros módulos, e devem ser objeto de análise específica.

O Grupo de Análise de Segurança do Departamento de Engenharia de Computação e Sistemas Digitais da Escola Politécnica da USP segue, para os sistemas críticos, uma metodologia de análise de segurança (CAMARGO; ALMEIDA JÚNIOR, 1999 In: ALMEIDA JÚNIOR, 2003, 2.5.2. Metodologia de Análise de Segurança) composta por quatro processos principais, detalhados por ALMEIDA JÚNIOR (2003) em oito etapas.

A primeira etapa da metodologia de análise de segurança de sistemas críticos, denominada de Determinação dos Requisitos Gerais de Segurança, implica na necessidade de entendimento do sistema em estudo, na geração de uma Descrição Geral do Sistema Crítico e de sua arquitetura, e na conseqüente produção dos Requisitos Gerais de Segurança.

Para a obtenção de informações, é importante, nessa primeira etapa, a existência de interações com o operador do sistema crítico.

$\mathrm{Na}$ segunda etapa, de Mapeamento dos Requisitos Gerais de Segurança, são determinados requisitos específicos, obtidos pela decomposição dos requisitos gerais, 
para cada um dos módulos ou subsistemas de equipamentos, dispositivos, programas computacionais ou procedimentos operacionais. Um relatório é elaborado, com a descrição detalhada do sistema.

A terceira etapa é a de Análise dos Módulos de Equipamentos e Dispositivos (Hardware), e, nesta, é realizada a classificação de equipamentos e dispositivos e a descrição da Análise de Segurança desses módulos.

$\mathrm{Na}$ quarta etapa, que analisa especificamente os módulos de programas computacionais, procede-se à análise de todas as rotinas, responsáveis, direta ou indiretamente, por aspectos de segurança crítica.

Dentre as atividades que fazem parte desta etapa estão: a preparação da documentação necessária de cada rotina e de cada variável e constante utilizadas nessas rotinas, a inspeção do código fonte através da aplicação de uma lista de inspeção específica para cada linguagem de programação (ALMEIDA JÚNIOR et al., 1999), e, finalmente, a condução de reuniões entre os analistas envolvidos no trabalho para a análise das rotinas do sistema e a análise de interferência entre rotinas.

Nas reuniões, os analistas debatem entre si os aspectos funcionais de cada rotina, procurando identificar situações que possam levar o sistema a condições inseguras. É nomeado um analista para a apresentação de cada rotina e os demais participantes da reunião têm como função realizar o questionamento da rotina.

A reunião também conta com a presença, segundo ALMEIDA JÚNIOR (2003), de, pelo menos, um profissional envolvido com a análise do hardware, cuja função é auxiliar no esclarecimento de questões relativas à implementação dos circuitos do Sistema Crítico.

Na quinta etapa, de Análise dos Mecanismos de Detecção e Recuperação de Falhas, é determinado o fator de cobertura de falhas existente no sistema.

$\mathrm{Na}$ sexta etapa, de Análise dos Procedimentos Operacionais, é realizada uma verificação de procedimentos operacionais envolvidos, em conjunto com a análise dos módulos de hardware e de software (programas computacionais). 
A sétima etapa é a de Análise de Interferência, quando se realiza a análise parcial de outros sistemas que apresentam interfaces com o sistema crítico. A análise é centrada nos aspectos interferentes relativos a informações vitais do sistema crítico.

Na última e oitava etapa, de Avaliação Final da Segurança, elabora-se um Relatório de Conclusões da Análise de Segurança, destacando-se: problemas diversos encontrados em rotinas de programas computacionais; falhas, ou entradas impróprias, de equipamentos ou dispositivos (hardware), que podem levar o sistema a situações potencialmente inseguras; e o grau de segurança do sistema.

Deve-se destacar que, em ambas, na sexta e na sétima etapas, também são conduzidas análises de interferências relacionadas com os programas computacionais. Na sexta etapa é realizada uma verificação de procedimentos operacionais. Na sétima etapa, uma análise parcial de outros sistemas (que apresentam interfaces com o sistema crítico) é realizada.

ALMEIDA JÚNIOR (2003) cita ainda a metodologia de Análise de Segurança chamada Software Deviation Analysis, como uma metodologia de análise alternativa baseada em especificações formais transformadas em diagramas que são comparados com possíveis desvios em relação ao funcionamento normal do sistema. O autor reforça a importância da aplicação desta técnica ao longo do ciclo de desenvolvimento do software.

ALMEIDA JÚNIOR (2003) aponta também que as normas auxiliam equipes de projeto na garantia de níveis mínimos de qualidade, promovem a uniformidade entre diversas equipes de trabalho, fornecem guias de projeto e proporcionam base legal no caso de disputas judiciais. As normas são utilizadas para a certificação dos sistemas.

A Norma IEC 61508 - Functional of Electrical/Electronic/Programmable Electronic Safety-Related Systems descreve a utilização de sistemas operacionais, software para redes de computadores, interfaces homem-máquina, ferramentas de suporte e linguagens de alto e de baixo nível, e estabelece requisitos para o ciclo de desenvolvimento do software. Descreve também técnicas de desenvolvimento de software para sistemas críticos. A Norma RTCA - EUROCAE DO 178B - Software Considerations in Airborne Systems and Equipment Certification, cobre apenas aspectos referentes ao software de sistemas embarcados e é o meio aceito para a 
certificação de todo o novo software utilizado em sistemas aéreos (STOREY, 1996 In: ALMEIDA JÚNIOR, 2003). A Norma NASA-STD-8719,13A - Technical Standard - Software Safety descreve uma metodologia para a produção de software seguro. Finalmente, a Norma ENV 50129 - Safety Related Electronics Systems for Signaling aplica-se a sistemas eletrônicos de supervisão e controle utilizados em aplicações metro-ferroviárias.

\subsection{Aspectos principais da representação de diferentes estruturas e processos}

\subsubsection{Fundamentos conceituais da cultura de segurança em ambientes e organizações virtuais}

Este capítulo apresenta as visões de sistema de conhecimento (TSOUKAS, 1996), de coordenação da ação cooperativa (MAGGI, 2006), de organização como cultura de segurança (ELLIOTT; SCACCHI, 2003) e cultura de segurança computacional (ALMEIDA JÚNIOR, 2003) como fundamentos conceituais para a cultura de segurança em ambientes e organizações virtuais.

Pretende-se estabelecer as condições para que temas de conteúdo, práticas e artefatos possam descrever a cultura de segurança de programas computacionais em ambientes e organizações virtuais.

\subsubsection{Apoio de ferramentas e funções dos ambientes e da organização virtual}

A atividade de pesquisa foi realizada em ambientes virtuais e com o apoio de uma organização virtual existente, de pequeno porte e voltada para a inovação.

Um programa específico para a gestão de conteúdos em hipertexto, baseado em Web (TWIKI), disponível sob licença de código aberto, foi utilizado como apoio para a interpretação da regulação entre diferentes estruturas e processos e para a representação da cultura de segurança dos ambientes e da organização virtual 
estudada. Outros programas e facilidades, compatíveis com o programa de gestão de conteúdos em hipertexto, foram indicados, representados, integrados e utilizados.

Uma revisão sobre as ferramentas disponíveis em código aberto para a gestão de conteúdos foi produzida por IVANOFF et al. (2003). Além das ferramentas da família WIKI, foram identificados os programas Plone, Zope e OpenCMS. Outras possibilidades de programas identificadas pelos autores envolveram:

- formação de empresas virtuais com agentes inteligentes;

- utilização de programas para a gestão de perfis profissionais;

- recuperação de informações e relacionamentos através de metabuscadores;

- utilização de mapas de conhecimento;

- $\quad$ sites intuitivos;

- Web Semântica.

Os diversos ambientes virtuais criados com o apoio do programa TWIKI levaram em consideração as pesquisas realizadas por IVANOFF et al. (2003). As principais funções a serem desempenhadas por ambientes, a partir desses estudos são:

- controle;

- relacionamento;

- comunicação;

- direcionamento estratégico;

- pesquisa;

- registros de indivíduos, grupos e organizações;

- integração de aplicações e tecnologias. 


\section{TEMAS DE CONTEÚDO PROPOSTOS PARA A REGULAÇÃO DE DIFERENTES ESTRUTURAS E PROCESSOS NOS AMBIENTES E NA ORGANIZAÇÃO VIRTUAL ESTUDADA}

Os temas de conteúdo apresentados referem-se ao caso específico dos ambientes e da organização virtual estudada, e estão relacionados com o processo de regulação de diferentes estruturas e processos envolvidos.

Os temas de conteúdo da cultura de segurança podem ser categorizados como inferidos e esposados (ELLIOTT; SCACCHI, 2003). Segundo os autores os temas de conteúdo esposados são aqueles apresentados em documentos da organização. Os temas de conteúdo inferidos são deduzidos pelo pesquisador.

Adaptabilidade, dependabilidade e compatibilidade foram adotadas como temas inferidos.

Credibilidade, confiança e mobilidade foram adotadas como temas esposados.

A Tabela 1, no final deste capítulo, apresenta um resumo das principais propriedades e dimensões do temas de conteúdo propostos.

\subsubsection{Adaptabilidade}

A adaptabilidade, para o caso dos ambientes e da organização virtual estudada, está relacionada inicialmente com a capacidade de efetivação de mudanças em conteúdos e programas e em diferentes estruturas e processos.

A adaptabilidade também está relacionada:

- com a possibilidade de personalização de programas, estruturas, processos e ambientes, quando aplicável;

- com a criação de índices de acessos a conteúdos, programas e serviços; 
- com a utilização de robôs que auxiliem na manutenção de conteúdos e programas necessários à operação dos ambientes e da organização virtual.

A relação entre processos de adaptação e cultura é abordada em KARDINER (1945).

\subsubsection{Dependabilidade}

A dependabilidade está relacionada com a aplicação de metodologias de análise de segurança, e em um dos aspectos principais, sob o ponto de vista técnico, com a necessidade de análise de interferências entre rotinas de programas computacionais.

A adoção de metodologias de análise de segurança é complexa para ambientes e organizações virtuais de pequeno porte. Partes da metodologia, entretanto, podem ser incentivadas e produzem resultados bastante significativos.

De acordo com a metodologia de análise do Grupo de Análise de Segurança do PCS USP (ALMEIDA JÚNIOR, 2003), a análise de interferência entre rotinas acontece em reuniões onde analistas debatem entre si os aspectos funcionais de cada rotina, procurando identificar situações que possam levar o sistema a condições inseguras. Questões relativas à implementação de equipamentos, dispositivos e circuitos do sistema crítico são esclarecidas nas atividades propostas pela metodologia de análise de segurança. Para a determinação dos requisitos gerais de segurança, interações são promovidas com o operador do sistema crítico. A verificação de procedimentos operacionais e uma análise parcial de outros sistemas que apresentam interfaces com o sistema crítico integram essas iniciativas.

A dependabilidade é um conceito da área de sistemas computacionais e está relacionado com os conceitos de confiabilidade, disponibilidade e mantenabilidade.

ALMEIDA JÚNIOR (2003, 2.1.1. Conceitos básicos de segurança crítica, p. 13) define a segurança crítica "como a probabilidade de um sistema, em um determinado período de tempo $\Delta \mathrm{t}$, desempenhar corretamente suas funções, ou falhar sem comprometer a integridade de pessoas e do meio ambiente, dado que este sistema estava seguro no instante inicial".

ALMEIDA JÚNIOR (2003) relaciona a segurança crítica com os conceitos de confiabilidade, disponibilidade e mantenabilidade. $\mathrm{O}$ autor afirma que "quanto maior 
a confiabilidade e a disponibilidade e quanto mais fácil for a manutenção do sistema crítico, maior a probabilidade de que a Segurança Crítica atinja melhores níveis, principalmente no que se refere a menores probabilidades de atingir estados inseguros".

ALMEIDA JÚNIOR (2003) apresenta as seguintes definições para os conceitos de confiabilidade, disponibilidade e mantenabilidade: "A confiabilidade indica a probabilidade de um sistema permanecer sem falhas por um período de tempo, considerando que, no instante inicial, o mesmo se encontrava funcionando corretamente. A disponibilidade é a medida da probabilidade de um sistema estar sem falha em um determinado instante de tempo. Por mantenabilidade entende-se a habilidade de um sistema ser mantido e, em termos quantitativos, é representada pelo valor do MTTR (Mean Time To Repair)".

A importância da propriedade de dependabilidade, para a cultura de segurança em ambientes e organizações virtuais, está relacionada com a situação em que é necessário executar a recuperação de falhas nos ambientes e na organização virtual, tanto as causadas pela operação normal da infra-estrutura, como as causadas por agentes externos, em invasões, por exemplo. Os ambientes e a organização virtual adquirem importância fundamental para as diferentes estruturas e processos que representam.

Não foi possível desenvolver, para a organização virtual estudada, um plano de contingência e recuperação de desastres, como sugere ALMEIDA JÚNIOR (2003). Foram adotados, entretanto, algumas ações simplificadas, que permitem a recuperação das situações de falha. Nos casos em que houve perda de grandes quantidades de conteúdo e relações em hipertexto, o processo é considerado como não reparável. Nos casos em que acontece o travamento de páginas por indicação recíproca de hipertextos, é possível editar as páginas com problemas e recuperar a operação do sistema de gestão de conteúdos em hipertexto, baseado em Web.

O sistema de gestão de conteúdos em hipertexto implantado para a atividade de pesquisa sofreu pelo menos uma invasão em que foram feitas modificações não autorizadas nas páginas Web. Depois da primeira invasão, decidiu-se pela divisão de 
uma única instalação do programa computacional TWIKI em várias instalações, com diferentes requisitos de acesso e, também, com versões diferentes do programa.

Uma das instalações ficou completamente fechada, tanto para pesquisa como para atualização externas, e foi utilizada para operação interna da organização virtual. Esta instalação permaneceu inalterada, na primeira versão do TWIKI, até a conclusão da dissertação. Entendeu-se que uma migração poderia provocar a perda de conteúdos e de relações em hipertexto. Além disso, por estar protegida por senhas, não sofreu nenhuma invasão externa.

A migração de versão na aplicação aberta ao público externo provocou a perda de arquivos carregados no ambiente e tornou indisponíveis relações de hipertexto em função da decisão de integração de várias instalações do programa TWIKI em apenas uma instalação. Descobriu-se posteriormente que o programa administra bem vários ambientes e que permite inclusive a navegação entre ambientes através de um mecanismo de indicação de apelidos para cada um dos ambientes.

A possibilidade de prever todas as situações em que o sistema de gestão de conteúdos em hipertexto ficará indisponível não é factível. Os fatores que determinam a indisponibilidade do sistema variam desde a falta de recursos para acesso à Internet até as situações em que o registro cruzado de conteúdos impede o acesso a um conjunto de páginas (a situação em que a referência a determinados conteúdos é demandada simultaneamente pelas próprias páginas referenciadas). As diferenças de conhecimento dos participantes também podem se caracterizar como fatores que tornam o sistema indisponível.

O registro cruzado de conteúdos representa um exemplo de competição ou conflito técnico de recursos. A cooperação, a competição e o conflito ocorrem com bastante frequiência a partir das atividades normais dos participantes da organização virtual (OGBURN; NIMKOFF, 1953; MACK; SNYDER, 1957; ELLIOTT; SCACCHI, 2003).

\subsubsection{Compatibilidade}

A compatibilidade está relacionada com o registro, a produção, o desenvolvimento e a utilização de estruturas, processos e programas computacionais. A compatibilidade 
também está relacionada com o acesso e a integração de conteúdos e programas disponíveis na Internet.

A compatibilidade em ambientes e organizações virtuais relaciona programas, sistemas, aplicações e organizações e deve levar em conta a necessidade de integração de programas em sistemas, suas aplicações e a sua utilização pelas organizações.

Finalmente, assim como a dependabilidade, a compatibilidade está associada à aplicação de metodologias de análise de segurança.

\subsubsection{Credibilidade}

A credibilidade está relacionada com a utilização de agendas, com a produção de uma taxonomia e com a elaboração de documentação. Também está relacionada com registros de:

- aspectos de segurança,

- estatísticas,

- atualizações,

- procedimentos $\mathrm{e}$

- melhores práticas.

A credibilidade está relacionada ainda com o foco nos assuntos de interesse da organização virtual.

\subsubsection{Confiança}

A confiança está relacionada com o registro de informações (no mínimo um perfil simplificado ou informações de contato) de participantes da organização virtual e de autorizações de acesso (indivíduos, grupos e ambientes virtuais), mesmo considerando que os participantes da organização virtual estão localizados em múltiplos contextos, ambientes, grupos e organizações. 
Também está relacionada com a integração e a comunicação através de portais e comunidades virtuais e com a realização de encontros e interações presenciais e virtuais.

Os diversos ambientes existentes são segmentados sob o ponto de vista de acesso e segurança e, pelo menos uma parte do sistema, está disponível para acesso público, pela Internet. O sistema funciona como um índice qualificado de assuntos relevantes para a inovação, que é o objetivo de existência da organização virtual.

A proposta de adoção da confiança, como um tema de conteúdo da cultura de segurança de ambientes e organizações virtuais, é reforçada por STEWART (2001 apud IVANOFF, 2004b). Segundo este autor, a construção de confiança nas situações em que prevalece o ambiente de redes deve ser apoiada por fatores relacionados com: competência, comunidade, compromisso, compensação e comunicação.

\subsubsection{Mobilidade}

A mobilidade em ambientes e organizações virtuais está relacionada com o trabalho cooperativo apoiado por computador (CSCW - Computer Supported Cooperative Work).

O sistema de gestão de conteúdos em hipertexto permite integrar as aplicações que podem ser acessadas pela Internet, facilitando muito a navegação entre links grandes de difícil memorização, e que, em geral, estão localizados depois de grande número de acessos em sites de interesse.

Essa característica permite o registro de fluxos de trabalho e de informação tornando atividades profissionais muito produtivas e permitindo também a criação de memórias de trabalho. Um exemplo de aplicação muito interessante, nesta linha, é a criação de um portal pessoal, adaptado às características de cada usuário. 
Tabela 1 - Temas de conteúdo propostos para a regulação de diferentes estruturas e processos nos ambientes e na organização virtual estudada

\begin{tabular}{|c|c|c|}
\hline Esposados & Inferidos & $\begin{array}{l}\text { Propriedades e dimensões da cultura de } \\
\text { segurança em ambientes e organizações virtuais }\end{array}$ \\
\hline & Adaptabilidade & $\begin{array}{l}\text { Adaptabilidade: Personalização de programas, } \\
\text { estruturas, processos e ambientes, quando aplicável. } \\
\text { Criação de índices de acessos a conteúdos } \\
\text { relacionados. Utilização de robôs. }\end{array}$ \\
\hline & Dependabilidade & $\begin{array}{c}\text { Dependabilidade: Utilização de diferentes versões de } \\
\text { programas. Análise de dependências técnicas e } \\
\text { sociais. Planejamento sobre as fases de recuperação } \\
\text { de desastres. }\end{array}$ \\
\hline & Compatibilidade & $\begin{array}{l}\text { Compatibilidade: Registro, produção, } \\
\text { desenvolvimento e utilização de estruturas, processos } \\
\text { e programas computacionais. Acesso e integração de } \\
\text { conteúdos e programas disponíveis na Internet. } \\
\text { Aplicação de metodologias de análise de segurança. }\end{array}$ \\
\hline Credibilidade & & $\begin{array}{l}\text { Credibilidade: Utilização de agendas, taxonomia e } \\
\text { documentação. Registros de aspectos de segurança, } \\
\text { estatísticas, atualizações, procedimentos e melhores } \\
\text { práticas. Foco nos assuntos de interesse da } \\
\text { organização virtual. }\end{array}$ \\
\hline Confiança & & $\begin{array}{c}\text { Confiança: Registro de participantes e de } \\
\text { autorizações de acesso (indivíduos, grupos e } \\
\text { ambientes virtuais). Integração e comunicação através } \\
\text { de portais e comunidades virtuais. Encontros } \\
\text { presenciais e virtuais. }\end{array}$ \\
\hline Mobilidade & & $\begin{array}{l}\text { Mobilidade: Trabalho colaborativo apoiado por } \\
\text { computador (gestão de conteúdos em hipertexto, } \\
\text { baseada em Web, gestão de programas e } \\
\text { configurações, utilização de portais). }\end{array}$ \\
\hline
\end{tabular}




\section{CULTURA DE SEGURANÇA E REGULAÇÃO DE DIFERENTES ESTRUTURAS E PROCESSOS NOS AMBIENTES E NA ORGANIZAÇÃO VIRTUAL ESTUDADA}

Neste capítulo, serão apresentados os principais componentes da cultura de segurança nos ambientes e na organização virtual estudada nas atividades de pesquisa.

As práticas e artefatos indicados a seguir foram obtidos a partir da aplicação da metodologia de pesquisa Grounded Theory conforme apresentado anteriormente.

As práticas e artefatos identificados envolvem, entre outros, a comunicação entre projetistas, desenvolvedores e usuários, a coordenação colaborativa de atividades, a gestão de dependências e o manejo de mudanças e da adaptação.

As práticas e artefatos foram principalmente identificados a partir de análise sobre os seguintes fatores:

- efeitos indesejáveis de dependências e rupturas sobre diferentes estruturas e processos;

- estruturas e processos de desenvolvimento de programas computacionais;

- estruturas e processos organizacionais que incluem os programas;

- mudanças culturais de indivíduos e grupos; e

- mudanças nas condições do ambiente.

A Tabela 2 apresenta os artefatos identificados para a cultura de segurança nos ambientes e na organização virtual estudada.

A Tabela 3 apresenta as práticas identificadas para a cultura de segurança nos ambientes e na organização virtual estudada. 
Tabela 2 - Artefatos da cultura de segurança nos ambientes e na organização virtual estudada

\begin{tabular}{|c|c|}
\hline Artefatos Eletrônicos & $\begin{array}{l}\text { Propriedades e dimensões da cultura de } \\
\text { segurança em ambientes e organizações virtuais }\end{array}$ \\
\hline $\begin{array}{l}\text { Programas, estruturas, processos e } \\
\text { ambientes personalizados, quando } \\
\text { aplicável. Índices de acesso a } \\
\text { conteúdos relacionados. Robôs. }\end{array}$ & $\begin{array}{c}\text { Adaptabilidade: Personalização de programas, } \\
\text { estruturas, processos e ambientes, quando aplicável. } \\
\text { Criação de índices de acessos a conteúdos } \\
\text { relacionados. Utilização de robôs. }\end{array}$ \\
\hline $\begin{array}{l}\text { Diferentes versões do programa de } \\
\text { gestão de conteúdos em hipertexto. } \\
\text { Registros de configurações de } \\
\text { programas e de rotinas disponíveis. } \\
\text { Mapas conceituais. }\end{array}$ & $\begin{array}{c}\text { Dependabilidade: Utilização de diferentes versões de } \\
\text { programas. Análise de dependências técnicas e } \\
\text { sociais. Planejamento sobre as fases de recuperação } \\
\text { de desastres. }\end{array}$ \\
\hline $\begin{array}{l}\text { Programas que podem ser } \\
\text { integrados ao sistema de gestão de } \\
\text { conteúdos em hipertexto como } \\
\text { planilhas e mapas dinâmicos. } \\
\text { Registros de outros programas. }\end{array}$ & $\begin{array}{l}\text { Compatibilidade: Registro, produção, } \\
\text { desenvolvimento e utilização de estruturas, processos } \\
\text { e programas computacionais. Acesso e integração de } \\
\text { conteúdos e programas disponíveis na Internet. } \\
\text { Aplicação de metodologias de análise de segurança. }\end{array}$ \\
\hline $\begin{array}{l}\text { Agendas, taxonomia e } \\
\text { documentação. Registros de } \\
\text { aspectos de segurança, } \\
\text { estatísticas, atualizações, } \\
\text { procedimentos e melhores práticas. }\end{array}$ & $\begin{array}{c}\text { Credibilidade: Utilização de agendas, taxonomia e } \\
\text { documentação. Registros de aspectos de segurança, } \\
\text { estatísticas, atualizações, procedimentos e melhores } \\
\text { práticas. Foco nos assuntos de interesse da } \\
\text { organização virtual. }\end{array}$ \\
\hline $\begin{array}{l}\text { Perfis de segurança dos } \\
\text { participantes, de grupos e dos } \\
\text { ambientes virtuais. Registros de } \\
\text { portais e comunidades virtuais. }\end{array}$ & $\begin{array}{c}\text { Confiança: Registro de participantes e de } \\
\text { autorizações de acesso (indivíduos, grupos e } \\
\text { ambientes virtuais). Integração e comunicação através } \\
\text { de portais e comunidades virtuais. Encontros } \\
\text { presenciais e virtuais. }\end{array}$ \\
\hline $\begin{array}{c}\text { Sistema de gestão de conteúdos } \\
\text { em hipertexto representando } \\
\text { diversos ambientes com } \\
\text { características de segurança } \\
\text { diferentes e integrando perfis de } \\
\text { participantes, a comunicação } \\
\text { virtual, as comunidades virtuais e } \\
\text { portais. }\end{array}$ & $\begin{array}{l}\text { Mobilidade: Trabalho colaborativo apoiado por } \\
\text { computador (gestão de conteúdos em hipertexto, } \\
\text { baseada em Web, gestão de programas e } \\
\text { configurações, utilização de portais). }\end{array}$ \\
\hline
\end{tabular}


Tabela 3 - Práticas da cultura de segurança nos ambientes e na organização virtual estudada

\begin{tabular}{|c|c|c|}
\hline Formais & $\begin{array}{l}\text { Informais / } \\
\text { Normas }\end{array}$ & $\begin{array}{l}\text { Propriedades e dimensões da cultura de } \\
\text { segurança em ambientes e organizações virtuais }\end{array}$ \\
\hline $\begin{array}{l}\text { Utilização de } \\
\text { conteúdos, } \\
\text { programas, } \\
\text { estruturas, } \\
\text { processos e } \\
\text { ambientes. }\end{array}$ & $\begin{array}{l}\text { Refinamento de } \\
\text { conteúdos, } \\
\text { programas, } \\
\text { estruturas, } \\
\text { processos e } \\
\text { ambientes. }\end{array}$ & $\begin{array}{c}\text { Adaptabilidade: Personalização de programas, } \\
\text { estruturas, processos e ambientes, quando aplicável. } \\
\text { Criação de índices de acessos a conteúdos } \\
\text { relacionados. Utilização de robôs. }\end{array}$ \\
\hline $\begin{array}{l}\text { Identificação de } \\
\text { participantes, } \\
\text { programas, } \\
\text { estruturas, } \\
\text { processos e } \\
\text { ambientes. }\end{array}$ & $\begin{array}{l}\text { Análise e gestão } \\
\text { de dependências } \\
\text { técnicas e } \\
\text { sociais. }\end{array}$ & $\begin{array}{c}\text { Dependabilidade: Utilização de diferentes versões de } \\
\text { programas. Análise de dependências técnicas e } \\
\text { sociais. Planejamento sobre as fases de recuperação } \\
\text { de desastres. }\end{array}$ \\
\hline $\begin{array}{l}\text { Registros e } \\
\text { seleção de } \\
\text { programas, } \\
\text { estruturas, } \\
\text { processos e } \\
\text { ambientes. }\end{array}$ & $\begin{array}{l}\text { Criação de } \\
\text { novos } \\
\text { programas, } \\
\text { estruturas, } \\
\text { processos e } \\
\text { ambientes. }\end{array}$ & $\begin{array}{l}\text { Compatibilidade: Registro, produção, } \\
\text { desenvolvimento e utilização de estruturas, processos } \\
\text { e programas computacionais. Acesso e integração de } \\
\text { conteúdos e programas disponíveis na Internet. } \\
\text { Aplicação de metodologias de análise de segurança. }\end{array}$ \\
\hline $\begin{array}{l}\text { Coordenação } \\
\text { colaborativa de } \\
\text { atividades }\end{array}$ & $\begin{array}{l}\text { Registro de } \\
\text { conteúdos, } \\
\text { estatísticas, } \\
\text { atualizações. }\end{array}$ & $\begin{array}{c}\text { Credibilidade: Utilização de agendas, taxonomia e } \\
\text { documentação. Registros de aspectos de segurança, } \\
\text { estatísticas, atualizações, procedimentos e melhores } \\
\text { práticas. Foco nos assuntos de interesse da } \\
\text { organização virtual. }\end{array}$ \\
\hline $\begin{array}{l}\text { Encontros } \\
\text { presenciais e } \\
\text { virtuais. }\end{array}$ & $\begin{array}{l}\text { Hierarquização } \\
\text { de ambientes de } \\
\text { colaboração. }\end{array}$ & $\begin{array}{c}\text { Confiança: Registro de participantes e de } \\
\text { autorizações de acesso (indivíduos, grupos e } \\
\text { ambientes virtuais). Integração e comunicação através } \\
\text { de portais e comunidades virtuais. Encontros } \\
\text { presenciais e virtuais. }\end{array}$ \\
\hline $\begin{array}{l}\text { Utilização do } \\
\text { sistema de } \\
\text { gestão de } \\
\text { conteúdos em } \\
\text { hipertexto. }\end{array}$ & $\begin{array}{l}\text { Desenvolvimento } \\
\text { da mobilidade } \\
\text { virtual. }\end{array}$ & $\begin{array}{l}\text { Mobilidade: Trabalho colaborativo apoiado por } \\
\text { computador (gestão de conteúdos em hipertexto, } \\
\text { baseada em Web, gestão de programas e } \\
\text { configurações, utilização de portais). }\end{array}$ \\
\hline
\end{tabular}




\subsection{Artefatos da cultura de segurança nos ambientes e na organização virtual estudada}

Os artefatos da cultura de segurança em ambientes e organizações virtuais incluem artefatos geralmente utilizados em estruturas e processos de desenvolvimento de programas computacionais $e$ estruturas e processos organizacionais que incluem os programas.

Os artefatos representam um dos componentes segundo os quais se pode descrever a cultura de segurança em ambientes e organizações virtuais.

\subsubsection{Artefatos associados à adaptabilidade}

\subsubsection{Portais e comunidades virtuais}

Quatro portais personalizados foram criados na área fechada dedicada a assuntos administrativos da organização virtual.

A criação dos portais personalizados tem como objetivos:

- facilitar o acesso rápido a conteúdos de interesse;

- organizar conjuntos de conteúdos relacionados;

- registrar acessos a links e sites externos;

- registrar acessos a portais externos e comunidades virtuais;

- estabelecer índices que facilitem o acesso a conteúdos, programas e serviços relacionados.

Os índices de acesso a conteúdos relacionados devem merecer atenção especial sob o ponto de vista de segurança. Ao longo de tempo os índices vão recebendo atualizações relevantes e tornam-se ferramentas valiosas para o desenvolvimento de atividades. Por esta razão, os índices associados a atividades administrativas e operacionais da organização virtual estão protegidos em áreas com acesso restrito. 
Além de indivíduos, a organização virtual agrega comunidades virtuais de interesses comuns. Ao longo das atividades de pesquisa, foram estabelecidos relacionamentos com trinta e cinco comunidades virtuais (Yahoogroups). Essas comunidades virtuais estão preferencialmente relacionadas a assuntos acadêmicos e de pesquisa e fornecem importantes subsídios para o desenvolvimento de assuntos relacionados com a organização virtual.

O sistema de gestão de conteúdos em hipertexto permite o registro de assuntos relevantes e a associação desses assuntos com as comunidades virtuais dedicadas ao estudo e pesquisa desses assuntos.

\subsubsection{Robôs}

A utilização de robôs em conjunto com o sistema de gestão de conteúdos em hipertexto permite diminuir o esforço repetitivo e igual de usuários e colaboradores (BOTS, 2006).

Os robôs facilitam a organização e reorganização de conteúdos, a identificação de páginas perdidas (não indicadas por outras páginas) e a resolução de ambigüidades em conteúdos com diferentes significados.

Os robôs não foram aplicados nos ambientes e na organização virtual criados para a atividade de pesquisa. A manutenção de conteúdos é uma atividade trabalhosa e nos casos em que é repetitiva, poderia se beneficiar muito da aplicação desses programas.

\subsubsection{Artefatos associados à dependabilidade}

\subsubsection{Ambientes virtuais e perfis de ambientes}

Diversos ambientes virtuais foram criados para acomodar diferentes intenções e interesses.

Nas áreas abertas ao público, os ambientes foram segmentados inicialmente por intenções relacionadas a assuntos e à autoridade para atualização de conteúdos desses assuntos. 
Os ambientes abertos ao público foram estabelecidos na penúltima versão do programa de gestão de conteúdos em hipertexto.

Um primeiro ambiente recebe o registro de assuntos relacionados com o tema de inovação e pode ser atualizado apenas por usuários autorizados e participantes da organização virtual.

Um segundo ambiente foi estabelecido para o registro de quaisquer assuntos provenientes de indivíduos, grupos e organizações externas e também pode ser atualizado apenas por usuários autorizados e participantes da organização virtual.

Para assuntos comerciais, envolvendo o relacionamento de fornecedores e consumidores, um terceiro ambiente independente foi estabelecido.

Além desses três ambientes, completam os ambientes disponíveis para acesso público, no total de sete ambientes:

- um ambiente geral, de apresentação da organização virtual e de seus ambientes. Esse ambiente funciona como índice para os demais;

- um ambiente com um blog onde notícias e comentários podem ser registrados;

- um ambiente dedicado a assuntos humanos e sociais;

- um ambiente de controle do programa de gestão de conteúdos em hipertexto.

Nas áreas fechadas para acesso externo, o acesso só é permitido para usuários envolvidos diretamente com a administração da organização virtual. Os ambientes fechados a acesso externo foram estabelecidos e continuam operando na antepenúltima versão do programa de gestão de conteúdos em hipertexto. Uma atualização dessa versão está prevista após o encerramento da atividade de pesquisa, relacionada com essa dissertação.

Estão contidos nas áreas fechadas:

- um ambiente para assuntos operacionais e administrativos da organização virtual;

- um ambiente dedicado a assuntos de pesquisa geral; 
- um ambiente de controle do programa de gestão de conteúdos em hipertexto.

\subsubsection{Mapas conceituais}

Com o objetivo de facilitar a compreensão das interligações de conteúdos, foi desenvolvida a opção de integrar mapas conceituais nas páginas Web.

A Figura 4 apresenta o mapa conceitual produzido dinamicamente na página com o título de "Mapas Mentais".

Segundo GIORNO (1999), mapas conceituais são:

- uma técnica gráfica para anotar e apresentar conceitos e seus relacionamentos conforme percebidos por pessoas (individualmente ou em grupo), em relação a um determinado tópico, área de conhecimento, processo, situação...

- a representação de relações significativas na forma de proposições - dois ou mais conceitos associados por meio de verbos formando uma única semântica.

Os fundamentos de mapas conceituais são (GIORNO, 1999):

- as pessoas pensam em conceitos - regularidades percebidas em eventos ou objetos, designadas por um mesmo nome - que podem ser externalizados e refinados em termos do modo como se pensa sobre eles.

- a experiência humana envolve não somente pensar e agir, mas também sentir, e somente com a consideração conjunta destas três atitudes, as pessoas conseguem enriquecer o significado de suas experiências. 


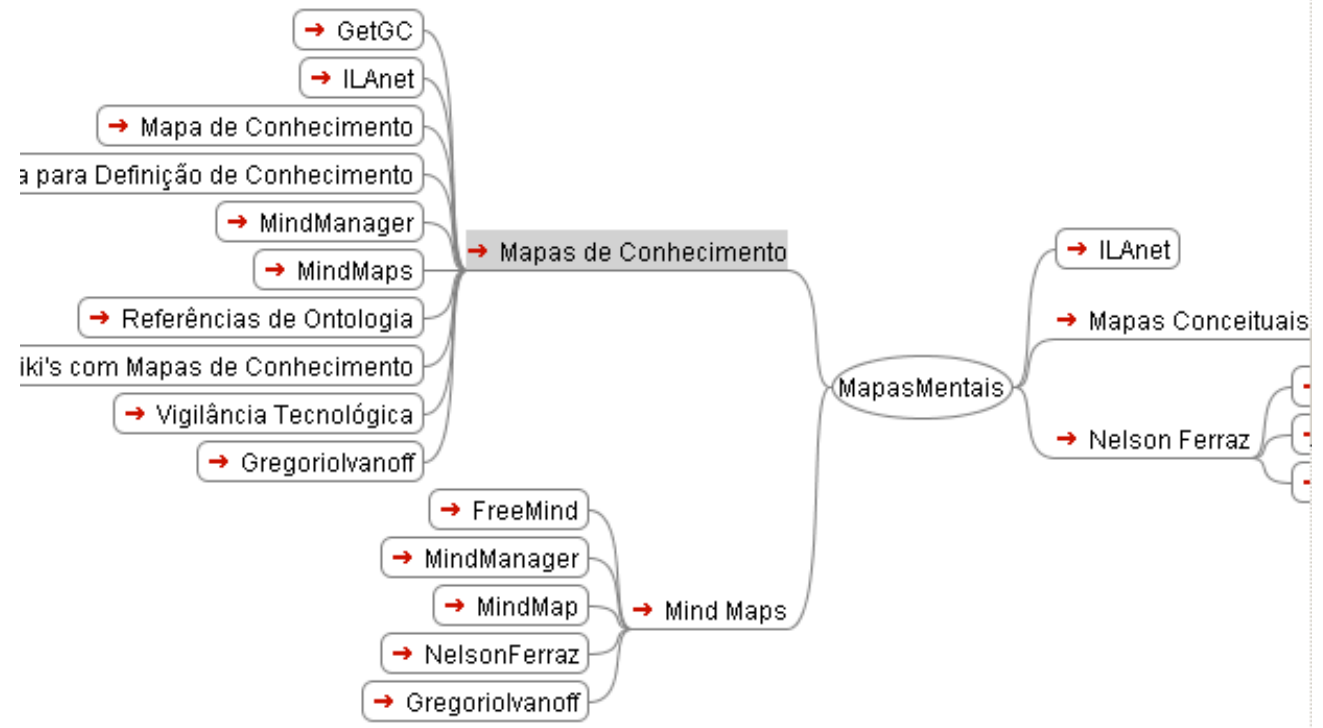

Figura 4 - Mapa conceitual da página Web com o título "Mapas Mentais", no sistema de gestão de conteúdos em hipertexto

\subsubsection{Artefatos associados à compatibilidade}

\subsubsection{Programas computacionais}

O programa de gestão de conteúdos é disponibilizado por seus desenvolvedores e as dependências entre rotinas existentes são registradas no site onde o programa na pode ser obtido. O mesmo procedimento pode ser aplicado a outros programas diferentes.

O sistema de gestão de conteúdos em hipertexto permite a integração, nas páginas Web, de uma grande variedade de programas. Esses programas não só facilitam a execução de atividades como também viabilizam algumas operações simplificadas sobre dados e variáveis. São exemplos de programas os que permitem a elaboração de listas, tabelas, cálculos, mapas de conteúdo etc. 
Diversos outros programas (e serviços), tais como, programas de correio eletrônico, programas de mensagens instantâneas, programas que integram a comunicação com telefones celulares e muitos outros, podem ter seu acesso registrado no sistema de gestão de conteúdos, facilitando a administração dessas múltiplas possibilidades. Nessa mesma linha está o registro de endereços de comunidades virtuais e de portais. Com o apoio do sistema de gestão de conteúdos em hipertexto, é possível desenvolver portais personalizados para usos específicos (Adaptabilidade).

Finalmente, novos programas podem ser desenvolvidos e integrados às páginas do sistema de gestão de conteúdos em hipertexto. Um exemplo de desenvolvimento é a elaboração de mapas conceituais dinâmicos nas páginas do sistema de gestão de conteúdos em hipertexto. A Figura 5 ilustra um mapa conceitual que representa a organização virtual e seus ambientes.

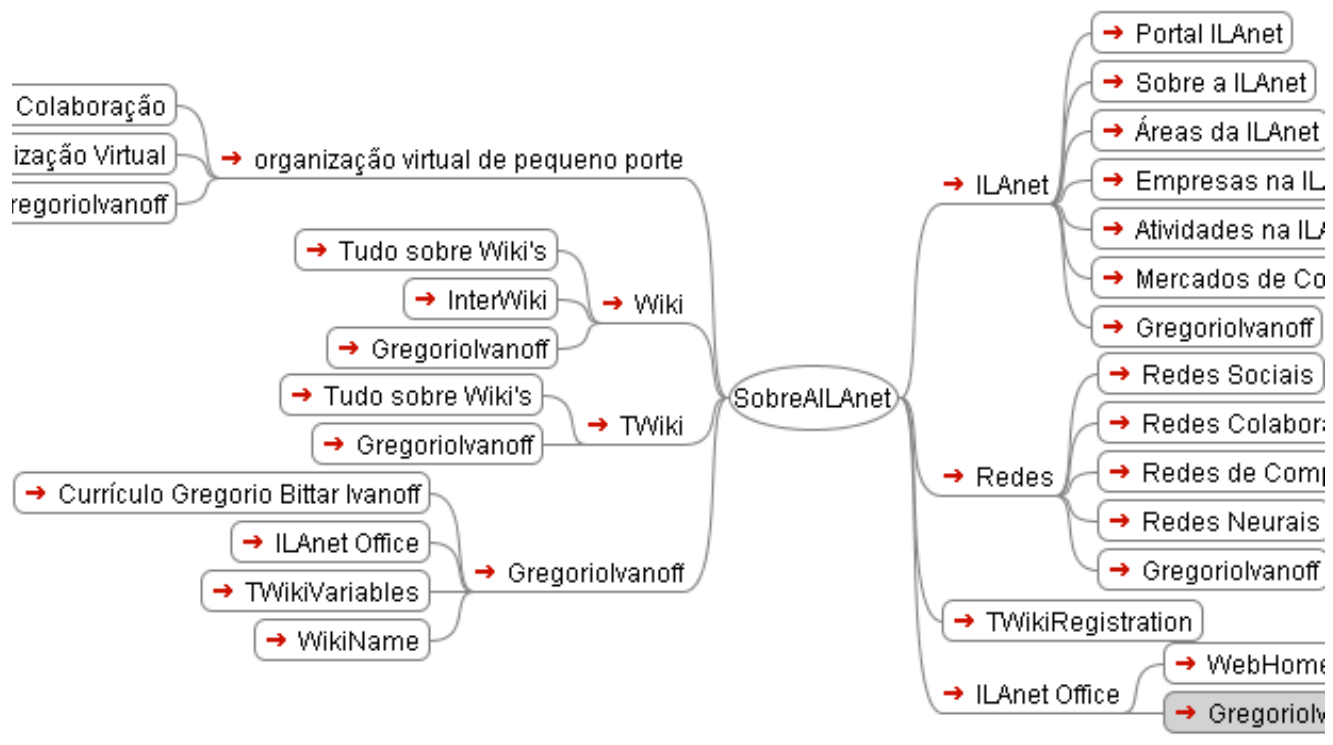

Figura 5 - Exemplo de página de conteúdos, produzida por programa computacional, com mapa conceitual que representa a organização virtual e seus ambientes 


\subsubsection{Artefatos associados à credibilidade}

\subsubsection{Agendas e taxonomia}

A elaboração de agendas de atividades representa um importante componente de integração entre participantes de diferentes estruturas e processos.

As agendas são utilizadas para o registro de encontros e reuniões e podem conter além de datas e participantes, os conteúdos a serem trabalhados.

A facilidade de registrar os conteúdos em hipertexto promove conversas entre os participantes sobre ambigüidades, diferenças de comunicação e interpretação de conceitos.

Ao longo do tempo, os conteúdos ganham maior refinamento e as páginas se tornam mais relevantes.

O sistema de gestão de conteúdos possui estatísticas que permitem o acompanhamento do número de acesso às páginas e registra também os participantes que executaram atualizações.

Versões anteriores de páginas atualizadas ficam disponíveis para consulta e podem ser utilizadas para recuperação de conteúdos.

Conteúdos perdidos em situações de invasão podem ser recuperados apenas com a utilização de versões de segurança.

Inconsistências de relacionamento entre conteúdos podem acontecer e devem ser resolvidas manualmente ou com o apoio de robôs.

\subsubsection{Artefatos associados à confiança}

\subsubsection{Perfis dos participantes}

O sistema de gestão de conteúdos em hipertexto permite registrar, com bastante facilidade, informações sobre participantes de atividades em diferentes estruturas e processos. 
$\mathrm{O}$ registro de perfis de participantes pode ser realizado a partir das funcionalidades do sistema e também pode ser expandido com conteúdos e hipertextos de acordo com as intenções de divulgação.

O sistema apresenta grandes facilidades para a descrição de grupos e organizações.

Nas áreas fechadas ao acesso público, foram desenvolvidos portais personalizados para facilitar o desenvolvimento de atividades dos participantes envolvidos com a administração dos ambientes e da organização virtual.

\subsubsection{Meios de comunicação}

Além da comunicação direta em encontros e reuniões presenciais e da comunicação fixa e celular, a comunicação da organização virtual se desenvolve com todos os meios eletrônicos disponíveis.

Os meios eletrônicos mais utilizados são:

- correio eletrônico;

- comunidades virtuais;

- sistema de gestão de conteúdo em hipertexto;

- comunidades externas de afinidades (Orkut, LinkedIn, Syxt e outras).

\subsubsection{Artefatos associados à mobilidade}

\subsubsection{Sistema de gestão de conteúdos em hipertexto}

O programa de gestão de conteúdos em hipertexto, baseado em Web, foi utilizado para representar os diversos ambientes de trabalho e a organização virtual. As duas diferentes versões do programa implantadas, por questões de segurança e em função dos compromissos relacionados com a sua utilização, se caracterizam como um sistema que foi utilizado para observar e administrar a regulação entre diferentes estruturas e processos. 
As duas instalações do programa de gestão de conteúdos em hipertexto representam a organização virtual estudada e permitem a ação / interação dos participantes em diversos ambientes virtuais.

Um pacote de serviços de hospedagem em servidor compartilhado disponível via Web foi contratado para a instalação dos programas necessários.

Além do registro de conteúdos, o programa de gestão de conteúdos aceita o registro de endereços Web, o que permite o livre acesso e a integração de programas e serviços disponíveis publicamente na Internet. Linguagens de programação Web e programas de apoio, como planilhas e mapas dinâmicos também podem ser integrados às páginas de conteúdo na Web.

O programa instalado, no início de 2003 , foi uma versão bastante simples com poucas funcionalidades (WIKI). Alguns melhoramentos foram implementados com sucesso. As funções de segurança eram praticamente inexistentes nesta versão simplificada.

Um programa equivalente com mais funcionalidades foi identificado e instalado posteriormente (TWIKI). As novas versões desse programa disponibilizadas por seus desenvolvedores foram instaladas. Correções foram aplicadas eventualmente para melhorar aspectos de segurança.

Ambos os programas - WIKI e TWIKI, estão disponíveis sob licença de código aberto na Internet. 


\subsection{Práticas da cultura de segurança nos ambientes e na organização virtual estudada}

As práticas da cultura de segurança em ambientes e organizações virtuais podem ser formais e informais (ELLIOTT; SCACCHI, 2003).

\subsubsection{Práticas associadas à adaptabilidade}

\subsubsection{Apoio do sistema de gestão de conteúdos em hipertexto para o registro de atividades}

A atividade de pesquisa explorou ações e interações na organização virtual e em um conjunto de ambientes. As atividades da organização virtual ocorrem através de encontros presenciais e virtuais. O sistema de gestão de conteúdos em hipertexto, baseado em Web, foi regularmente utilizado para registrar as atividades.

Os principais usos do sistema de gestão de conteúdos em hipertexto são:

- a elaboração de agendas de atividades;

- o registro de conteúdos e referências relevantes;

- o refinamento de conteúdos e programas;

- a utilização de programas de apoio em páginas Web;

- a elaboração de perfis de participantes.

O servidor Web, onde está instalada a ferramenta de gestão de conteúdos em hipertexto, sofreu invasões, com a alteração indevida da página inicial de acesso. Nessas invasões, as demais páginas de conteúdo podiam ser acessadas normalmente, mas como os principais índices de conteúdos estavam registrados na primeira página, o trabalho relacionado aos conteúdos ficou completamente prejudicado. Mudanças foram realizadas para distribuir as páginas com os índices de conteúdos em locais de acesso protegidos por senhas e, em alguns casos, não disponíveis publicamente. 
As aplicações foram restabelecidas a partir de cópias de segurança, armazenadas no provedor. A informação recebida do provedor é de que cópias de segurança são realizadas diariamente e ficam disponíveis por até sete dias.

Uma pesquisa nas bases de informação sobre a ferramenta disponíveis na Internet revelou a existência da fragilidade no programa e também a forma de correção desta fragilidade. Uma nova fragilidade foi identificada posteriormente e também foi corrigida. Uma nova versão do programa integrou as diversas correções.

Imagina-se que a invasão foi propiciada pela própria divulgação da fragilidade nas bases de informação disponíveis. Uma pesquisa utilizando como argumento o nome do invasor, apontou diversos servidores com o mesmo problema. $\mathrm{O}$ registro da invasão foi feito em língua portuguesa o que permitiu imaginar que a procedência do invasor era mesmo do Brasil, apesar da ferramenta e de suas bases de informação estarem disponíveis em língua inglesa.

O conhecimento das bases de informação e das comunidades de desenvolvedores que trabalham com os programas foi essencial para que a cópia de segurança fosse restabelecida em condições aceitáveis. O restabelecimento das condições iniciais foi rápido, em algumas horas, e o impacto sobre as pesquisas ao conteúdo foi bastante reduzido, considerando a média de 10.000 acessos/mês às páginas abertas ao público em geral.

\subsubsection{Práticas relacionadas com a dependabilidade}

\subsubsection{Análise e gestão de dependências}

A gestão de dependências está relacionada tanto com aspectos técnicos como com aspectos sociais.

Estão incluídos na gestão de dependências:

- a seleção de programas a serem utilizados para a operação e a administração da organização virtual;

- os ambientes virtuais a serem disponibilizados;

- a definição sobre restrições de acesso; 
- a seleção de procedimentos de segurança;

- a definição de procedimentos de atualização;

- a seleção e a obtenção de aprovação para o relacionamento da organização virtual com indivíduos, grupos e organizações tradicionais;

- a seleção e a autorização de participantes da organização virtual.

\subsubsection{Registro de participantes da organização virtual}

O registro de informações sobre os participantes está relacionado com o desenvolvimento de atividades pela organização virtual.

Os participantes desenvolvem suas atividades normais em suas organizações de origem e participam de atividades relacionadas com a organização virtual.

São registradas no sistema de gestão de conteúdos apenas as atividades relacionadas com a organização virtual. Eventualmente são disponibilizadas informações e links para currículos dos participantes.

O registro de informações específicas dos participantes e de sua participação em atividades é geralmente realizado nos ambientes de administração da organização virtual, fechados ao acesso público.

\subsubsection{Práticas associadas à compatibilidade}

\subsubsection{Aplicação de metodologias de análise de segurança}

Durante o período em que foram conduzidas as atividades de pesquisa, foram utilizadas, simultaneamente, várias versões do programa de gestão de conteúdos em hipertexto. No período de encerramento das atividades de pesquisa, foi feita a opção pela não implantação da versão mais atual do programa, assim que a mesma foi disponibilizada. Considerando que as versões instaladas estavam estabilizadas e que não apresentavam problemas de segurança, optou-se por planejar a migração de versão para o período posterior ao encerramento das atividades de pesquisa. 
Para a decisão de atualização de versões, foram levadas em consideração as dependências entre programas e o impacto em indicadores de acessos públicos, que uma interrupção temporária do sistema principal ocasionaria.

\subsubsection{Práticas associadas à credibilidade}

\subsubsection{Coordenação colaborativa de atividades}

A coordenação colaborativa de atividades está relacionada com a utilização de agendas de atividades, de taxonomia e de documentação.

Para a organização virtual estudada, a coordenação colaborativa de atividades envolve projetistas, desenvolvedores e usuários e está relacionada com estruturas e processos de desenvolvimento de programas computacionais e com estruturas e processos organizacionais que incluem os programas. Inclui atividades de análise, de gestão de dependências técnicas e sociais, de coordenação e de tomada de decisões.

Está relacionada com a aplicação da metodologia de análise de segurança, com a arquitetura da organização virtual, e com os indivíduos, grupos e organizações tradicionais que participam e contribuem com as atividades.

\subsubsection{Registros de conteúdos, estatísticas e atualizações.}

Poucos participantes estão autorizados a atualizar o sistema de gestão de conteúdos em hipertexto. A autorização para atualização foi dada preferencialmente a pesquisadores envolvidos com o tema de inovação e com o objetivo de pesquisa dessa dissertação. Os pesquisadores se reúnem com regularidade mínima mensal para o debate de ações e resultados de pesquisa.

A atualização nas áreas abertas é feita por cinco pesquisadores.

A atualização na área fechada dedicada à pesquisa geral pode ser realizada por dez pesquisadores. Essa área, entretanto, é utilizada apenas para exemplificar o funcionamento do sistema e não recebe ainda um grande número de atualizações.

A atualização na área fechada dedicada a assuntos administrativos e operacionais da organização virtual é realizada por três pesquisadores. Essa área também é acessada, 
para consultas, por mais dois participantes que desempenham funções administrativas e operacionais da organização virtual.

O sistema de gestão de conteúdos em hipertexto fornece estatísticas de acesso e de atualização das páginas Web.

\subsubsection{Práticas associadas à confiança}

\subsubsection{Comunicação entre os participantes}

A comunicação entre desenvolvedores e usuários é realizada através de reuniões e encontros presenciais e através de meios eletrônicos.

O sistema de gestão de conteúdos colabora para que a comunicação fique registrada e os principais assuntos sejam progressivamente categorizados.

\subsubsection{Hierarquização de ambientes de colaboração}

O sistema de gestão de conteúdos em hipertexto inclui duas instalações completas do programa de apoio, em versões diferentes. Uma das instalações foi utilizada para assuntos internos e não está disponível para acesso público. A outra instalação está disponível para visualização na Internet. A atualização da instalação aberta é permitida apenas a usuários registrados, com a utilização de senhas de acesso.

A instalação disponível para acesso público conta com sete ambientes, segmentados de acordo com grandes áreas de conteúdo e interesse.

A instalação de uso interno conta com apenas três ambientes, sendo um operacional, um de pesquisa e um de controle do programa de gestão de conteúdos em hipertexto.

\subsubsection{Práticas associadas à mobilidade}

\subsubsection{Registro de programas e de estruturas e processos}

A operação da organização virtual e dos múltiplos ambientes virtuais depende de um conjunto significativo de programas e serviços. 
O registro e o controle de atividades e artefatos necessários são realizados com o apoio do sistema de gestão de conteúdos em hipertexto.

Informações e relacionamentos sobre estruturas e processos de desenvolvimento dos programas e estruturas e processos organizacionais que incluem os programas também são registrados.

São exemplos de estruturas e processos de desenvolvimento:

- laboratórios de pesquisa;

- universidades;

- fábricas de software;

- comunidades virtuais;

- organizações de desenvolvimento em geral;

- grupos de desenvolvimento.

São exemplos de estruturas e processos organizacionais que incluem os programas:

- indivíduos e grupos;

- organizações em geral;

- organizações de desenvolvimento.

\subsubsection{Registro de senhas e de procedimentos de acesso}

Como a organização virtual se relaciona a um grande número de organizações e ambientes tradicionais, o registro de senhas e procedimentos de acesso é necessário.

Os participantes são responsáveis pelas informações relacionadas a senhas e procedimentos de acesso em ambientes e organizações tradicionais.

Senhas de acesso aos ambientes da organização virtual podem ser registrados no ambiente fechado dedicado à administração e à operação da organização virtual. 


\subsection{Aspectos principais da cultura de segurança e da regulação de diferentes estruturas e processos nos ambientes e na organização virtual estudada}

A Tabela 4 apresenta um resumo dos temas de conteúdo propostos, práticas e artefatos identificados para os ambientes e para a organização virtual estudada.

Os temas de conteúdo, práticas e artefatos facilitam a interpretação sobre a cultura de segurança das diferentes estruturas e processos envolvidos e sobre a sua regulação.

A identificação de pontos vulneráveis é facilitada, assim como o planejamento de ações e interações que possam desenvolver a cultura de segurança. 


\section{Tabela 4 - Cultura de segurança nos ambientes e na organização virtual estudada}

\begin{tabular}{|c|c|c|c|c|}
\hline \multicolumn{2}{|c|}{ Temas de Conteúdo } & \multicolumn{2}{|c|}{ Práticas } & \multirow{2}{*}{$\begin{array}{c}\text { Artefatos } \\
\text { Artefatos } \\
\text { Eletrônicos }\end{array}$} \\
\hline Esposados & Inferidos & Formais & Informais / Normas & \\
\hline & Adaptabilidade & $\begin{array}{c}\text { Utilização de } \\
\text { conteúdos, } \\
\text { programas, } \\
\text { estruturas, processos } \\
\text { e ambientes. }\end{array}$ & $\begin{array}{l}\text { Refinamento de } \\
\text { conteúdos, } \\
\text { programas, } \\
\text { estruturas, processos } \\
\text { e ambientes. }\end{array}$ & $\begin{array}{c}\text { Programas, } \\
\text { estruturas, processos } \\
\text { e ambientes } \\
\text { personalizados, } \\
\text { quando aplicável. } \\
\text { Índices de acesso a } \\
\text { conteúdos } \\
\text { relacionados. Robôs. }\end{array}$ \\
\hline & Dependabilidade & $\begin{array}{c} \\
\text { Identificação de } \\
\text { participantes, } \\
\text { programas, } \\
\text { estruturas, processos } \\
\text { e ambientes. }\end{array}$ & $\begin{array}{l}\text { Análise e gestão de } \\
\text { dependências } \\
\text { técnicas e sociais. }\end{array}$ & $\begin{array}{l}\text { Diferentes versões } \\
\text { do programa de } \\
\text { gestão de conteúdos } \\
\text { em hipertexto. } \\
\text { Registros de } \\
\text { configurações de } \\
\text { programas e de } \\
\text { rotinas disponíveis. } \\
\text { Mapas conceituais. }\end{array}$ \\
\hline & Compatibilidade & $\begin{array}{c}\text { Registros e seleção } \\
\text { de programas, } \\
\text { estruturas, processos } \\
\text { e ambientes. }\end{array}$ & $\begin{array}{l}\text { Criação de novos } \\
\text { programas, } \\
\text { estruturas, processos } \\
\text { e ambientes. }\end{array}$ & $\begin{array}{c}\text { Programas que } \\
\text { podem ser } \\
\text { integrados ao } \\
\text { sistema de gestão de } \\
\text { conteúdos em } \\
\text { hipertexto como } \\
\text { planilhas e mapas } \\
\text { dinâmicos. Registros } \\
\text { de outros programas. }\end{array}$ \\
\hline Credibilidade & & $\begin{array}{l}\text { Coordenação } \\
\text { colaborativa de } \\
\text { atividades }\end{array}$ & $\begin{array}{l}\text { Registro de } \\
\text { conteúdos, } \\
\text { estatísticas, } \\
\text { atualizações. }\end{array}$ & $\begin{array}{c}\text { Agendas, taxonomia } \\
\text { e documentação. } \\
\text { Registros de } \\
\text { aspectos de } \\
\text { segurança, } \\
\text { estatísticas, } \\
\text { atualizações, } \\
\text { procedimentos e } \\
\text { melhores práticas. }\end{array}$ \\
\hline Confiança & & $\begin{array}{l}\text { Encontros } \\
\text { presenciais e } \\
\text { virtuais. }\end{array}$ & $\begin{array}{l}\text { Hierarquização de } \\
\text { ambientes de } \\
\text { colaboração. }\end{array}$ & $\begin{array}{c}\text { Perfis de segurança } \\
\text { dos participantes, de } \\
\text { grupos e dos } \\
\text { ambientes virtuais. } \\
\text { Registros de portais } \\
\text { e comunidades } \\
\text { virtuais. }\end{array}$ \\
\hline Mobilidade & & $\begin{array}{l}\text { Utilização do sistema } \\
\text { de gestão de } \\
\text { conteúdos em } \\
\text { hipertexto. }\end{array}$ & $\begin{array}{l}\text { Desenvolvimento da } \\
\text { mobilidade virtual. }\end{array}$ & $\begin{array}{c}\text { Sistema de gestão } \\
\text { de conteúdos em } \\
\text { hipertexto } \\
\text { representando } \\
\text { diversos ambientes } \\
\text { com características } \\
\text { de segurança } \\
\text { diferentes e } \\
\text { integrando perfis de } \\
\text { participantes, a } \\
\text { comunicação virtual, } \\
\text { as comunidades } \\
\text { virtuais e portais. }\end{array}$ \\
\hline
\end{tabular}




\section{LIMITES DE SEGURANÇA NA RELAÇÃO ENTRE PESSOAS E PROGRAMAS COMPUTACIONAIS}

Esta dissertação explora temas de conteúdo, práticas e artefatos como componentes da cultura de segurança em ambientes e organizações virtuais com o objetivo de desenvolver a segurança de programas computacionais.

Os estudos foram conduzidos em uma organização virtual de pequeno porte existente e em um conjunto de ambientes virtuais.

Um conjunto de temas de conteúdo foi proposto e foram identificados práticas e artefatos que caracterizam a cultura de segurança dos ambientes e da organização virtual estudada.

A exploração de ambientes e organizações virtuais em outras situações diferentes da considerada nesta atividade de pesquisa pode ser realizada, e pode levar à proposição de temas de conteúdo e à identificação de práticas e artefatos eventualmente diferentes.

Além disso, as condições que afetam a segurança de programas também sofrem modificações e a mudança de condições perigosas deve ser levada em consideração, possivelmente alterando temas de conteúdo, práticas e artefatos.

A reflexão sobre limites de segurança na relação entre pessoas e programas deve levar em consideração, a mudança de condições perigosas e a emergência de novos conceitos.

Esse capítulo aborda oportunidades para futuras pesquisas.

\subsection{A mudança de condições perigosas}

Diversos aspectos foram identificados nesta dissertação e permitem afirmar que as condições perigosas para a segurança de programas computacionais continuarão em contínua mutação. 
Além dos casos e conceitos já apresentados nessa dissertação e dos conceitos de mobilidade virtual e de inteligência do ambiente, que serão indicados nos itens a seguir, avanços de outras características também devem ser adequadamente avaliados.

Espera-se um aumento da utilização de robôs e a criação de novos tipos de ameaças, como vírus, por exemplo.

Novas aplicações, estruturas e processos envolvendo os programas são criados e disponibilizados continuamente e também devem ter seus impactos avaliados.

Os programas estão sendo utilizados, por exemplo, para a leitura de artigos técnicos.

GUERNSEY (2003) informa sobre a disponibilidade de programas que apresentam a capacidade para esquadrinhar vertiginosamente 250 mil páginas por hora. Compara este produto com outro que tem capacidade menor, de 15 mil páginas por hora, e, com o ritmo humano, de 60 páginas por hora.

O texto informa que os programas de garimpagem de textos apresentam resultados superiores aos programas buscadores, classificando as informações, estabelecendo ligações entre documentos que, por outros critérios, seriam considerados sem conexão entre si e fornecendo mapas visuais (alguns com aparência de galhos de árvore ou raios de rodas) para conduzir os usuários por novos caminhos cuja existência eles podem não ter percebido.

O conceito de organização virtual também está se difundindo e novas alternativas podem surgir a partir desse avanço.

NOLL (2002) apresenta os principais fundamentos para a sua proposta de concretização de processos em organizações virtuais:

- a necessidade de modelagem de processos diferenciada com relação a abordagem de organizações tradicionais;

- a necessidade de cooperação para a realização de objetivos comuns;

- a sincronização de processos através do compartilhamento de produtos do trabalho;

- o compartilhamento de recursos; 
- a decomposição do processo de desenvolvimento de software em fragmentos;

- a concretização de fluxos de trabalho;

- a independência entre instâncias de concretização;

- a utilização de repositórios distribuídos e compartilhados.

\subsection{Mobilidade virtual em diferentes estruturas e processos}

O conceito de mobilidade admite diferentes pontos de vista. A mobilidade está relacionada com equipamentos, pessoas e com os próprios programas computacionais. O conceito de mobilidade pode estar relacionado também com sistemas, aplicações, atividades ou processos.

O conceito de mobilidade pode ser interpretado, ainda, em mais uma possibilidade que é a mobilidade virtual.

Várias definições foram encontradas para o conceito de mobilidade virtual. A interpretação que desperta a maior atenção é aquela que considera "canais" disponíveis no ambiente virtual, através dos quais é possível navegar segundo objetivos pré-estabelecidos (MARKS, 2005).

O caso mais interessante é de um vírus de computador que navega por esses "canais", utilizando listas de senhas, e que descobre vulnerabilidades em redes e se comunica de volta com o seu criador, através de possibilidades oferecidas por salas de bate-papo (chat rooms).

O conceito de canais virtuais já é utilizado em muitas outras situações, como por exemplo, as redes privadas virtuais (VPN - Virtual Private Networks), e, no caso do vírus citado, os IRC (Internet Relay Channels), que suportam as salas de bate-papo.

\subsubsection{Mobilidade na relação do homem com o trabalho}

A mobilidade está associada à relação do homem com o trabalho.

Mudanças na realidade do trabalho envolvendo a mobilidade afetam as relações sociais entre as pessoas e organizações envolvidas. No seu processo evolutivo, os programas computacionais sofrem grande influência, mas também influenciam, os 
processos de adaptação de pessoas, organizações e equipamentos. $\mathrm{O}$ ambiente no qual as atividades profissionais se desenvolvem fica sujeito a grandes variações.

O emprego tradicional se enfraquece e cede espaço para relações menos dependentes das organizações e mais apoiadas no próprio indivíduo e em seus conhecimentos. As relações atuais de trabalho envolvem novas alternativas de mobilidade. O vínculo passa a ser de curto prazo, e se fundamenta em contratos diversificados, trabalho autônomo, tele-trabalho e rupturas nas carreiras (MALVEZZI, 2003).

O resultado da adaptação de atividades profissionais e de programas computacionais é a ampliação e a diversificação de espaços e de alternativas de atuação, e o surgimento de novas categorias de atividades profissionais, de programas computacionais e de relações entre atividades e programas.

Segundo MALVEZZI (2000), a mobilidade aparece como conceito, na psicologia organizacional e na relação do homem com o trabalho, a partir da administração científica. Na era da globalização, nos anos 1990, o crescimento da mobilidade faz com que a carreira envolva tarefas e missões mais complexas, deixando de significar principalmente a ascensão na escala hierárquica. Na década de 90 , as fronteiras ficam mais porosas fazendo com que o espaço organizacional seja considerado mais pelos processos que pelas estruturas. A explosão de sistemas de informação e de redes eletrônicas e sociais distancia o trabalhador de estruturas, hierarquias e manuais. Dentre os novos conceitos estão: a empresa virtual, o trabalho a distância, a homogeneização das tarefas de profissões distintas no teclado do computador e a diminuição significativa do trabalho manual.

MALVEZZI (2000) aponta como aspecto central da globalização, a compressão do espaço e do tempo pela utilização da tecnologia da tele-informação. A globalização também se caracteriza pelo aspecto econômico, a partir da facilidade para a inserção de capital financeiro, de capital intelectual e tecnologia aos negócios. A rápida circulação de objetos e sujeitos poderia ser considerado o aspecto antropológico da globalização, tornando o capital simbólico um dos fatores mais relevantes na formação do valor e do significado das pessoas e objetos. A abertura para as pessoas viverem distintas e variadas identidades poderia ser considerada o aspecto psicológico da globalização. 
Para as gerações mais novas, a mobilidade não gera tanto estresse. Sua capacidade de adaptação às mudanças é maior que a de grande parte dos indivíduos, principalmente aqueles que já estão na metade da carreira profissional.

MALVEZZI (2000) afirma que: “ [...] o ambiente de trabalho não está mais limitado à variáveis físicas ao redor da estação de trabalho, ou da estrutura da empresa, mas transcende os muros das empresas e da dimensão do espaço de trabalho entendido como emprego. Dentro da empresa sem fronteiras, da carreira sem fronteiras e do emprego "just in time" o trabalhador torna-se igualmente, um indivíduo globalizado. [...] o trabalho está se tornando uma realidade mais flexível, mais dependente do conhecimento e menos estruturado pela empresa que pelo mercado".

Um interessante exemplo de mobilidade, na relação do homem com o trabalho, é apresentado por TEIXEIRA (2005), com o caso do Centro de Saúde Escola do bairro do Butantã, na cidade de São Paulo.

A informação, sobre as atividades do Centro de Saúde Escola Samuel Barnsley Pessoa (CSE do Butantã), foi apontada em apresentação do LInC - Laboratório de Inteligência Coletiva para o GetGC - Grupo de Estudos de Tecnologia em Gestão de Conhecimento, da PUC SP. A página do LInC apresenta o projeto de Centro de Saúde com o título: Comunidade Virtual do Projeto Acolhimento e Rede de Conversações: o desempenho dos serviços de saúde da perspectiva da Inteligência Coletiva. A comunidade conta com a participação de órgãos governamentais brasileiros e de instituições de ensino e pesquisa brasileiras e estrangeiras.

A página inicial da comunidade informa como principais objetivos:

"Trata-se do espaço de comunicação, compartilhamento, trabalho colaborativo, documentação e divulgação do Projeto Acolhimento e Redes de Conversações: o desempenho dos serviços de saúde da perspectiva da Inteligência Coletiva (relação entre capital social, cultural e tecnológico). Mais amplamente oferece-se como um espaço de compartilhamento, geração de informações e troca de experiências em Saúde e Inteligência Coletiva. As principais áreas de interesse são: o campo da Saúde Coletiva, com destaque para as práticas em serviços (em especial, as práticas em atenção básica à saúde) e para os processos de geração, gestão e uso de informações em saúde; o vasto e emergente campo da Inteligência Coletiva". 
As Figuras 6 e 7 ilustram a organização virtual do Centro de Saúde e os tipos de conversas conduzidas nas diversas instâncias.

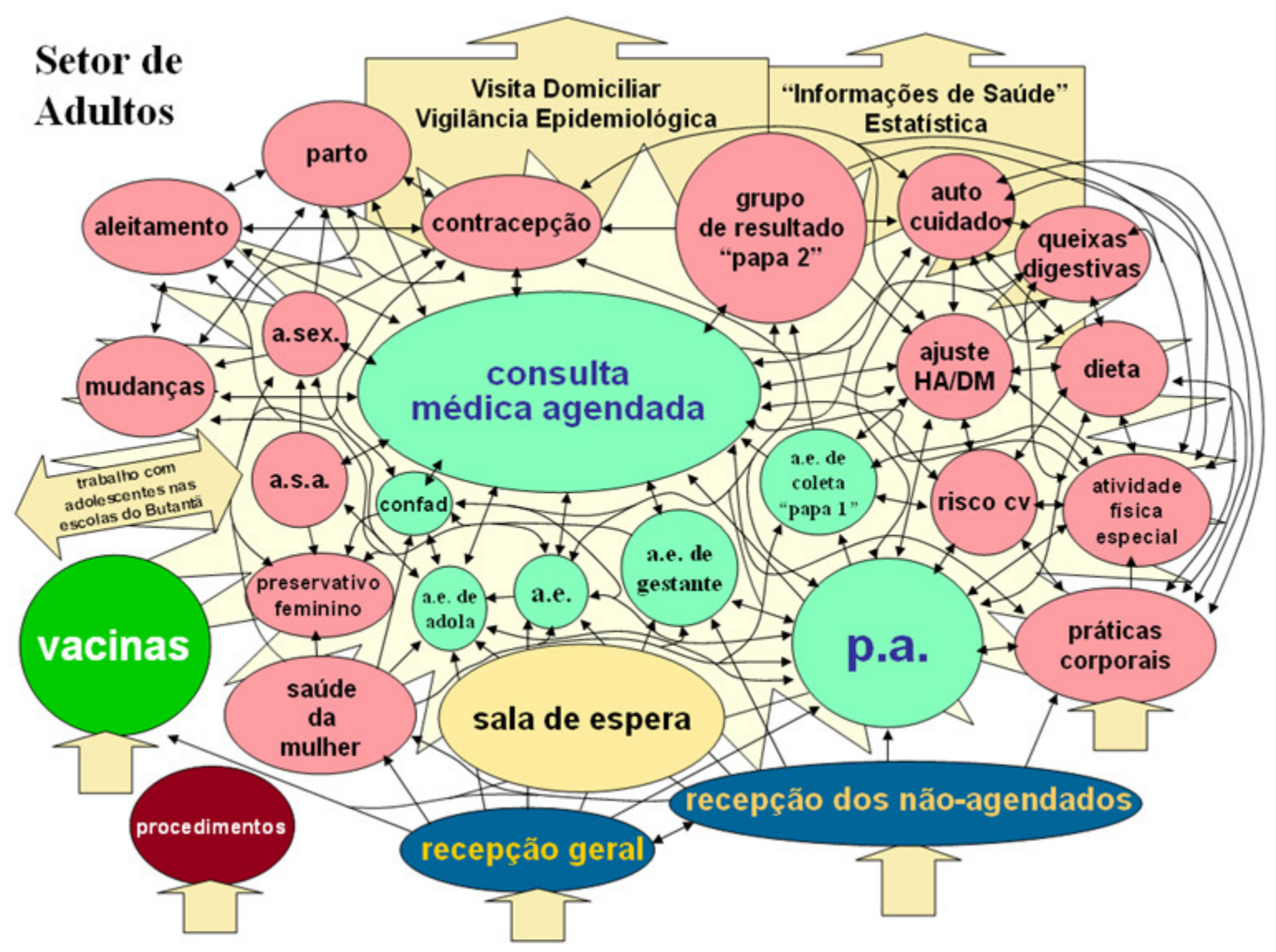

Figura 6 - Diagrama do espaço de conversação do Setor de Atenção à Saúde do Adulto do Centro de Saúde Escola Samuel Barnsley Pessoa, em 2001 


\begin{tabular}{|c|c|}
\hline Conversas individuais & Conversas em grupo \\
\hline p.a. $=$ pronto atendimento médico & Encontro para práticas corporais (aberto) \\
\hline \multirow{2}{*}{$\begin{array}{l}\text { consulta médica agendada: } \\
\text { pré-natal }\end{array}$} & Atividade fisica para grupos especiais \\
\hline & Conhecimento do risco cardiovascular (CV) \\
\hline "doenças crônicas" (HA/DM) & Ajuste dos niveis pressóricos (HA) e glicêmicos (DM) \\
\hline \multirow{3}{*}{$\begin{array}{c}\text { ginecologia } \\
\text { (DIU, DST, colposcopia/biópsia, } \\
\text { menopausa etc.) }\end{array}$} & Autocuidado entre idosos (>50 anos) \\
\hline & Dieta: cuidados alimentares para grupos especiais \\
\hline & Queixas digestivas: cuidados alimentares \\
\hline \multirow{2}{*}{$\begin{array}{c}\text { confad = "conflito familiar e doméstico" } \\
\text { (atendimento individual por } \\
\text { profissional de nivel superior } \\
\text { especialmente treinado) }\end{array}$} & $\begin{array}{l}\text { Saúde reprodutiva e sexual: } \\
\text { ênfase nos meios de contracepção }\end{array}$ \\
\hline & \multirow[t]{2}{*}{$\begin{array}{l}\text { Saúde reprodutiva e sexual: } \\
\text { ênfase no preservativo feminino }\end{array}$} \\
\hline a.e. = atendimento de enfermagem (geral) & \\
\hline a. e. de coleta de papanicolaou & Resultado de papanicolaou \\
\hline \multirow[t]{3}{*}{ a. e. de gestantes } & $\begin{array}{l}\text { Cuidados na gestação: } \\
\text { mudanças no corpo e na vida }\end{array}$ \\
\hline & $\begin{array}{l}\text { Cuidados na gestação: } \\
\text { aleitamento e outros cuidados com o bebê }\end{array}$ \\
\hline & $\begin{array}{l}\text { Cuidados na gestação: o parto } \\
\text { (inclui uma visita à maternidade) }\end{array}$ \\
\hline \multirow[t]{2}{*}{ a. e. de adolescentes } & Adolescência e saúde \\
\hline & Adolescência e sexualidade \\
\hline
\end{tabular}

Figura 7 - Descrição sumária dos conteúdos das conversas mapeadas

\subsubsection{Mobilidade na relação do homem com a tecnologia}

A mobilidade está associada à relação do homem com a tecnologia. Neste caso a mobilidade pode ser micro-mobilidade, mobilidade local e mobilidade remota. Foram identificadas também modalidades de mobilidade no trabalho.

Segundo LINDGREN e WIBERG (2000), a mobilidade remota é caracterizada quando usuários remotos interagem entre si usando tecnologia. Além da mobilidade remota, os autores apresentam os conceitos de micro mobilidade e mobilidade local. Na micro-mobilidade, um artefato pode ser movimentado ou manipulado para vários objetivos em torno de um domínio circunscrito. Na mobilidade local, o movimento pode ser entre salas, andares e prédios de uma mesma área. 
Os autores discutem em seu texto formas de trabalho colaborativo apoiado por computador e seu impacto para quem desenvolve as atividades. Para engenheiros que desenvolvem suas atividades em campo, por exemplo, a mobilidade desempenha função central.

Citando KRISTOFFERSEN (1998), os autores apresentam ainda três modalidades de mobilidade no trabalho: visitando, viajando e vagando. Visitando significa trabalhar em diferentes locais de forma coerente, mas por período limitado. Viajando é trabalhar enquanto trafega em um veículo, como um avião ou trem. Vagando é trabalhar enquanto se move localmente (IVANOFF, 2004a).

A mobilidade no trabalho, na sociedade atual, requer a gestão de responsabilidades, conflitos e habilidades. Dentre as tarefas envolvidas estão novas maneiras de coordenar atividades de trabalho e respectivas responsabilidades, divisão de trabalho entre o pessoal fixo e os que se movimentam, novas práticas de trabalho para ambos os tipos de trabalhadores e finalmente novas maneiras de organizar os trabalhadores dispersos dentro dos times de colaboração (IVANOFF, 2004a).

\subsubsection{Mobilidade virtual de pessoas e programas computacionais}

A terceira interpretação do conceito de mobilidade está associada à relação do homem com os programas computacionais. Neste caso a mobilidade pode ser mobilidade virtual tanto para as pessoas como para os programas computacionais. Um primeiro exemplo vem da crítica produzida por MCKAY et al. (2005) sobre os jovens e suas possibilidades de comunicação através da Internet. Dentre as muitas possibilidades estão as salas de bate-papo ou chat rooms, o correio eletrônico, as mensagens instantâneas, a publicação na Web, os sites, os blogs, os jogos online, a integração com os telefones celulares e as suas possibilidades de mensagens de texto e multimídia.

Essa nova possibilidade reforça a interação, através do meio virtual, fazendo com que muitas atividades que antes exigiam deslocamentos passem a ser realizadas, de maneira progressivamente mais integrada, com o apoio de programas 
computacionais. Tanto a comunicação como as conversas deverão ser profundamente influenciadas por essas novas possibilidades.

Um segundo exemplo de modelo de organização virtual é apresentado pela cidade de Halton, no Reino Unido. Trata-se de estrutura na qual as autoridades locais e outros provedores de serviços públicos podem desenvolver suas próprias agendas de governo eletrônico.

A Figura 8 apresenta o modelo proposto por Halton.

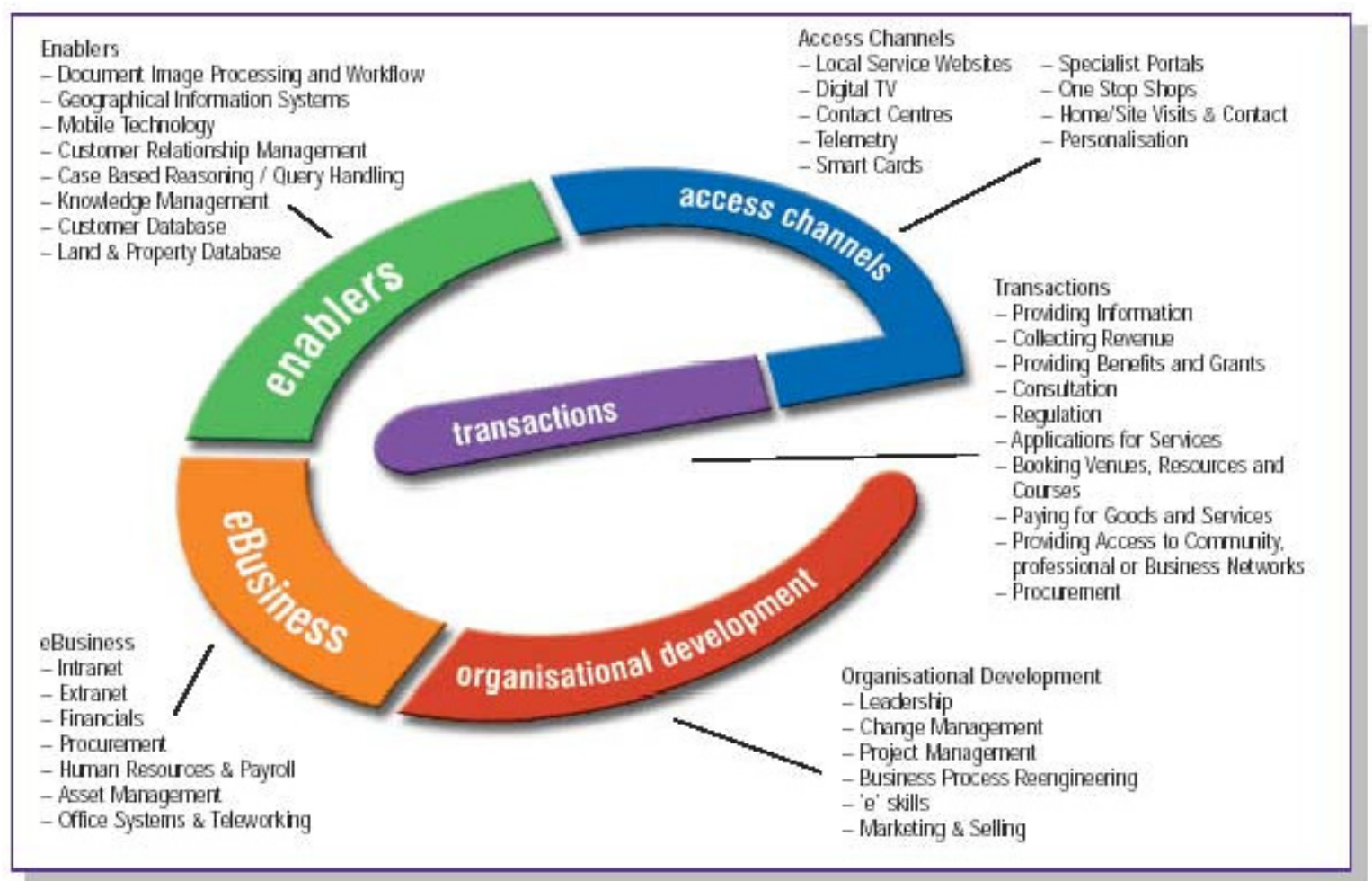

Figura 8 - Modelo de organização virtual apresentado pela cidade de Halton, no Reino Unido

\subsection{Apoiando a perspectiva de inteligência do ambiente}

O conceito de inteligência do ambiente está relacionado com um conjunto de cenários, elaborado pela Comunidade Européia, sobre uma visão de sociedade de informação que irá transformar a maneira como as pessoas vivem, aprendem, trabalham e se divertem. A Comunidade Européia entende que a visão de sociedade de informação proposta não se realizará a menos que governos, empresas e cidadãos depositar grande confiança em uma inteligência do ambiente correta, contínua e 
segura, tanto sob o ponto de vista crítico como sob o ponto de vista de sistema de informação. A pesquisa sobre dependabilidade é essencial para a comunidade européia para apoiar a perspectiva de inteligência do ambiente. As direções futuras podem ser exploradas em termos de quatro aspectos principais da inteligência do ambiente: abertura, mobilidade, adaptabilidade e manuseabilidade (workability). A informação sobre o conceito de inteligência do ambiente foi obtida no site do CORDIS (2006). CORDIS (2006) é um espaço de informação dedicado a atividades de inovação e pesquisa e desenvolvimento da Europa. Seus principais objetivos são: facilitar a participação em atividades de pesquisa e inovação européias; melhorar a exploração de resultados de pesquisa em setores cruciais para a competitividade da Europa; promover a difusão de conhecimento incentivando o desempenho de inovação das empresas e a aceitação de novas tecnologias pela sociedade.

\subsection{Considerações finais}

O esforço principal dessa dissertação foi explorar ações e interações e identificar alternativas que permitissem minimizar os efeitos indesejáveis de dependências e rupturas em estruturas e processos de desenvolvimento de programas computacionais e em estruturas e processos organizacionais que incluem os programas.

Para a realização da atividade de pesquisa, foi selecionada a metodologia Grounded Theory, considerando que a aproximação do assunto a ser investigado, deveria ser realizada "sem uma teoria a ser testada, mas, pelo contrário, com o desejo de entender uma determinada situação e como e porque seus participantes agem de determinada maneira, como e porque determinado fenômeno ou situação se desdobra deste ou daquele modo" (LEVACOV, 2004).

O objetivo da atividade de pesquisa se estabeleceu como o desenvolvimento da segurança de programas computacionais através da exploração e caracterização da cultura de segurança em ambientes e organizações virtuais.

Com o apoio de novos conceitos, dependências e rupturas em diferentes estruturas e processos puderam ser avaliadas em conjunto.

Diferentes alternativas de fundamentos conceituais foram identificados para categorizar os conceitos de ambiente e organização virtual, como sistema de 
conhecimento (TSOUKAS, 1996), como coordenação da ação cooperativa (MAGGI, 2006), como cultura de segurança (ELLIOTT; SCACCHI, 2003) e como cultura de segurança computacional (ALMEIDA JÚNIOR, 2003).

A partir da análise integrada de diferentes estruturas e processos, descontinuidades entre diferentes níveis de contextos de comunicação, informação ou aprendizagem, foram caracterizadas como situações ambíguas, em que mensagens são transmitidas simultaneamente em diferentes níveis de contexto, ou em que uma resposta é demandada em um nível de contexto superior e negada em um nível inferior.

Efeitos indesejáveis de dependências e rupturas foram apresentados e associados a aspectos que posteriormente foram utilizados para promover a cultura de segurança dos ambientes e da organização virtual estudada.

Os temas de conteúdo para a cultura de segurança dos ambientes e da organização virtual foram então propostos: adaptabilidade, compatibilidade, dependabilidade, credibilidade, confiança e mobilidade.

A partir da análise de informações e experiências, artefatos e práticas que compõem a cultura de segurança dos ambientes e da organização virtual estudados foram identificados.

As principais práticas e artefatos identificados, para os ambientes e para a organização virtual estudados, foram, a comunicação entre desenvolvedores e usuários, a coordenação colaborativa de atividades, a gestão de dependências e o manejo de mudanças e da adaptação.

Para o desenvolvimento das atividades de pesquisa, foi utilizado um programa específico para a gestão de conteúdos em hipertexto, baseado em Web.

Aspectos de segurança desse programa e de outros programas e serviços foram explorados e documentados com a utilização do conceito de cultura de segurança em ambientes e organizações virtuais.

A necessidade de contínua verificação de efeitos indesejáveis de dependências e rupturas em diferentes estruturas e processos foi reforçada, considerando a possibilidade de mudança de condições perigosas relacionadas com os programas. 
A dissertação buscou, também, abrir o espaço para o debate sobre limites de segurança na relação entre pessoas e programas computacionais, apontando como possibilidades futuras de pesquisa: a mobilidade virtual em diferentes estruturas e processos, e a perspectiva de inteligência do ambiente.

A pesquisa sobre a segurança de programas computacionais apresenta desafios multidisciplinares e de grande amplitude.

Conhecimentos de engenharia elétrica, de engenharia de computação, de engenharia de produção, de administração de empresas e de psicologia foram necessários para a uma primeira compreensão desses desafios.

O aprofundamento e a qualidade de conclusões sobre os desafios da segurança de programas computacionais certamente merecerão pesquisas mais aprofundadas. 


\section{Bibliografia}

AGÊNCIA ESTADO. Brasileiro usa internet a seu jeito, 2005. Disponível em: <http://br.news.yahoo.com/051201/25/zugq.html>. Acesso em: 8 fev. 2006.

ALMEIDA JÚNIOR, J.R.; CAMARGO JÚNIOR, J.B.; CUGNASCA, P.S. Metodologia de Análise de Segurança em Sistemas de Controle Computadorizados. In: CONGRESSO E EXPOSIÇÃO INTERNACIONAL DE AUTOMAÇÃO CONAI'2002, 10, São Paulo, SP, 5 a 18 de julho de 2002.

ALMEIDA JÚNIOR, J.R.; CAMARGO JÚNIOR, J.B.; BASSETO, B.A.; CUNHA, R.S.; PAZ, S.M. Uma Lista de Inspeção para a Análise de Software Crítico, p.67-74. In: SSI'99 - SIMPÓSIO SOBRE SEGURANÇA EM INFORMÁTICA, São José dos Campos, SP, 14 a 16 de setembro de 1999.

ALMEIDA JÚNIOR, J.R. Segurança em Sistemas Críticos e em Sistemas de Informação - Um Estudo Comparativo. 2003. 191f. Tese (Livre Docência) - Escola Politécnica da Universidade de São Paulo. Departamento de Engenharia de Computação e Sistemas Digitais. São Paulo, 2003.

BARNARD, C. J. The Functions of the Executive. 30 ed. (1968) Cambridge (Mass.): Harvard University Press, 1938.

BATESON, G. Steps Toward an Ecology of Mind, 1978.

BOTS. In: Wikipedia:História dos Bots. Disponível em: <http://pt.wikipedia.org/wiki/Wikipedia:Hist\%C3\%B3ria_dos_Bots>. Acesso em: 04 jun. 2006.

CORDIS. Community Research \& Development Information Service, European research and development $(\mathrm{R} \& \mathrm{D})$ and innovation activities. Disponível em: <http://cordis.europa.eu.int/en/home.html>. Acesso em: 7 fev. 2006. 
DAS, C. R., J. T. KREULEN, and M. J. THAZHUTHAVEETIL. Dependability modeling for multiprocessors. IEEE Computer, October 1990. p. 7-19.

EFE Tóquio. Sistemas travam na estréia do BTMU, Gazeta Mercantil, 5 jan. 2006, Caderno de Finanças, p. B-2.

ELLIOTT, M.; SCACCHI, W. Free Software: A Case Study of Software Development in a Virtual Organizational Culture, April 2003. University of California, Irvine. Disponível em: <http://www.ics.uci.edu/ melliott/reports/ElliottScacchi-FinalRep-04.pdf>. Acesso em: 23 abr. 2006.

EMPIRICA Gesellschaft für Kommunikations und Technologieforschung Gmbh. Modelo FlexWork N. 009 - (Versão v.01 - 11/10/01). Como utilizar as TIC para criar equipes de especialistas independentemente das restrições de espaço e tempo. Disponível em: <http://www.empirica.com> e <http://www.flexwork.eu.com>. Acesso em: 12 out. 2003.

FELlER, J.; FITZGERALD, B. Understanding Open Source Software Development. New York: Pearson Education, 2001.

FIDIS. Future of Identity in the Information Society. Disponível em: $<$ http://www.fidis.net/256.0.html> $\mathrm{e}$ <http://www.fidis.net/fileadmin/public/fidis.jf.pdf>. Acesso em: 1 mai. 2006.

GIORNO, F. Mapas Conceituais (Mapas Mentais). GetGC - Grupo de Estudos de Tecnologia em Gestão de Conhecimento, PUC SP, fev. 1999.

GRINTER, R.E. Understanding Dependencies: A Study of the Coordination Challenges in Software Development. 130p. Dissertação - UC Irvine, 1996. Disponível em: <http://web.archive.org/web/20000816123808/http://www.belllabs.com/user/beki/thesis.html>. Acesso em: 3 dez. 2005.

GUERNSEY, L. A vertiginosa garimpagem de dados, The New York Times, 18 dez. 2003. Revista Digital, Pólo RS - Agência de Desenvolvimento. Disponível em: $<$ http://www.revistadigital.com.br/tendencias.asp?NumEdicao=235>. Acesso em: 8 fev. 2006. 
HALTON. Implementing Electronic Government, Halton Borough Council, Position Statement, 31 out. 2002. Disponível em: $<$ http://www2.halton.gov.uk/pdfs/councilplans/ieg2statement>. Acesso em: 27 jul. 2003.

HART, T.; BUCHHOFER, R.; VACCARO, M. Portable Electronic Devices as Memory and Organizational Aids After Traumatic Brain Injury: A Consumer Survey Study, Journal of Head Trauma Rehabilitation. Lippincott Williams \& Wilkins, Inc. September - October, 2004.

IANNACCI, F. The Linux managing model, First Monday, volume 8, number 12, December 2003. Disponível em: <http://firstmonday.org/issues/issue8_12/iannacci/index.html>. Acesso em: $27 \mathrm{fev}$. 2006.

IVANOFF, G. Mobilidade Remota, Jornal do IE, São Paulo, Instituto de Engenharia, ano I, no. 03 abr. 2004a. Disponível em: <http://www.ie.org.br>. Acesso em: 27 fev. 2006.

Construção de Confiança, Jornal Evolução, São Paulo, Instituto de Engenharia, ano XXIII, no. 60, mar. 2004b. Disponível em: <http://www.ie.org.br>. Acesso em: 27 fev. 2006.

IVANOFF, G.; E. SPINA; M. SPINOLA; P. FRANCISCHINI Sistemas de Gestão de Conhecimento em Software Livre, KM BRASIL 2003, Atas... São Paulo, Sociedade Brasileira de Gestão de Conhecimento, 2003.

JOHNSON, A. M.; MALEK M. Survey of software tools for evaluating reliability, availability and serviceability ACM Computing Surveys 20, no. 4, Dec. 1998, p. 227-269.

JØRGENSEN, N. Putting it all in the trunk: Incremental software development in the FreeBSD Open Source project, Information Systems Journal, volume 11, number 4 (October), 2001, p. 1-19 
KANGAS K. A Mobile Code Approach to Interact with Ubiquitous Embedded Systems. 105p. Diploma thesis. Department of Electrical Engineering, University of Oulu, Oulu, Finland, 2000.

KARDINER, A. The Concept of Basic Personality Structure as an Operational Tool in the Social Sciences. In: LINTON, R. The Science of Man in the World Crisis. Nova York: Columbia University Press, 1945. p. 107-122. Tradução de Maria Isaura Pereira de Queiroz. In: CARDOSO, F. H.; IANNI, O. Homem e Sociedade. São Paulo: Companhia Editora Nacional, 1973. p. 103-122.

KARLSTAD. Universidade de. Disponível em: <http://www.kau.se/eng/>. Acesso em: 1 mai. 2006.

KRISTOFFERSEN, S. et al. Developing scenarios for Mobile CSCW, Proceedings of the First Workshop on Human Computer Interaction with Mobile Devices, 1998, p. 34-47.

KROGH, G.; ICHIJO, K.; NONAKA, I. Facilitando a Criação do Conhecimento. Rio de Janeiro: Campus, 2001.

LALA, P., Self-Checking And Fault-Tolerant Digital Design, Morgan Kauffman, 2000 .

LANDAUER, C.; BELLMAN, K. L., Computational Infrastructure for Experiments in Cognitive Leverage. In: BEYNON, M.; NEHANIV, C.L.; DAUTENHAHN, K., Lecture Notes in Computer Science, Volume 2117, Cognitive Technology: Instruments of Mind : 4th International Conference, CI 2001, Proceedings..., Warwick, UK: August 6-9, 2001.

LAPRIE, J. C.; COSTE A., Dependability: A unifying concept for reliable computing Proc 12TH INT. SYMP. FAULT-TOLERANT COMPUTING, 1982, p. $18-21$.

LEUF, B.; CUNNINGHAM, W. The Wiki Way, 2001. 
LEVACOV, M. Teoria Fundamentada (nos ou em dados), 2004. Disponível em: $<$ http://milonga.ilea.ufrgs.br/ mlevacov/grounded_theory.html>. Acesso em: 23 abr. 2006.

LINDGREN, R.; WIBERG, M. Knowledge Management and Mobility in a SemiVirtual Organization: Lessons Learned from the Case of Telia Nära, IEEE, Proceedings of the 33rd Hawaii International Conference on System Sciences, 2000.

MACK, R.W.; SNYDER, R.C. The Analysis of social conflict - toward an overview and synthesis. Conflict Resolution, Northwestern University, Vol. I, No. 2, p. 212248, Jun. 1957, Approaches to the Study of Social Conflict: A Colloquium.

MAGGI, B. Do agir organizacional, São Paulo: Editora Edgard Blücher, 2006.

MCKAY, S.; THURLOW, C.; ZIMMERMAN, H.T. Wired whizzes or technoslaves? Young people and their emergent communication technologies, Young People And Communication Technologies, Talking Adolescence, 11, p. 185-203.

MALVEZZI, S. O enfrentamento da adaptação como expressão da relação homem trabalho, Disciplina PST-5716 O homem e o trabalho na administração tradicional e na emergente, Instituto de Psicologia da USP, Departamento de Psicologia Social e do Trabalho, 2003.

S. Psicologia Organizacional - Da Administração Científica à Globalização: Uma História de Desafios, 2000.

MARKS, P. Computer viruses become hacker informants. NewScientist.com, 09 Jun. 2005. Disponível em: <http://www.newscientist.com/article.ns?id=dn7500>. Acesso em 8 fev. 2006.

MATTISON, D. Quickwiki, Swiki, Twiki, Zwiki and the Plone Wars - Wiki as a PIM and Collaborative Content Tool, Infotoday, Vol. 11, No. 4, April 2003. Disponível em: <http://www.infotoday.com/searcher/apr03/mattison.shtml>. Acesso em: 5 fev. 2006. 
NITRD, National Coordination Office for Networking and Information Technology Research and Development, 2006. Disponível em: <http://www.nitrd.gov>. Acesso em: 1 abr. 2006.

NOLL, J. Process Enactment in Virtual Software Organizations, Proceedings SERP '02, Las Vegas, NV, 2002.

OGBURN, W.F.; NIMKOFF, M.F. Co-operation, Competition, and Conflict, In: A Handbook of Sociology. Londres: Routledge \& Kegan Paul Ltd., 1953, p. 232-250. Tradução de Maria Isaura Pereira de Queiroz. In: CARDOSO, F. H.; IANNI, O. Homem e Sociedade. São Paulo: Companhia Editora Nacional, 1973. p. 236-261.

PIRIE, I.B. Software - How do we know it is safe? In: IEEE ASME RAILROAD CONFERENCE, 1999. p.122-129.

SAFEWARE ENGINEERING CORPORATION. Disponível em http://www.safeware-eng.com/. Acesso em: 10 fev. 2006.

SATOH, I. Mobile Agents for Ambient Intelligence, National Institute of Informatics, Tokyo, Japan, 2004a.

Selection of Mobile Agents, National Institute of Informatics, Tokyo, Japan, 2004b.

A Location Model for Pervasive Computing Environments, National Institute of Informatics, Tokyo, Japan, 2005.

STAR, S.L.; RUHLEDER, K. Steps Toward an Ecology of Infrastructure: Design and Access for Large Information Spaces, Information Systems Research, Vol. 7, No. 1, Mar. 1996, p. 111-134.

STEWART, T. The Wealth of Knowledge. New York: Currency Doubleday, 2001.

STOREY, N. Safety-Critical Computer Systems. New York: Addison Wesley, 1996. 453p. 
STRAUSS, A.; CORBIN, J. Basics of Qualitative Research Techniques and Procedures for Developing Grounded Theory, 2 ed. Thousand Oaks: Sage Publications, 1998.

STRAUSS, A. Qualitative analysis for social scientists. Cambridge, UK: University of Cambridge Press, 1987.

TAKAGI, A. ${ }^{1}$, T. YAMABE ${ }^{2}$, T. NAKAJIMA ${ }^{1,3}$, A Context Information Acquisition Framework for Personal Devices, ${ }^{1}$ Department of Computer Science, Waseda University, ${ }^{2}$ Nokia Research Center, Nokia Japan Co., Ltd, ${ }^{3}$ Nokia Research Center, Nokia Corporation.

TEIXEIRA, R. Projeto 450 dias: Acolhimento e vínculo em redes de conversações. Centro de Saúde Escola Samuel Barnsley Pessoa (CSE do Butantã). Faculdade de Medicina da USP. Disponível em: <http://www.pucsp.br/linc/wakka/wakka.php?wakka=CseButanta>. Acesso em: 27 jul. 2005.

TSOUKAS, H., The Firm as a Distributed Knowledge System: A Constructionist Approach, Strategic Management Journal, Vol. 17 (Winter Special Issue) 11-25, 1996.

YANAY, N., The Social Construction of Autonomy: A Motivational Model Social Behavior and Personality, Society for Personality Research (Inc.), 22(3), 209-226, 1994.

ZUBOFF, S.; MAXMIN, J. O Novo Jogo dos Negócios. Rio de Janeiro: Campus, 2003. 